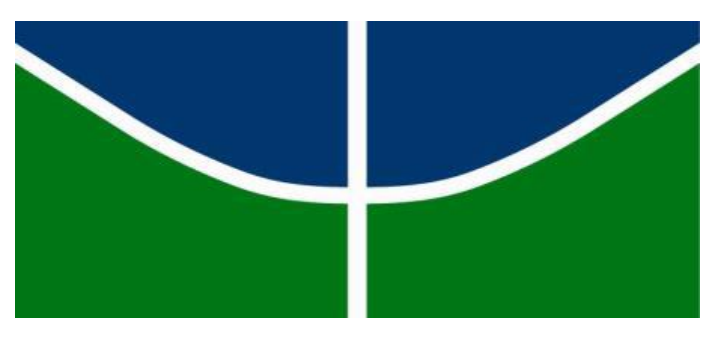

Universidade de Brasília

Instituto de Química

Programa de Pós-Graduação em Química

João Guilherme Moura Santos

Sensores Voltamétricos de ITO Modificados

com Filmes Ultrafinos de Óxidos de Ferro

para Detecção de ĺons Cobre

Brasillia-DF, 2016 
João Guilherme Moura Santos

\title{
Sensores Voltamétricos de ITO Modificados com Filmes Ultrafinos de Óxidos de Ferro para Detecção de Íons Cobre
}

\begin{abstract}
Tese apresentada ao Programa de Pós-Graduação em Química do Instituto de Química da Universidade de Brasília, na área de concentração Química Analítica, como requisito parcial para obtenção do título de Doutor em Química.
\end{abstract}

Orientador: Prof. Dr. Jurandir Rodrigues de Souza

Co-orientador: Prof. Dr. Leonardo Giordano Paterno

Brasília-DF, 2016 


\section{Folha de Aprovação}

Comunicamos a aprovação da Defesa de Tese de Doutorado do (a) aluno (a) João Guilherme Moura Santos, matrícula no 12/0178842, intitulada "Sensores Voltamétricos de ITO Modificados com Filmes Ultrafinos de Óxidos de Ferro para deteç̧ão de ĺons Cobre", apresentada no (a) Auditório do CDT da Universidade de Brasília (UnB) em 25 de outubro de 2016.

Prof. Dr. Jurandir Rodrigues de Souza

Presidente de Banca (IQ/UnB)

Prof. Dr. Flávio Colmati Junior Membro Titular (IQ/UFG)

Prof.a Dra. Nizamara Simenremis Pereira Membro Titular (IFB)

Prof. Dr. Alexandre Fonseca Membro Titular (IO/UnB)

Prof. Dr. José Joaquín Linares León Membro Titular (IQ/UnB)

Prof. Dr. Jez Willian Batista Braga Membro Suplente (IQ/UnB) 


\section{AGRADECIMENTOS}

Agradeço primeiramente a Deus pelo dom da vida. O fenômeno da vida é complexo demais para ser modelado e obra inteligentíssima. É um privilégio que deve ser exercido com sabedoria, prudência e equilíbrio.

Dedico esse trabalho aos meus amados pais João Alves dos Santos (João da Bomba) e Maria do Carmo Moura Santos (Dona Fia) que me proporcionaram a oportunidade de estudar e expandir os meus horizontes além do que eu jamais podia imaginar. Eles não tiveram a oportunidade de estudar mais com sabedoria souberam reconhecer no momento oportuno a importância do conhecimento. Dedico também esse trabalho aos meus queridos irmãos Raimundo Tiago, Roseli, Rosilda e Keila.

Dedico esse trabalho as minhas filhinhas amadas Sofia e Maria Clara. Que os meus passos de perseverança e busca do conhecimento possam inspirá-las. Que elas encontrem suas vocações e trilhem no caminho do conhecimento, do discernimento e principalmente da sabedoria.

Dedico esse trabalho a minha amada companheira Raiane Meireles que me apoiou e me proporcionou as condições para que eu pudesse me dedicar aos meus estudos. Que cuidou de mim e do nosso lar e me ofereceu o apoio e carinho nesse período tão importante da minha vida. Aos meus sogros Vanda e Mauro pela amizade e hospitalidade que só eles sabem proporcionar.

Ao meu Orientador Prof. Dr. Jurandir Rodrigue Souza por ter aberto as portas do LQAA para que eu possa realizar os meus estudos, pela confiança e pela orientação segura me encorajando a desenvolver o meu senso científico crítico. Um agradecimento especial ao prof. Dr. Leonardo Paterno pelo apoio fundamental para que eu pudesse desenvolver a minha tese. Obrigado Leo por tudo que você fez por mim. Sem o seu apoio eu não teria chegado até aqui. 
Quero agradecer grandemente aos meus colegas do LEQA, Camila, Ariadne, Naamã e Joelma pelo companheirismo, auxílio e carinho em todos os momentos que estivemos juntos nesta jornada de estudos e atividades experimentais.

Aos meus companheiros de lutas do Instituto Federal de Goiás (IFG), João Modesto, Luiz Dezanete, Silvio Sandro, Agenor Andrade, Ulisses, Luiz Loja, Adriano e todos os demais pelo companheirismo, conselhos e apoio.

Aos professores Dr Flávio Colmati, Dr Alexandre Fonseca, Dr. José Joaquín

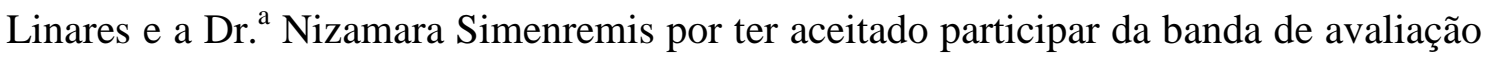
da minha tese de doutorado. A todos aqueles que de uma forma ou de outra contribuíram para esse trabalho. 


\section{RESUMO}

Neste trabalho propomos um sensor preparado com ITO quimicamente modificado com filmes ultrafinos de nanopartículas de óxidos de ferro (ION) fabricados pela técnica de LBL. O crescimento do filme de ION foi realizado ex situ com sucesso através da espectrometria UV-Vis indicando um crescimento linear relativamente ao número de bicamadas. Adicionalmente, espectros Raman do filme ultrafino de ION mostraram bandas de absorção características da magnetita e imagens de Microscopia de Força Atômica (AFM) mostraram uma camada de np- $\mathrm{Fe}_{3} \mathrm{O}_{4}$ altamente empacotada. A presença de np- $\mathrm{Fe}_{3} \mathrm{O}_{4}$ nos nanofilmes influenciaram o comportamento eletroquímico dos eletrodos de ION. O efeito do número de bicamadas de np- $\mathrm{Fe}_{3} \mathrm{O}_{4} / \mathrm{PSS}$ no desempenho dos eletrodos de ION foi um leve aumento das correntes anódicas e catódicas produzidas pela oxidação-redução do par redox $\mathrm{Fe}(\mathrm{CN})_{6}{ }^{3-/ 4-}$. O par redox $\mathrm{Fe}(\mathrm{CN})_{6}^{3-/ 4-}$ exibiu um comportamento quase- reversível sobre o eletrodo ION como já observado com outros eletrodos de trabalho. A detecção de $\mathrm{Cu}^{2+}$ foi realizada utilizando eletrodos com ION (np- $\left.\mathrm{Fe}_{3} \mathrm{O}_{4} / \mathrm{PSS}\right)_{3}$ por voltametria de redissolução anódica. Os parâmetros amplitude de pulso, velocidade de varredura, $\mathrm{pH}$, eletrólito suporte, potencial de deposição, tempo de deposição e velocidade de agitação foram estudados. A faixa de $\mathrm{pH}$ ideal ficou entre 4 e 5 e o eletrólito de trabalho escolhido foi o tampão Britton-Robinson pH 3. Os limites de detecção e quantificação foram estimados em 0,32 e $1,1 \mu \mathrm{g} \mathrm{L}^{-1}$ respectivamente. A faixa linear é bastante ampla e vai de 1,10 a 400 $\mu \mathrm{g} \mathrm{L}^{-1}$. Os eletrodos de ION também apresentaram boa seletividade frente a íons comuns. Amostras de café em pó comercial foram utilizadas para quantificação de $\mathrm{Cu}^{2+}$ com eletrodos ION e também por FAAS. Os resultados mostraram se estatisticamente equivalentes para um nível de confiança de $95 \%$. A precisão também foi avaliada através de estudos de repetitividade ficando em torno de 2,9\%. Os sensores contendo ION mostraram-se bastante promissores para detecção de íons $\mathrm{Cu}^{2+}$ em amostras de café. As superfícies dos eletrodos são facilmente regeneradas sem etapas adicionais. Os sensores propostos neste trabalho abrem uma nova perspectiva de sensores Enzyme-less para detecção de íons metálicos em matrizes complexas.

Palavras- chave: Filmes ultrafinos, Óxidos de ferro, Cobre, Voltametria. 


\begin{abstract}
In this work, we developed a Indium Tin Oxide coated glass (ITO) sensor modified with iron oxides nanoparticles (ION) ultrathin films made by Layer by Layer. The growing of the nanoparticles film was successful accompanied ex situ by Ultra Violet- visible spectrometry. The growing process was linear in relation to the number of bilayer deposited on ITO surface. Additionally, Raman spectrums of the films showed absorption bands of magnetite. Moreover, images of Atomic Force Microscopy presented a $\mathrm{Fe}_{3} \mathrm{O}_{4}$ nanoparticles highly packed. $\mathrm{Fe}_{3} \mathrm{O}_{4}$ nanoparticles influenced the electrochemical behavior of the ION electrodes. The process of adding new bilayers $\mathrm{Fe}_{3} \mathrm{O}_{4}$ nanoparticles on ITO surface increased anodic and cathode currents from redox couple $\mathrm{Fe}(\mathrm{CN})_{6}^{3-/ 4-}$. The redox couple $\mathrm{Fe}(\mathrm{CN})_{6}^{3-14-}$ had a quasi-reversible behavior on ITO electrodes which was observed on others work electrodes. The $\mathrm{Cu}^{2+}$ detection was carry out into electrochemical cell of three electrodes on a sensor surface with three 3 bilayers of $\mathrm{Fe}_{3} \mathrm{O}_{4}$ nanoparticles by anodic stripping voltammetry (ASV). We studied the influence of the pulse amplitude, scan rate, $\mathrm{pH}$, support electrolytes, deposition potential, deposition time and stirring rate parameters at $\mathrm{ASV} \mathrm{Cu}^{2+}$ response. The ideal $\mathrm{pH}$ range was from 4 to 5 and the support electrolyte chosen was $\mathrm{pH} 3$ BrittonRobinson buffer. The detection and quantification limits estimates to $\mathrm{Cu}^{2+}$ response were 0.32 and $1.10 \mu \mathrm{g} . \mathrm{L}^{-1}$ respectively. The linear range went from 1.10 to $400 \mu \mathrm{g} . \mathrm{L}^{-1}$. The ION electrodes presented a good selectivity relatively the common ions. Powder coffee samples purchased at local commerce was utilized to copper quantification by Differential Pulse Anodic Striping Voltammetry on ION electrodes and also by Flame Atomic Absorption Spectrometry. The results showed a good agreement at $95 \%$ at confidence level. The accuracy was available by repetitive studies and the relative standard deviation was $2.9 \%$. ION sensors showed promising to $\mathrm{Cu}^{2+}$ ions detection at coffee samples. Electrodes surfaces were easily regenerated without additional steps. Finally, ION electrodes opened a new Enzyme-less perspective to metals detection at complex matrices.
\end{abstract}

Key-words: Ultrathin films, Iron oxides, Copper and Voltammetry. 


\section{LISTA DE FIGURAS}

Figura 1. Forma de onda da utilizada em voltametria cíclica.

Figura 2. Voltamograma cíclico típico do par redox $\mathrm{Fe}(\mathrm{CN})_{6}^{3-14-} 6 \mathrm{mM} \mathrm{em} \mathrm{KNO}_{3} 1 \mathrm{M}$, mostrando os potenciais de pico anódico (Epa) e catódico (Epc) e as correntes de pico anódica (Ipa) e catódica (Ipc). Fonte: adaptado de Kissinger (1983). [19] 7

Figura 3 - Forma de onda utilizada na voltametria de pulso diferencial, mostrando a amplitude de pulso ( $\Delta E)$, o tempo de pulso típico de $50 \mathrm{~ms}$, os pontos de amostragem de corrente 1 e 2. Adaptado de Wang (1986).[18] 8

Figura 4. Perfil de potencial em função do tempo que ocorre durante a voltametria de redissolução anódica (ASV) e um destaque mostrando o voltamograma relacionado. Fonte: adaptado de Wang, J. (2006).[22]...

Figura 5. Processo esquemático para formação de filmes ultrafinos através da técnica Layer-by-Layer (LBL) mostrando a formação de uma única bicamada. A repetição desse processo leva a formação de multicamadas. 16

Figura 7. (a) Eletrodo de trabalho (WE) de ITO com filme de ION, mostrando a região de contato elétrico, a fita mágica delimitando a área mais escura onde o filme de ION foi depositado. (b) Célula eletroquímica utilizada para realizar estudos para detecção de $\mathrm{Cu}^{2+}$ por DPASV mostrando o eletrodo de referência (RE), eletrodo auxiliar $(C E) e$ o eletrodo de trabalho (WE).

Figura 6. Micrografia TEM de $n p-\mathrm{Fe}_{3} \mathrm{O}_{4}$ (obtida da suspensão coloidal de $n p-\mathrm{Fe}_{3} \mathrm{O}_{4}$, em destaque) e um histograma de distribuição de tamanho de partículas acompanhado de uma regressão log-normal. 37

Figura 8. Espectros $U V$-vis dos nanocompósitos com diferentes números (n) de bicamadas de (np-Fe3O4/PSS), sendo $n$ 1, 3, 5, 7 e 10. O gráfico em destaque apresenta a uma relação linear, medida a 360 e $480 \mathrm{~nm}$, entre a absorbância do nanocompósito e o número de bicamadas depositadas sobre o substrato de ITO.

Figura 9. Espectro Raman do filme nanocompósito de (np-Fe $\left.\mathrm{O}_{4} / \mathrm{PSS}\right)_{3}$. Comprimento de onda do laser: $514 \mathrm{~nm}$; intensidade de excitação: 0,3 $\mathrm{mW}$. 40 
Figura 10. Imagens AFM topográfica (a) e de fase (b) de um filme nanocompósito de $\left(n p-\mathrm{Fe}_{3} \mathrm{O}_{4} / \mathrm{PSS}\right)_{3}$

Figura 11. (a) Voltamogramas cíclicos e (b) correntes de pico para três eventos redox dos eletrodos de ION em função do número de bicamadas de (np-Fe ${ }_{3} \mathrm{O}_{4} / \mathrm{PSS}$ ). Ipcl e Ipc2 correspondem a primeira e segunda onda catódica respectivamente. Ipal corresponde a corrente de pico anódica. 43

Figura 12. Voltametria cíclica de $1,00 \mathrm{mmol} \mathrm{L}^{-1} \mathrm{~K}_{3} \mathrm{Fe}(\mathrm{CN})_{6} \mathrm{em} \mathrm{KCl} 1,00 \mathrm{~mol} \mathrm{~L}^{-1}$ medido com eletrodos de ION com diferente número de bicamadas ( $n$ ) de (np$\mathrm{Fe}_{3} \mathrm{O}_{4} / \mathrm{PSS}$ ). Plain ITO corresponde a superfície de ITO sem o filme. Os filmes variaram de 1 a 10 bicamadas. (a) Voltamogramas cíclicos adquiridos na velocidade de varredura de $50 \mathrm{mV} \mathrm{s}^{-1}$, (b) Correntes de pico anódica e catódica em função de $v^{1 / 2} e(c) \Delta E p$ em função de log $v$.

Figura 13. Voltamogramas de PDASV apresentando a influência da amplitude de pulso no sinal analítico de $\mathrm{Cu}^{2+} 100 \mu \mathrm{g} \mathrm{L^{-1 }}$ sobre o eletrodo ION (np-Fe $\left.\mathrm{O}_{4} / \mathrm{PSS}\right)_{3}$. As amplitudes de pulso foram de 25, 50, 75, 100,125 e $150 \mathrm{mV}$. A deposição ocorreu sob o potencial de -0,4 V por $120 \mathrm{~s}$. Varredura anódica de -0,4 a +0,6 V e velocidade de varredura de $5 \mathrm{mVs}^{-1}$.

Figura 14. Voltamogramas de DPASV apresentando a influência da velocidade de varredura no sinal analítico de $\mathrm{Cu}^{2+} 100 \mu \mathrm{g} \mathrm{L}^{-1}$ sobre o eletrodo ION $\left(\mathrm{np}-\mathrm{Fe}_{3} \mathrm{O}_{4} / \mathrm{PSS}\right)_{3}$. As velocidades de varredura foram 2, 5, 10 e $15 \mathrm{mV} \mathrm{s}^{-1}$. Eletrólito suporte HAc 0,100 mol $L^{-1}$. Potencial de deposição -0,4 V. Varredura de -0,4 a +0,6 V, amplitude de pulso de $50 \mathrm{mV}$.

Figura 15. Programação de potencial na voltametria de pulso diferencial mostrando os parâmetros Amplitude de pulso ( $\Delta E)$, Degrau de voltagem $\left(V_{S}\right)$, Tempo de Pulso $(t) e$ Tempo entre pulsos $(P d)$. A velocidade de varredura é a razão entre $V_{S}$ e Pd. 52

Figura 16. Voltamogramas de DPASV mostrando a influência do pH da solução eletrolítica (Tampão Robson-Britton) no sinal analítico de uma solução de cobre de $100 \mu \mathrm{g} \mathrm{L}^{-1}$ sobre o eletrodo ION $\left(n p-\mathrm{Fe}_{3} \mathrm{O}_{4} / \mathrm{PSS}\right)_{3}$. A deposição ocorreu no potencial de $-0,4 \mathrm{~V}$ por $120 \mathrm{~s}$. Amplitude de pulso foi de $50 \mathrm{mV}$ e velocidade de varredura de $10 \mathrm{mV}$ $s^{-1}$ 54 
Figura 17. Representação esquemática da superfície do eletrodo de ITO contendo nanofilme de ION dando ênfase aos grupos $-\mathrm{SO}_{3}{ }^{-}$sobre a superfície. Em pH baixo, ocorre a diminuição da concentração de $\mathrm{Cu}^{2+}$ próximo a superfície do eletrodo.

Figura 18. Voltamogramas de DPASV mostrando a influência da concentração do eletrólito ácido acético ( $\left.\mathrm{CH}_{3} \mathrm{COOH}\right)$ 0,010 M (pH 3,4); 0,100 M (pH 2,9) e 0,500 M ( $\mathrm{pH}$ 2,5) no sinal analítico de uma solução de cobre de $100 \mu \mathrm{g} \mathrm{L}^{-1}$ sobre o eletrodo $\mathrm{ION}\left(\mathrm{np}-\mathrm{Fe}_{3} \mathrm{O}_{4} / \mathrm{PSS}\right)_{3}$. A deposição ocorreu no potencial de -0,4 V por $120 \mathrm{~s}$. Amplitude de pulso foi de $50 \mathrm{mV}$ e velocidade de varredura de $10 \mathrm{mV} \mathrm{s}^{-1}$. 56

Figura 19. Densidade de corrente para soluções de $C u^{2+} 100 \mu \mathrm{g} L^{-1}$ em função da natureza do eletrólito. Os eletrólitos utilizados foram ácido clorídrico (HCl), ácido fosfórico $\left(\mathrm{H}_{3} \mathrm{PO}_{4}\right)$, ácido cítrico $\left(\mathrm{C}_{6} \mathrm{H}_{3} \mathrm{O}_{7}\right)$ e ácido acético $\left(\mathrm{CH}_{3} \mathrm{COOH}\right)$ todos na concentração de 0,100 M. A deposição ocorreu no potencial de -0,4 V por $120 \mathrm{~s}$. Amplitude de pulso foi de $50 \mathrm{mV}$ e velocidade de varredura de $10 \mathrm{mV} \mathrm{s}^{-1}$.

Figura 20. Voltamogramas de DPASV apresentando a influência do potencial de deposição no sinal analítico de $\mathrm{Cu}^{2+} 100 \mu \mathrm{g} \mathrm{L}^{-1}$ sobre o eletrodo ION (np-Fe $\left.\mathrm{O}_{4} / \mathrm{PSS}\right)_{3}$. Os potencial de deposição foram -0,25, -030, -0,35, -0,40, -0,45 e -0,50 V. Eletrólito suporte $\mathrm{CH}_{3} \mathrm{COOH}$ 0,100 mol L-1. Potencial de deposição -0,4 V. Varredura de -0,4 a $+0,6 \mathrm{~V}$, amplitude de pulso de $50 \mathrm{mV}$.

Figura 21. Voltamogramas DPASV apresentando a influência do tempo de deposição no sinal analítico de $\mathrm{Cu}^{2+} 100 \mu \mathrm{g} \mathrm{L}^{-1}$ sobre o eletrodo ION (np-Fe $\left.{ }_{3} \mathrm{O}_{4} / \mathrm{PSS}\right)_{3}$. Os tempos de deposição foram de 15, 30, 60, 120, 240 e 480 s. O eletrólito suporte foi HAc 0,100 mol $\mathrm{L}^{-1}$. Potencial de deposição -0,4 V. Varredura de -0,4 a +0,6 V, amplitude de pulso de $50 \mathrm{mV}$. 61

Figura 22. Voltamogramas PDASV apresentando a influência da velocidade de agitação no sinal analítico de $\mathrm{Cu}^{2+} 100 \mu \mathrm{g} \mathrm{L}^{-1}$ sobre o eletrodo ION (np-Fe $\left.\mathrm{O}_{3} / \mathrm{PSS}\right)_{3}$. As velocidades de agitação foram 0, 400, 800, 1200, 1600 e $2000 \mathrm{rpm}$. A deposição ocorreu sob o potencial de -0,4 V por 120 s. Varredura anódica de -0,4 a +0,6 V, amplitude de pulso de $50 \mathrm{mV}$ e velocidade de varredura de $5 \mathrm{mV} \mathrm{s}{ }^{-1}$.

Figura 23. (a) Sinal analítico (área do pico) em função da concentração obtidos através de PDASV para soluções de $\mathrm{Cu}^{2+}$ de concentrações de 5 a $400 \mathrm{em}_{\mu} \mathrm{g} \mathrm{L}^{-1}$ sobre o eletrodo ION (np-Fe $\left.{ }_{3} \mathrm{O}_{4} / \mathrm{PSS}\right)_{3}$. A deposição ocorreu sob o potencial de -0,4 V por 
120s. Varredura de -0,4 a +0,6 V, Amplitude de pulso $50 \mathrm{mV}$ e velocidade de varredura de $10 \mathrm{mVs}^{-1}$.

Figura 24. Voltamogramas de DPASV de solução de $C u^{2+}$ de concentrações de 5 a 25 em $\mu \mathrm{g} \mathrm{L}^{-1}$ sobre o eletrodo ION (np-Fe $\left.{ }_{3} \mathrm{O}_{4} / \mathrm{PSS}\right)_{3}$. A deposição ocorreu sob o potencial de -0,4 V por $120 \mathrm{~s}$. Varredura de -0,4 a +0,6 V, Amplitude de pulso $50 \mathrm{mV} e$ velocidade de varredura de $10 \mathrm{mV} \mathrm{s}^{-1}$. Eletrólito suporte foi tampão BR $\mathrm{pH}$ 3. Em destaque uma curva analítica dos valores de J em função da concentração 66

Figura 25. Corrente de pico obtidos por PDASV para soluções de Cu2+ de concentrações de 20 ( $\pm 17,9 \%), 80( \pm 2,9 \%)$ e $160\left(( \pm 2,2 \%) \mu \mathrm{g}^{-1}\right.$ sobre o eletrodo ION (np-Fe $\left.\mathrm{F}_{3} / \mathrm{PSS}\right)_{3}$. Os valores de $\mathrm{CV}$ foram de respectivamente 17,9; 2,9 e $\mathrm{A}$ deposição ocorreu sob o potencial de -0,4 V por $120 \mathrm{~s}$. Varredura de -0,4 a +0,6 V, Amplitude de pulso $50 \mathrm{mV}$ e velocidade de varredura de $10 \mathrm{mV} \mathrm{s}$.

Figura 26. (a) Voltamogramas de PDASV para amostra café em pó orgânico comercialmente disponível $\left(0,1 \mathrm{~mL}\right.$ de amostra $+0,1 \mathrm{ml}$ de padrão 2,5 $\mathrm{mg} \mathrm{L}^{-1}$ em $5 \mathrm{~mL}$ de eletrólito tampão $\mathrm{BR}$ pH 3) e adições de 10, 20, 30 e $40 \mu \mathrm{L}$ de padrão de $\mathrm{Cu}^{2+} 5 \mathrm{mg}$ $L^{-1}$ sobre o eletrodo ION (np-Fe $\left.{ }_{3} \mathrm{O}_{4} / \mathrm{PSS}\right)_{3}$. Em destaque, uma curva de adição de padrão para os voltamogramas. A deposição ocorreu sob o potencial de -0,4 V por 120s. Varredura anódica de -0,4 a +0,6 V, amplitude de pulso de $50 \mathrm{mV}$ e velocidade de varredura de $10 \mathrm{mV} \mathrm{s}^{-1}$. Uma purga adicional de $60 \mathrm{~s}$ foi realizada entre cada adição.

Figura 27. Curva analítica para determinação de $\mathrm{Cu}^{2+}$ em amostras de café por Espectrometria de Absorção Atômica em Chama (FAAS) na faixa de concentração de 0,5 a 2,5 $\mathrm{mg} \mathrm{L}^{-1}$. As condições experimentais estão resumidas na Tabela 4. 71 


\section{LISTA DE TABELAS}

Tabela 1. Resumo de alguns trabalhos apresentados na literatura que realizaram a determinação de $\mathrm{Cu}^{2+}$ por métodos de redissolução.

Tabela 2. Reagentes utilizados na síntese das nanopartículas de magnetita $e$ preparação do eletrodo ${ }^{a}$, preparação de soluções tampão e padrões ${ }^{b}$ e digestão da amostrac. 26

Tabela 3. Condições experimentais para a determinação de $C u^{2+}$ por DPASV ${ }^{a}$. 31

Tabela 4. Condições experimentais para determinação de Cobre por Espectrometria de Absorção Atômica em Chama em amostras de Café em pó comercial.

Tabela 5. Potenciais eletroquímicos para processos redox ocorrendo em eletrodos com diferentes números de bicamadas de (np- $\left.\mathrm{Fe}_{3} \mathrm{O}_{4} / \mathrm{PSS}\right)$. Eletrólito tampão acetato pH 4,6. Velocidade de varredura $50 \mathrm{mV} \mathrm{s}^{-1}$. 44

Tabela 6. Dados da Voltametria Cíclica da constante heterogênea de transferência eletrônica aparente $\left(k_{a p}{ }^{0}\right)$ para sistemas redox medidos com eletrodos de ION com número diferente de bicamadas de (np-Fe $\left.{ }_{3} \mathrm{O}_{4} \mathrm{PSS}\right)$ e para o eletrodo de ITO base. .... 47

Tabela 7. Leituras de uma solução do branco utilizadas para determinação do limite de detecção para detecção de $\mathrm{Cu}^{2+}$ com eletrodos de ION $\left(n p-\mathrm{Fe}_{3} \mathrm{O}_{4} / \mathrm{PSS}\right)_{3}$

Tabela 8. Resultados de determinação de $\mathrm{Cu}^{2+}$ em amostras de café em pó comercialmente disponíveis utilizando o eletrodo de ION (np-Fe $\left.\mathrm{F}_{3} \mathrm{O}_{4} / \mathrm{PSS}\right)_{3}$ e por Espectrofotometria de Absorção Atômica em Chama (FAAS)........................................ 72

Tabela 9. Efeito de íons interferentes relativamente ao sinal analítico médio de $\mathrm{Cu}^{2+}$ 49,0 $\mathrm{g} \mathrm{L} \mathrm{L}^{-1}$ em tampão BR pH 3 medido com o eletrodo ION (np- $\left.\mathrm{Fe}_{3} \mathrm{O}_{4} / \mathrm{PSS}\right)_{3}$. As medidas foram realizadas por DPASV nas condições apresentadas na Tabela 3......... 74 


\section{LISTA DE ABREVIATURAS E SIGLAS}

ITO

AFM

CV

TEM

PDASV

FAAS

ION

PSS

$\mathrm{np}-\mathrm{Fe}_{3} \mathrm{O}_{4} / \mathrm{PSS}$

LBL

LB

$\mathbf{s}$

RSD

$\Delta \mathrm{E}$

$\mathrm{I}_{\mathrm{p}}$

$\mathrm{I}_{\mathrm{pa}}$

$I_{p c}$

$\mathrm{E}_{\mathrm{p}}$

$\mathrm{E}_{\mathrm{pa}}$

$\mathrm{E}_{\mathrm{pc}}$

$\Delta \mathrm{E}_{\mathrm{p}}$

$\mathbf{k}^{0}{ }_{\text {app }}$

$\mathrm{W}_{1 / 2}$
Placas de vidro recobertas com um filme de óxido de estanho dopado com índio.

Microscopia de Força Atômica

Voltametria Cíclica

Microscopia Eletrônica de Transmissão

Voltametria de Redissolução Anódica por Pulso Diferencial

Espectrometria de Absorção Atômica em Chama

Nanopartículas de Óxidos de Ferro $\left(\mathrm{np}-\mathrm{Fe}_{3} \mathrm{O}_{4}\right)$

Poliestireno sulfonato de sódio

Bicamada do filme de nanocompósito

Camada sobre camada (layer-by-layer)

Langmuir-Blodgett

Desvio padrão de uma amostra

Desvio Padrão Relativo

Amplitude de pulso

Corrente de pico

Corrente de pico anódico

Corrente de pico catódico

Potencial de pico

Potencial de pico anódico

Potencial de pico catódico

Separação entre o potencial de pico anódico e catódico

Constante de transferência eletrônica aparente

Largura da meia altura do pico 


$\begin{array}{ll}\text { E}_{1 / 2} & \text { Potencial de meia onda } \\ \text { Eo } & \text { Potencial padrão do eletrodo } \\ \Gamma & \text { Sensibilidade } \\ \text { R } & \text { Coeficiente de correlação de Pearson } \\ \text { T } & \text { Tempo de pulso } \\ \text { F } & \text { Constante de Faraday } \\ \text { A } & \text { Área do eletrodo } \\ \text { C } & \text { Concentração }\end{array}$




\section{SUMÁRIO}

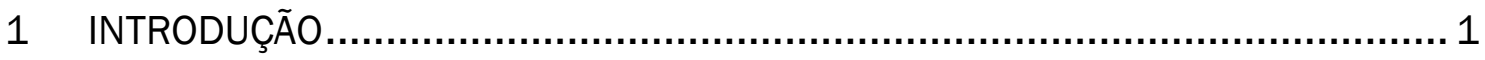

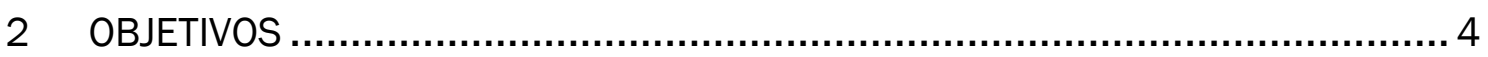

2.1 OBJETIVO GERAL ..................................................................... 4

2.2 OBJETIVOS ESPECÍFICOS ...................................................... 4

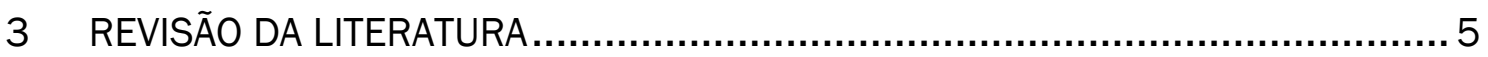

3.1 TÉCNICAS ELETROANALÍTICAS..................................................... 5

3.1.1 Voltametria Cíclica (CV) ........................................................ 5

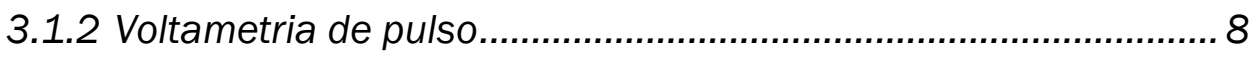

3.1.3 Voltametria de redissolução ..................................................... 9

3.2 VOLTAMETRIA DE REDISSOLUÇÃO ANÓDICA SOBRE ELETRODOS SÓLIDOS 12

3.3 ITO

3.4 FILMES ULTRAFINOS POR LBL .................................................. 15

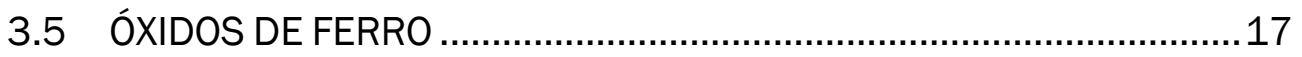

3.6 SENSORES DE NANOPARTÍCULAS DE ÓXIDOS DE FERRO (ION)......18

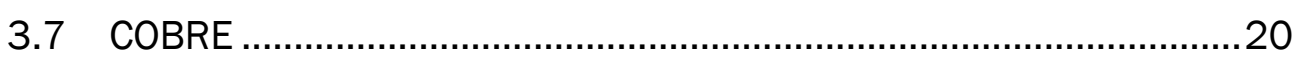

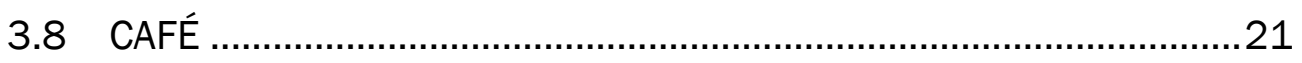

3.9 COBRE E OUTROS METAIS EM CAFÉ ...........................................22

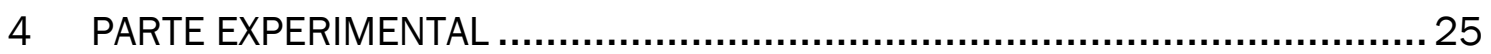

4.1 REAGENTES E SOLUÇÕES .........................................................2 25

4.2 DETECÇÃO DE Cu2+ UTILIZANDO ELETRODO DE ITO MODIFICADO

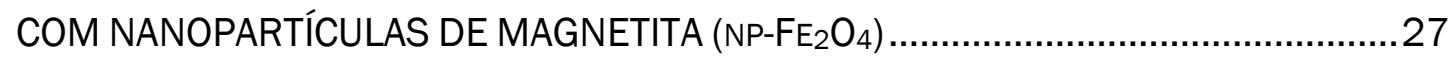

4.2.1 Síntese das nanopartículas de magnetita $\left(\mathrm{np}-\mathrm{Fe}_{3} \mathrm{O}_{4}\right) \ldots \ldots \ldots \ldots . . . . .27$

4.2.2 Deposição dos filmes ................................................................28

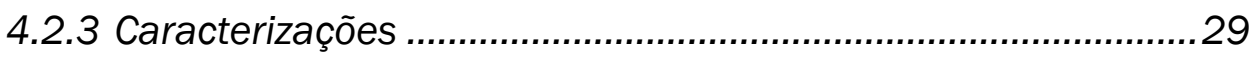

4.3 REDISSOLUÇÃO ANÓDICA POR PULSO DIFERENCIAL DE ÍONS

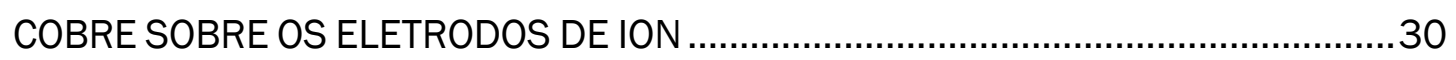

4.3.1 Parâmetros inerentes ao sinal de pulso diferencial ..................31

4.3.2 Parâmetros de redissolução anódica........................................31 


\subsection{PARÂMETROS DE VALIDAÇÃO PARA DETECÇÃO DE IONS COBRE} COM O ELETRODE DE ION

4.4.1 Faixa de Trabalho e Sensibilidade 32

4.4.2 Limite de Detecção (LD) e Limite de Quantificação (LQ) 33

4.4.3 Precisão. 33

4.4.4 Seletividade. 34

4.4.5 Comparação entre métodos .....................................................35

4.4.6 Estabilidade dos eletrodos de ITO modificados com ION ...........36

5.4 NANOFILMES DE ÓXIDOS DE FERRO 37

5.4.1 Deposição, Estrutura e Morfologia 37

5.4.2 Propriedades Eletroquímicas 42

5.5 REDISSOLUÇÃO ANÓDICA POR PULSO DIFERENCIAL PARA

DETECÇÃO DE ÍONS CU(II) SOBRE OS ELETRODOS DE ION (NP-FE $\left.\mathrm{O}_{4} / \mathrm{PSS}\right)_{3}$ 48

5.5.1 Amplitude de pulso 48

5.5.2 Velocidade de varredura 50

5.5.3 Influência do pH, natureza e concentração da solução eletrolítica no sinal analítico de $\mathrm{Cu}^{2+}$ sobre o eletrodo de ION (np-Fe $\left.{ }_{3} \mathrm{O}_{4} / \mathrm{PSS}\right)_{3}$ 52

5.5.4 Influência do potencial de deposição no sinal analítico de $\mathrm{Cu}^{2+}$ sobre o eletrodo de ION (np- $\left.\mathrm{Fe}_{3} \mathrm{O}_{4} / \mathrm{PSS}\right)_{3}$

5.5.5 Influência do tempo de deposição no sinal analítico de $\mathrm{Cu}^{2+}$ sobre o eletrodo de ION $\left(n p-\mathrm{Fe}_{3} \mathrm{O}_{4} / \mathrm{PSS}\right)_{3}$ 60

5.5.6 Influência da velocidade de agitação no sinal analítico de $\mathrm{Cu}^{2+}$ sobre o eletrodo de ION (np-Fe $\left.{ }_{3} \mathrm{O}_{4} / \mathrm{PSS}\right)_{3}$

5.6.7 Durabilidade dos eletrodos de ITO com ION

5.7 PARÂMETROS DE VALIDAÇÃO ANALÍTICA PARA DETECÇÃO DE CU2+ SOBRE ELETRODOS ION (NP-FE3 $\left.\mathrm{O}_{4} / \mathrm{PSS}\right)_{3}$

5.7.1 Faixa de trabalho e Sensibilidade do sinal analítico de $\mathrm{Cu}^{2+}$ sobre eletrodos de $\mathrm{ION}\left(\mathrm{np}-\mathrm{Fe}_{3} \mathrm{O}_{4} / \mathrm{PSS}\right)_{3}$ 
5.7.2 Limite de Detecção e Limite de Quantificação do Método proposto para determinação de $\mathrm{Cu}^{2+}$ sobre eletrodos de ION (np-Fe $\left.\mathrm{O}_{4} / \mathrm{PSS}\right)_{3}$ 67

5.7.3 Avaliação da precisão do sinal analítico de $\mathrm{Cu}^{2+}$ sobre eletrodos

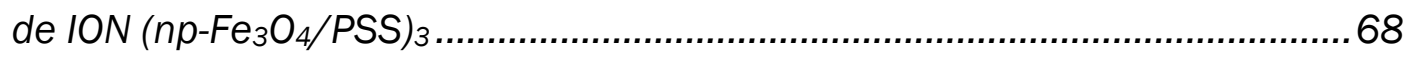

5.7.4 Determinação de $\mathrm{Cu}^{2+}$ em amostras de café em pó ..................70

5.7.5 Estudo de interferentes na determinação de $\mathrm{Cu}^{2+}$ utilizando

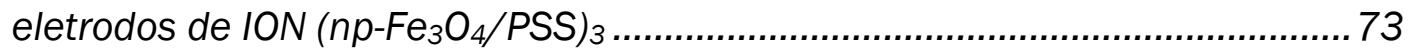

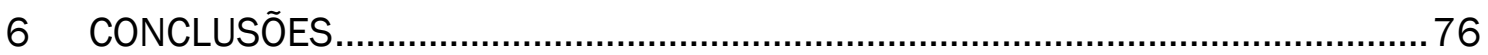

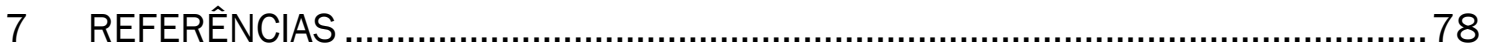




\section{INTRODUÇÃO}

A voltametria é uma das técnicas mais apropriadas para determinação de metais em nível traço em diferentes tipos de matrizes tais como alimentos, produtos industrializados, medicamentos e amostras ambientais. $\mathrm{O}$ eletrodo líquido de mercúrio por gota suspensa é um dos melhores eletrodos voltamétricos para análise traço de metais. Contudo, a toxidade do mercúrio bem como a sua faixa de trabalho restrita para faixa de potenciais positivos tem estimulado a busca por materiais alternativos. Entre os métodos eletroquímicos para determinação de metais em nível traço, um dos mais relevantes é a Voltametria de Redissolução (SV) a qual envolve uma etapa de préconcentração do metal sobre a superfície do eletrodo.

Uma alternativa que tem se mostrado viável para determinação de metais em nível traço são os eletrodos sólidos Mercury-free quimicamente modificados. O ITO é um óxido de estanho $(\mathrm{SnO})$ dopado com óxido de índio $\left(\mathrm{In}_{2} \mathrm{O}_{3}\right)$ o qual comporta-se como um semicondutor do tipo p. Filmes finos de ITO sobre o vidro além de se um condutor elétrico também apresenta uma excelente transparência a luz. Estas placas de vidro cobertas com ITO tem sido usadas com sucesso como substrato para confecção de sensores Mercury-free para detecção de alguns analitos. Entre as técnicas usadas para modificação da superfície dos eletrodos, a técnica Layer-by-Layer (LBL) descrita por Decher [1] constitui uma das técnicas mais simples e versáteis.

Nanopartículas de óxidos de ferro (ION) tem um papel marcante em processos de conversão/estocagem de energia e sensores químicos. ION tem um baixo custo de preparação e uma faixa ampla de propriedades eletroquímicas e fotoeletroquímicas. $\mathrm{Na}$ área de sensores químicos, o ION tem sido empregado na construção de eletrodos nanoestruturados para a detecção de alguns analito incluindo peróxido de hidrogênio, dopamina (DA), ureia e glicose. [2-10] Nestes dispositivos, o ION pode agir de diferentes maneiras tais como um eletrocatalisador, ancorando enzimas e hemoglobina ou eventualmente no aumento do tempo de vida do eletrodo. Eletrodos modificados com ION têm sido usados também na detecção de gases e cátions metálicos importantes em solução. [11-14] 
Apesar da utilização de placas com ION no desenvolvimento de sensores, existe uma lacuna na literatura na aplicação da técnica LBL para modificação de superfícies com ION para determinação de metais. Entre os metais de grande interesse na análise de traço, o cobre é um dos mais relevantes. O cobre é um elemento essencial e sua necessidade humana em adultos é em torno de $0,9 \mathrm{mg}$ por dia. Porém em excesso o cobre é tóxico. Assim como outros íons metálicos, o cobre exerce sua função biológica em combinação com proteínas específicas. A principal função dos íons cobre nos organismos está associada a transferência de energia nas células. Adicionalmente, o cobre associado a proteínas também atua nos processos envolvendo transporte de oxigênio. [15] Os distúrbios genéticos síndrome de Wilson e síndrome de Menkes podem afetar a capacidade do corpo humano de utilizar o cobre de maneira apropriada. [16]

Estudos diversos da literatura mostram que os íons $\mathrm{Cu}^{2+}$ podem ser um dos parâmetros importantes para atribuições de qualidade ao café comercializado, pois seus níveis variam de acordo com a origem geográfica, a variedade e a forma de apresentação do café. Os íons metálicos têm sido utilizados como descritores químicos (diferenciadores, marcadores) da qualidade do café por serem mais estáveis e menos afetados pelas condições de armazenamento do que vitaminas e outros tipos de compostos orgânicos presentes em sua composição.

Devido à importância do café à balança comercial brasileira e a crescente demanda dos mercados interno e externo por produtos de qualidade, existe uma necessidade premente de metodologias de aferição da qualidade do café produzido e comercializado no Brasil. Por um lado, a qualidade do café bebida é atestada por análise sensorial, em que degustadores especializados atribuem classificação à bebida com base em requisitos subjetivos. No entanto, a classificação está baseada em propriedades organolépticas que dão apenas uma caracterização qualitativa da bebida.

Em particular, a determinação quantitativa dos níveis de cobre no café não pode ser dada por análise sensorial. A diferenciação do café pela forma de apresentação é fundamental para estudos nutricionais, pois fornece dados sobre a variação dos macro e micronutrientes e dos valores consumidos destes elementos nas dietas por meio do 
café. Todas essas diferenciações têm sido atestadas por meio da determinação de níveis de íons metálicos, especialmente do $\mathrm{Cu}^{2+}$.

Métodos sofisticados tais como espectrometria de absorção atômica (AAS), espectrometria de massa com plasma acoplado indutivamente (ICP-MS), espectrometria de massas (MS) e espectrometria de fluorescência de raios X (R-FS) são ainda bastante utilizados para determinação de metais em níveis traço ou sub traço em amostras de alimentos. Por outro lado, técnicas que envolvam instrumental robusto e de baixo custo, com possibilidade de miniaturização e portabilidade apresentam-se como alternativas importantes para substituição dessas técnicas em aplicações específicas. Neste aspecto, a utilização de sensores voltamétricos apresenta-se como uma alternativa altamente viável devido ao baixo custo de fabricação, portabilidade, seletividade e sensibilidade analíticas adequadas. [17] 


\section{OBJETIVOS}

\subsection{OBJETIVO GERAL}

Confeccionar sensores voltamétricos de ITO através da técnica LBL contendo filmes ultrafinos de nanopartículas de óxidos de ferro para detecção de cobre em amostras de café.

\subsection{OBJETIVOS ESPECÍFICOS}

(a) Fabricar e caracterizar sensores de ITO quimicamente modificados com filmes ultrafinos de óxidos de ferro nanoestruturados através da técnica de LBL.

(b) Estudar a morfologia e o comportamento eletroquímico dos sensores de ITO modificados com nanopartículas de óxidos de ferro (ION) através de técnicas eletroquímicas tais como voltametria cíclica e voltametria de redissolução anódica por pulso diferencial.

(c) Avaliar o desempenho analítico dos sensores de ITO modificados com filmes ultrafinos de ION para determinação de Cobre e amostras de café. 


\section{REVISÃO DA LITERATURA}

\subsection{TÉCNICAS ELETROANALÍTICAS}

\subsubsection{Voltametria Cíclica (CV)}

A voltametria cíclica é uma das técnicas eletroanalíticas mais utilizadas em estudos eletroquímicos e eletroanalíticos. Normalmente é a primeira técnica a ser utilizada quando se busca compreender um determinado sistema. [18] A forma de onda da voltametria cíclica (Figura 1) consiste numa rampa de potencial linear no sentido do potencial inicial $\left(\mathrm{E}_{\mathrm{i}}\right)$ para o potencial de inversão $\left(\mathrm{E}_{\mathrm{f}}\right)$ seguido de uma rampa de potencial linear no sentido inverso. Durante a aplicação da varredura de potencial, a corrente gerada entre o eletrodo de trabalho e o eletrodo de referência é monitorada. $\mathrm{O}$ voltamograma consiste do gráfico da corrente em função do potencial.

Um voltamograma cíclico típico é apresentado na Figura 2. [19] Neste voltamograma o potencial inicial é de $0,8 \mathrm{~V}$. O potencial então varia linearmente até o potencial de inversão de $-0,2 \mathrm{~V}$. Então o potencial varia linearmente de $-0,2 \mathrm{~V}$ retornando ao potencial de $0,8 \mathrm{~V}$. Este é um voltamograma típico de uma solução $6 \mathrm{mM}$ do par redox $\mathrm{Fe}(\mathrm{CN})_{6}{ }^{3-/ 4-}$ no eletrólito $\mathrm{KNO}_{3} 1 \mathrm{M}$ numa célula típica com três eletrodos (eletrodo de trabalho, eletrodo de referência e eletrodo auxiliar). Os quatro parâmetros mais importantes de um voltamograma cíclico são o potencial de pico anódico $\left(\mathrm{E}_{\mathrm{pa}}\right)$, o potencial de pico catódico $\left(\mathrm{E}_{\mathrm{pc}}\right)$, a corrente de pico anódica $\left(\mathrm{I}_{\mathrm{pa}}\right)$ e a corrente de pico catódica $\left(\mathrm{I}_{\mathrm{pc}}\right)$. Em 0,8 V a corrente é próxima de zero. Quando potencial aproxima de 0,2 V ( $\left.\mathrm{E}_{\mathrm{pa}}\right)$, a corrente aumenta rapidamente alcançando um valor máximo $\left(\mathrm{I}_{\mathrm{pa}}\right)$ indicando a oxidação de $\mathrm{Fe}^{\mathrm{II}}(\mathrm{CN})_{6}{ }^{4-} \mathrm{em} \mathrm{Fe}^{\mathrm{III}}(\mathrm{CN})_{6}{ }^{3-}$. Então a corrente diminui até o potencial de inversão de $-0,2 \mathrm{~V}$. Na varredura inversa (de $-0,2 \mathrm{~V}$ até voltar para $0,8 \mathrm{~V}$ ) o 
$\mathrm{E}_{\mathrm{pc}}$ e a $\mathrm{I}_{\mathrm{pc}}$ representam respectivamente o potencial e a corrente relativa a redução do $\mathrm{Fe}^{\mathrm{III}}(\mathrm{CN})_{6}^{3-} \mathrm{em} \mathrm{Fe}^{\mathrm{II}}(\mathrm{CN})_{6}^{4-}$.

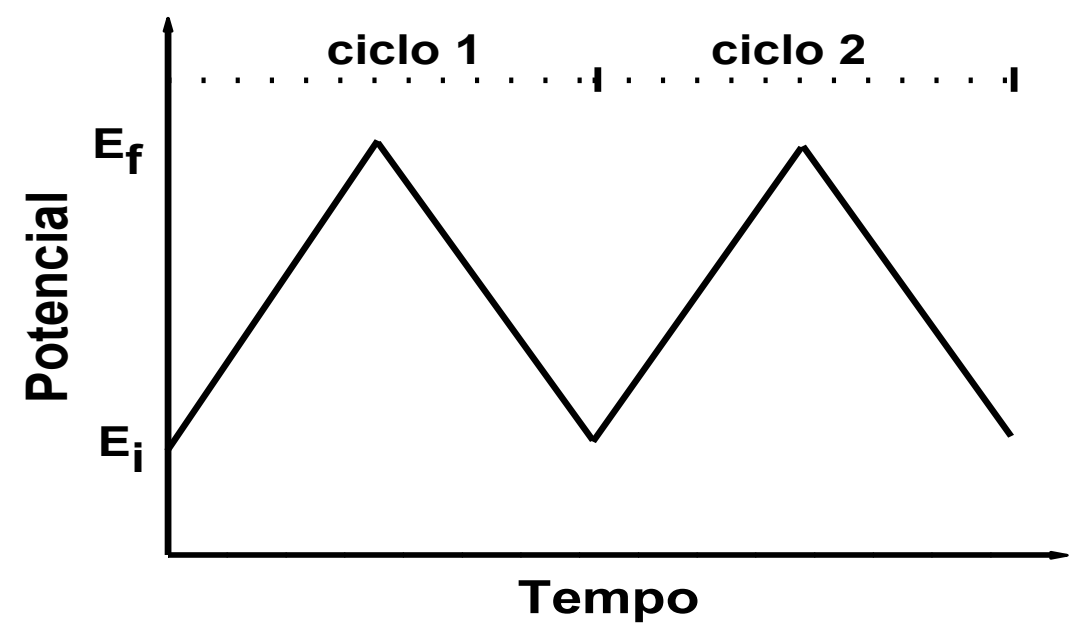

Figura 1. Forma de onda da utilizada em voltametria cíclica. 


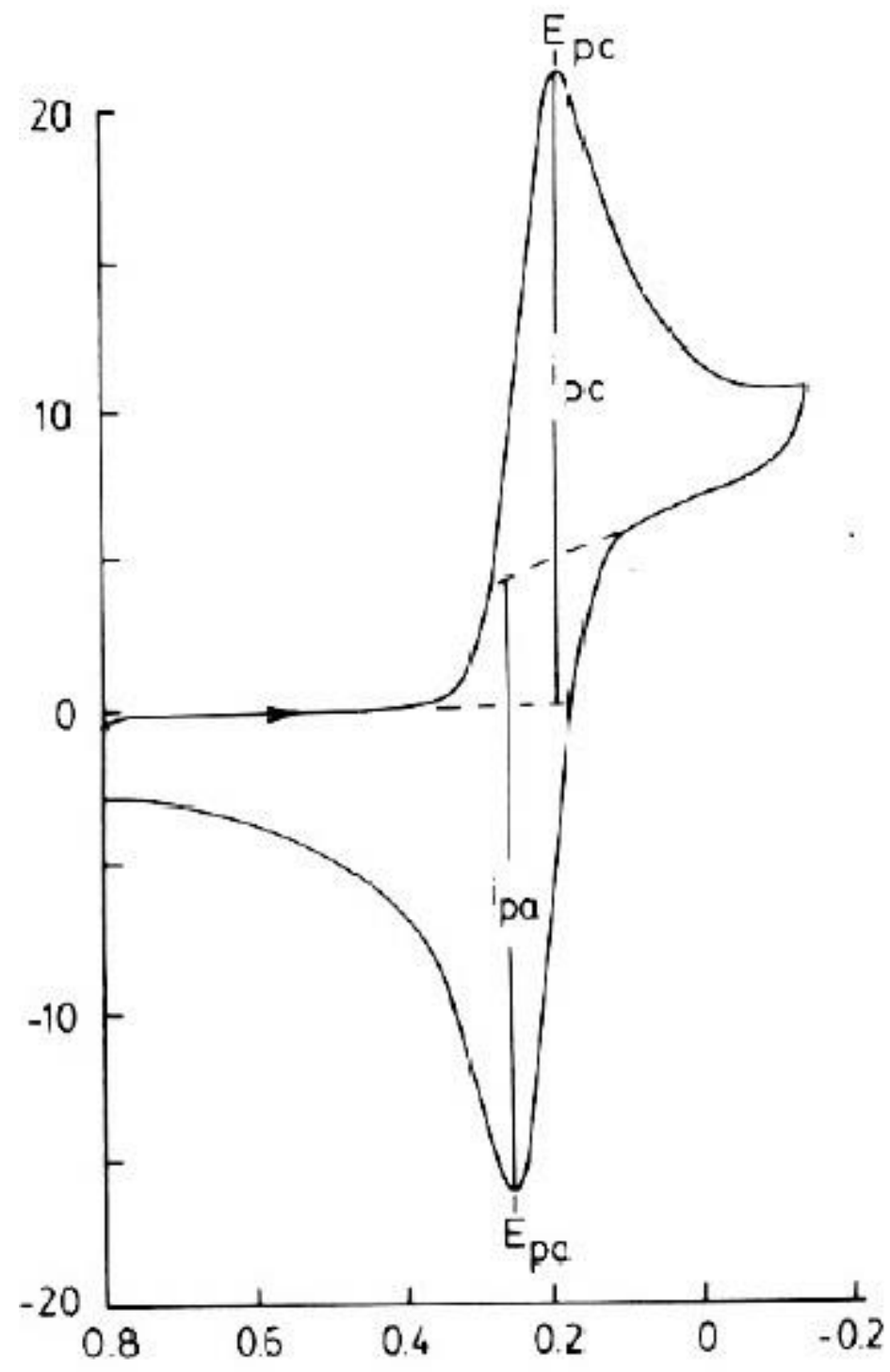

Figura 2. Voltamograma cíclico típico do par redox $\mathrm{Fe}(\mathrm{CN})_{6}^{3-/ 4-} 6 \mathrm{mM}$ em $\mathrm{KNO}_{3} 1 \mathrm{M}$, mostrando os potenciais de pico anódico (Epa) e catódico (Epc) e as correntes de pico anódica (Ipa) e catódica (Ipc). Fonte: adaptado de Kissinger (1983). [19] 


\subsubsection{Voltametria de pulso}

A voltametria de pulso diferencial (DPV) é uma das técnicas mais apropriadas para determinações quantitativas em eletroanalítica. A forma da onda em DPV é apresentada na Figura 3. Uma série de pulsos periódicos e de amplitude (denominada de amplitude de pulso) de duração idênticos são aplicados sobre uma rampa de potencial iniciando no potencial inicial $\left(\mathrm{E}_{\mathrm{i}}\right)$ e terminando no potencial final $\left(\mathrm{E}_{\mathrm{f}}\right)$. $\mathrm{O}$ incremento de potencial presente na rampa de potencial é mantido constante onde cada pulso termina num valor $\mathrm{E}+\Delta \mathrm{E}$ (incremento). As amplitudes de pulso tipicamente variam de 5 a $100 \mathrm{mV}$ e tem uma duração de $50 \mathrm{~ms}$. O intervalo entre o fim de um pulso e o fim do próximo pulso é da ordem de 0,5 a $5 \mathrm{~s}$ e é denominado de tempo de passo (ou tempo de gota em polarografia). A corrente é amostrada em 1 (17 ms antes do pulso) e 2 (17 ms antes do fim do pulso) e a diferença entre as correntes amostradas ( $\Delta \mathrm{i}$ ) é plotada em função do potencial aplicado. [18]

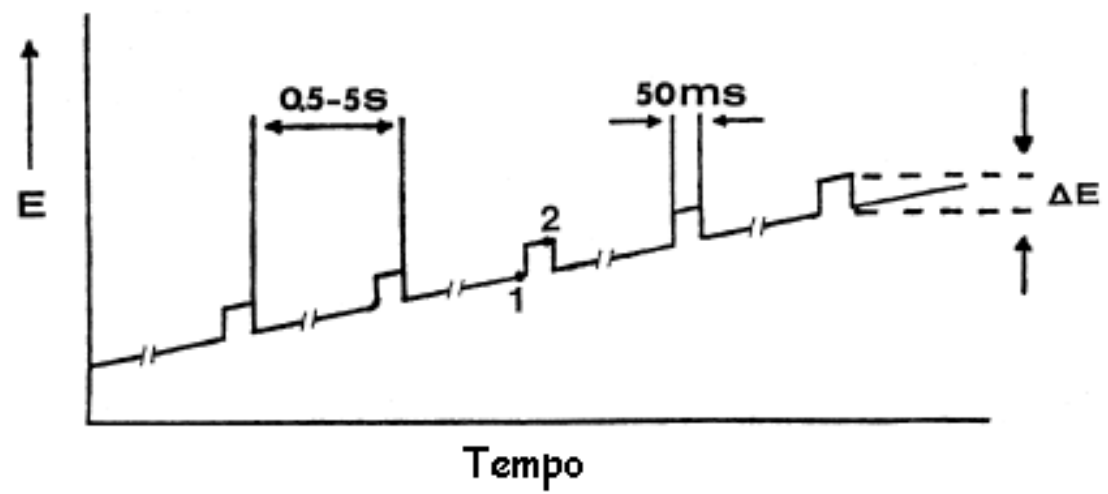

Figura 3 - Forma de onda utilizada na voltametria de pulso diferencial, mostrando a amplitude de pulso $(\Delta \mathrm{E})$, o tempo de pulso típico de $50 \mathrm{~ms}$, os pontos de amostragem de corrente 1 e 2 . Adaptado de Wang (1986).[18] 


\subsubsection{Voltametria de redissolução}

As técnicas de redissolução compreendem uma das técnicas analíticas mais sensíveis para determinação de metais em concentrações traço $\left(\mu \mathrm{g} \mathrm{L}^{-1}\right)$ ou sub traço. A alta sensibilidade dos métodos de redissolução está relacionada com uma etapa de préconcentração (deposição) do analito sobre a superfície do eletrodo de trabalho. Em seguida ocorre a etapa de determinação onde ocorre a redissolução do analito para solução eletrolítica (Figura 4). Esta pré-concentração do analito pode ser realizada de forma eletrolítica ou não eletrolítica (por exemplo: adsorção) utilizando um eletrodo de trabalho líquido $(\mathrm{Hg})$ ou sólido (exemplo: $\mathrm{Pt}, \mathrm{Au}$ e carbono vítreo). Além da alta sensibilidade, uma vantagem adicional da voltametria de redissolução é a possibilidade de determinações simultâneas. [20]

As determinações por voltametria de redissolução são realizadas numa célula eletroquímica contendo três eletrodos: um eletrodo de trabalho (WE), um eletrodo de referência (RE) e um contra eletrodo (CE). Um dos eletrodos de trabalho mais usados é o eletrodo de mercúrio de gosta suspensa (EMGS). Apesar das vantagens dos eletrodos de mercúrio tais como renovação da superfície do eletrodo de forma reprodutível e o alto sobrepotencial para o hidrogênio, este tipo de eletrodo apresenta o inconveniente de ser altamente tóxico. [20]

Eletrodos planares de filmes de mercúrio e bismuto também foram e ainda são usados na voltametria de redissolução. Filmes de mercúrio podem ser facilmente formados, por exemplo, sobre a superfície de um eletrodo de carbono vítreo. Eletrodos sólidos de $\mathrm{Pt}, \mathrm{Au}$, carbono vítreo entre outros são alvo de intenso estudo em determinações voltamétricas em substituição aos eletrodos com mercúrio. Modificações das superfícies desses eletrodos sólidos são realizadas no sentido de promover maior seletividade e sensibilidade analíticas. [21]

Uma das modalidades mais importantes da voltametria de redissolução é a voltametria de redissolução anódica (ASV) que ocorre em 3 etapas: etapa de deposição, etapa de repouso e etapa de redissolução. Na etapa de deposição um potencial fixo é 
mantido o suficiente para reduzir o analito alvo sobre a superfície do eletrodo de trabalho. A deposição ocorre num tempo rigorosamente cronometrado (e usualmente sob agitação), tendo o objetivo de promover o aumento da concentração do analito na superfície do eletrodo de trabalho através da convecção. Na etapa de repouso, a agitação é interrompida para que o sistema entre em equilíbrio. Finalmente, na etapa de redissolução o analito é reoxidado através de uma varredura anódica e devolvido de volta para a solução na sua forma inicial. [20,21] A Figura 4 apresenta o perfil de potencial em função do tempo e um destaque mostrando o voltamograma relacionado. 


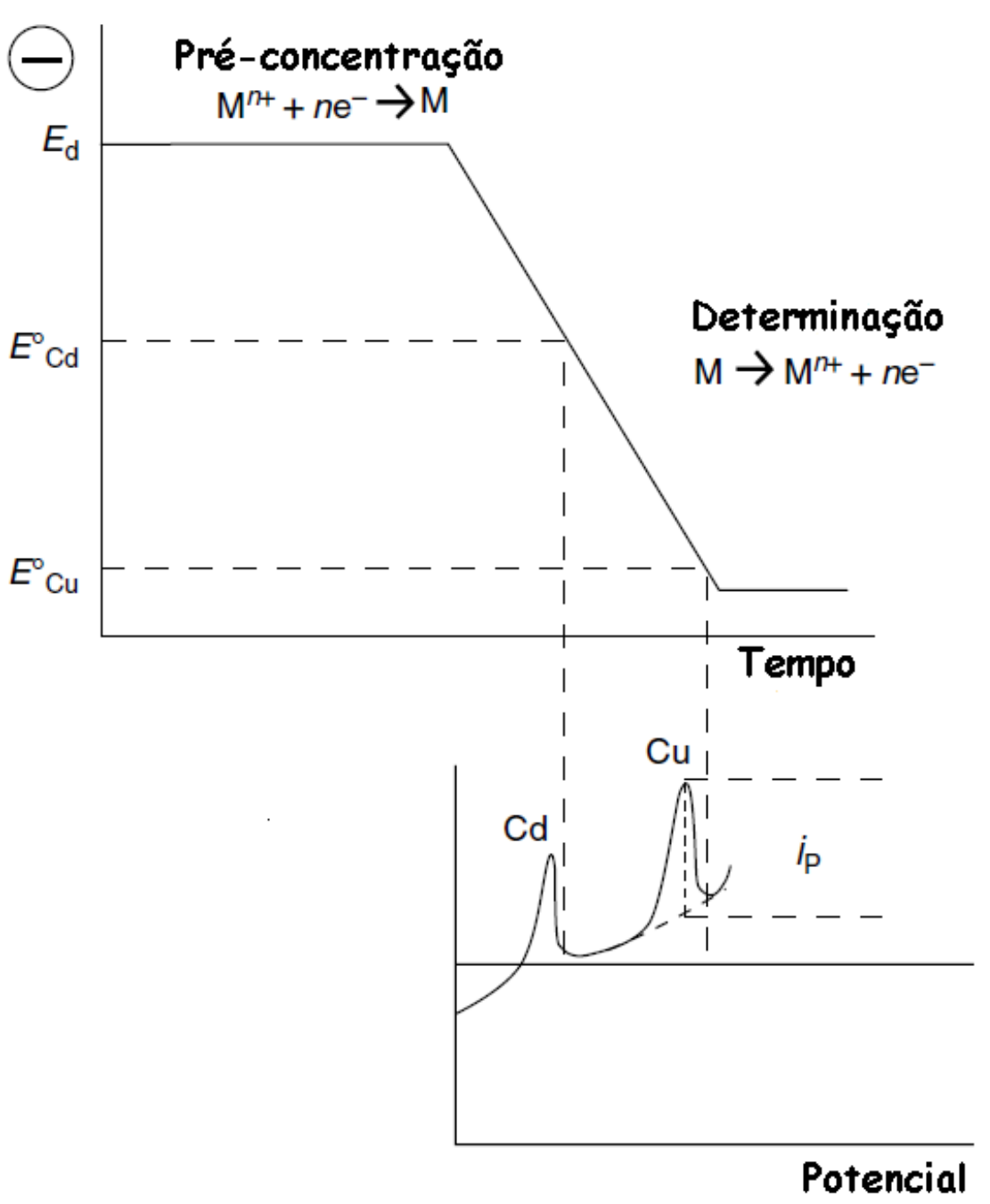

Figura 4. Perfil de potencial em função do tempo que ocorre durante a voltametria de redissolução anódica (ASV) e um destaque mostrando o voltamograma relacionado. Fonte: adaptado de Wang, J. (2006).[22] 


\subsection{VOLTAMETRIA DE REDISSOLUÇÃO ANÓDICA SOBRE ELETRODOS SÓLIDOS}

O mercúrio é um dos melhores eletrodos para análise traço de metais. Contudo, a toxidade do mercúrio bem como a sua faixa de trabalho restrita para faixa de potenciais positivos tem estimulado a busca por materiais alternativos. Entre os métodos eletroquímicos para determinação de metais em nível traço, um dos mais relevantes é a Voltametria de Redissolução (SV) . A SV envolve uma etapa de pré-concentração do metal sobre a superfície do eletrodo.[23,24] Essa etapa ocorre por três mecanismos básicos: adsorção, ligação química ou eletrodeposição.[25]

A eletrodeposição de metais sobre eletrodos sólidos ocorre geralmente pela formação de uma monocamada do metal alvo sobre a superfície do eletrodo seguida pela deposição do metal sobre essa monocamada. Os métodos de redissolução em eletrodos sólidos, apesar de algumas complicações que podem ocorrer, são simples, versáteis. Eletrodos sólidos, quimicamente modificados ou não, tem mostrado bons resultados para a determinação da concentração de metais em amostras reais.[25]

A voltametria de redissolução anódica (ASV) é uma das técnicas eletroanalíticas mais sensíveis disponíveis. [18,26] Uma vantagem da SV realizada sobre eletrodos sólidos para análise de traço é que a deposição do metal cobre uma área muito pequena da superfície do eletrodo. Isso pode contribuir para simplificação dos processos de regeneração mecânica e/ou eletroquímica da superfície do eletrodo. Em alguns casos também é possível trabalhar na presença de oxigênio dissolvido em virtude da diferença da redução do oxigênio que ocorre sobre o eletrodo sólido comparado ao eletrodo de mercúrio.[25]

Um dos trabalhos pioneiros abordando os mecanismos de eletrodeposição de íons cobre sobre eletrodos sólidos foi apresentado por Oda et al (1996). [27] Neste trabalho os autores estudaram em detalhes o envolvimento de alguns ânios no processo de eletrodeposição de íons cobre sobre a superfície de eletrodos de platina. Outros trabalhos foram propostos para análise de cobre por ASV utilizando eletrodos sólidos base e quimicamente modificados são apresentados na Tabela 1. 
A detecção de cobre por ASV utilizando etapa de pré-concentração por eletrodeposição, tem sido realizada utilizando eletrodos Mercury-free de várias configurações e propostas. Cada um desses sistemas apresentam algumas vantagens e desvantagens. 
Uma desvantagem comum da utilização desses sensores é a necessidade de etapa inicial de preparação da superfície bastante criteriosa e frequentemente demorada. Esses sistemas geralmente requerem uma repetição dessas etapas iniciais após poucas leituras. A modificação de eletrodos de Ouro com ligantes que apresentam o grupo sulfidrila HS- tem a vantagem de ligar espontaneamente sobre a superfície de outro formando monocamadas automontadas. $\mathrm{O} \mathrm{Cu}^{2+}$ pode ser depositado diretamente sobre essas monocamadas ou essa monocamada pode servir de substrato para ancoramento de outras moléculas. Apesar da ligação espontânea de grupos HS- sobre o Ouro, geralmente é necessário um tempo demasiadamente longo nesse processo o que pode limitar a utilização desses sensores em determinações de rotina.

Tabela 1. Resumo de alguns trabalhos apresentados na literatura que realizaram a determinação de $\mathrm{Cu}^{2+}$ por métodos de redissolução.

\begin{tabular}{lcccc}
\hline Eletrodo & $\begin{array}{c}\text { Faixa dinâmica } \\
(\mathrm{mM})\end{array}$ & $\begin{array}{c}\text { Sensibilidade } \\
\mu \mathrm{A} / \mathrm{mM} \mathrm{cm}^{2}\end{array}$ & $\begin{array}{c}\text { LD } \\
(\mathrm{nM})\end{array}$ & Ref. \\
\hline Rotatório de Au & 10 a 100 & & $0,2\left(\mathrm{t}_{\mathrm{d}}=90 \mathrm{~s}\right)$ & {$[28]$} \\
Au/MAS & 0 a 40 & & $\mathrm{NR}^{*}$ & {$[29]$} \\
MPPA/3D-BGNs/Au & 0,05 a 350 & 15,1 & 5 & {$[30]$} \\
Microfio de Au & $\mathrm{NR}$ & $\mathrm{NR}$ & $50\left(\mathrm{t}_{\mathrm{d}}=120\right.$ & {$[31]$} \\
& & & $\mathrm{s})$ & \\
UMEAs modificados & 0 a 10 & 25,9 & $\mathrm{NR}$ & {$[32]$} \\
Au nanoporoso & & & & \\
* NR = valor não reportado & & & &
\end{tabular}




\subsection{ITO}

O ITO é um óxido de estanho $(\mathrm{SnO})$ dopado com óxido de índio $\left(\operatorname{In}_{2} \mathrm{O}_{3}\right)$ o qual comporta-se como um semicondutor do tipo p. Filmes finos de ITO sobre o vidro além de se um condutor elétrico também apresenta uma excelente transparência a luz. Essas placas de vidro cobertas com uma fina cama de ITO tem sido usadas com sucesso como substrato para confecção de sensores para detecção de pesticidas [33], biosensor para detecção de peróxido de hidrogênio [33], sensor amperométrico para detecção de colesterol [34], sensores de gases. [35]

Placas de vidro com ITO tem um baixo custo, são acessíveis e são bastante conveniente para desenvolvimentos de sensores. Neste trabalho, placas de vidro com ITO serviram de substrato para deposição de filmes de nanopartículas de óxidos de ferro para detecção de cobre através da técnica LBL.

\subsection{FILMES ULTRAFINOS POR LBL}

A técnica Layer-by-Layer (LBL) descrita por Decher [1] constitui uma das técnicas mais simples e versáteis para montagem de filmes ultrafinos. A técnica de LBL expandiu a possibilidade utilização de outros materiais para produção de filmes como alternativa aos filmes construídos pela técnica de Langmuir-Blodgett (LB).

Nos filmes LB, monocamadas de moléculas de ácidos graxos são transferidas para um substrato sólido. O substrato é imerso em um sistema composto por uma fase líquida onde moléculas de ácidos graxos estão presentes na superfície aquosa. A parte hidrofílica ou lipofílica dos ácidos graxos podem ser atraída para o substrato formando uma monocamada organizada sobre o substrato de espessura do comprimento do ácido graxo. Conforme a natureza da superfície do substrato (hidrofílica ou hidrofóbica), e o tipo de material empregado para formar a monocamada, filmes de diferentes tipos podem ser obtidos. Algumas desvantagem do método LB são: (a) requer ambientes de 
trabalho extremamente limpos, (b) limitado a poucos tipos de materiais que podem ser depositados ao substrato e (c) processo de formação de filme lento. [36]

Em contrapartida, os filmes LBL podem ser amplia a diversidade de materiais que podem ser utilizados para formação dos filmes (Ex. proteínas, ácidos nucléicos, vírus, enzimas e polímeros), tem uma produção simples, de baixo custo e de construção mais rápida. $\mathrm{O}$ fundamento do método $\mathrm{LBL}$ consiste na deposição de policátions e poliânions depositados alternadamente sobre a superfície de um substrato eletricamente carregado. As forças intermoleculares predominantes são de natureza eletrostática no método LBL proposto por Decher e colaboradores.

No método LBL (Figura 5), um substrato sólido é imerso por um breve período de tempo numa solução aquosa contendo um polieletrólito a ser depositado. A carga desse polieletrólito substância deve ser contrária à do substrato para que ocorra adsorção por atração eletrostática. Posteriormente, o conjunto é lavado para eliminar o excesso de material e seco sob um jato de ar ou nitrogênio. Em seguida o substrato é novamente imerso numa solução contendo um outro polieletrólito, agora de carga contrária à daquele inicialmente depositado, de maneira a resultar numa bicamada formada por camadas moleculares catiônicas e aniônicas, alternadamente adsorvidas. A repetição deste processo leva à formação de filmes ultrafinos com multicamadas. [37]

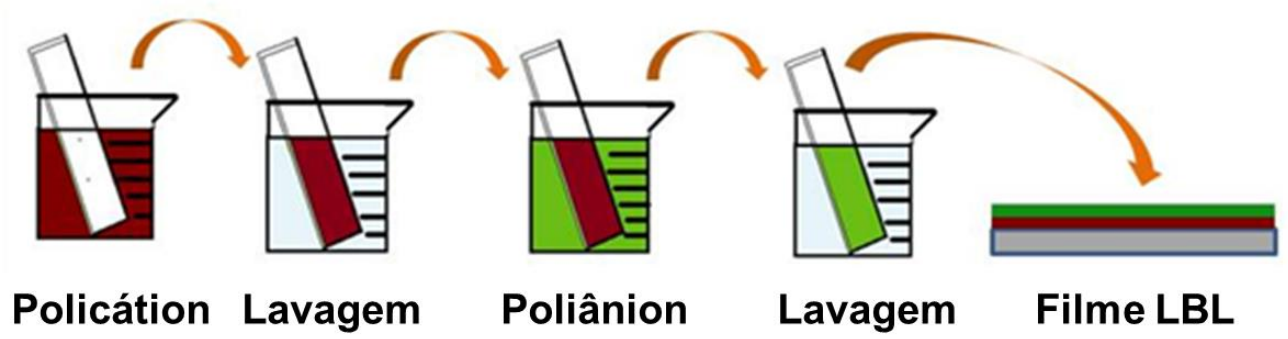

Figura 5. Processo esquemático para formação de filmes ultrafinos através da técnica Layer-by-Layer (LBL) mostrando a formação de uma única bicamada. A repetição desse processo leva a formação de multicamadas. 


\section{5 ÓXIDOS DE FERRO}

Os óxidos de ferro são substâncias bastante comuns que são largamente encontradas na crosta terrestre, em águas naturais, em organismos vivos e até mesmo no ar. Os óxidos de ferro apresentam rotas sintéticas laboratoriais bem definidas e conhecidas e são objeto de pesquisa em várias áreas do conhecimento tais como medicina, geoquímica, química ambiental e mineralogia. São conhecidos 16 tipos de compostos denominados coletivamente de óxidos de ferro os quais podem ser óxidos, hidróxidos ou óxido-hidróxidos de ferro. Entre os óxidos de Ferro, uma das formas mais importantes são a Hematita $\left(\alpha-\mathrm{Fe}_{2} \mathrm{O}_{3}\right)$, a Magnetita $\left(\mathrm{Fe}_{3} \mathrm{O}_{4}\right)$ e a Magemita $\left(\gamma-\mathrm{Fe}_{2} \mathrm{O}_{3}\right)$. [38]

A magnetita é um mineral preto e ferromagnético contendo Ferro nos dois estados de oxidação mais comuns: Fe(II) e Fe(III). A magnetita apresenta um sistema de cristalização cúbico com estrutura do tipo espinélio inversa. Nesta estrutura os átomos de oxigênio formam uma rede cúbica de face centrada com os átomos de ferro ocupando os sítios intersticiais. Cada célula unitária da estrutura espinélio contém oito células cúbicas de face centrada formadas por átomos de oxigênio. Os sítios tetraédricos são ocupados por íons $\mathrm{Fe}^{3+}$ e os sítios octaédricos são ocupados por um número igual de íons $\mathrm{Fe}^{2+}$ e $\mathrm{Fe}^{3+}$. [39]

A magnetita é um dos mais importantes minerais de óxidos de ferro e juntamente com a titanomagnetita é a responsável pelas propriedades magnéticas das rochas. Em alguns organismos, a magnetita é biossintetizada com a finalidade de auxiliar os organismos na sua orientação espacial. Existem uma grande diversidade de nomes para esse mineral (Ex. ferrita ferrosa, óxido de ferro negro, óxido de ferro (II) e ferro (III), entre outros) o qual reflete os múltiplos interesses nesse óxido. [38]

Um dos processos mais utilizados para síntese da nanopartículas de óxidos de ferro é a co-precipitação química em meio aquoso a qual pode ser resumida em duas etapas. A primeira etapa é chamada de nucleação que ocorre quando a concentração das espécies atinge um nível de supersaturação crítico. A segunda etapa é a de crescimento 
dos núcleos que ocorre por difusão dos solutos para a superfície dos cristais. Para formação de nanopartículas com pouca dispersão de tamanhos estes dois estágios devem ocorrer em momentos separados, não havendo formação de novos núcleos durante o período de crescimento das já existentes. [40,41] Após a co-precipitação das nanopartículas é realizada uma etapa de lavagem para a remoção de resíduos e contraíons da base. A última etapa consiste na peptização das partículas de magnetita precipitadas em uma solução aquosa ácida e deixadas em agitação por 24 h. [42]

\subsection{SENSORES DE NANOPARTÍCULAS DE ÓXIDOS DE FERRO (ION)}

Nanopartículas de óxidos de ferro (ION) tem um papel marcante em processos de conversão/estocagem de energia e sensores químicos. ION tem um baixo custo de preparação e uma faixa ampla de propriedades eletroquímicas e fotoeletroquímicas. $\mathrm{Na}$ área de sensores químicos, o ION tem sido empregado na construção de eletrodos nanoestruturados para a detecção de alguns analito incluindo peróxido de hidrogênio, dopamina (DA), ureia e glicose. [2-10] Nestes dispositivos, o ION pode agir de diferentes maneiras tais como um eletrocatalisador, ancorando enzimas e hemoglobina ou eventualmente no aumento do tempo de vida do eletrodo. Eletrodos modificados com ION tem sido usados também na detecção de gases e cátions metálicos importantes em solução. [11-14]

Adekunle et al. [2] tem empregado nanopartículas de magnetita $\left(\mathrm{Fe}_{3} \mathrm{O}_{4}, \sim 30\right.$ $\mathrm{nm}$ ) eletroquimicamente depositadas sobre um eletrodo base de nanotubos de carbono de parede única (SWCNT) para a detecção de DA. Os autores propuseram que essas nanopartículas são responsáveis por um efeito eletrocatalítico gerado através da sua interação com SWCNT e também em virtude de sua interação específica com as moléculas de DA (formação de quelato através do $\mathrm{Fe}^{3+}$ ). Mais recentemente, Cao e $\mathrm{Hu}$ [5] bem como Zhao et al. [6] observaram que np- $\mathrm{Fe}_{3} \mathrm{O}_{4}$ pode agir por transferência eletrônica direta entre hemoglobina e eletrodos de grafite e melhorar a atividade biocatalítica para a redução de oxigênio, peróxido de hidrogênio, ácido tricloroacético e 
nitrito. Os autores descobriram também que $\mathrm{np}-\mathrm{Fe}_{3} \mathrm{O}_{4}$ podem proporcionar uma matriz mais compatível para proteínas tais como hemoglobina, evitando a sua desnaturação. Cummings et al. [7] descobriram que um eletrodo ITO revestido com nanopartículas de magemita (np- $\mathrm{Fe}_{3} \mathrm{O}_{4}, \sim 10 \mathrm{~nm}$ ) podem apresentar espécies de $\mathrm{Fe}(\mathrm{IV})$ superficiais que catalisam a oxidação de glicose para gluconolactona em meio de tampão carbonato. McKenzie et al. [8] mostraram que as nanopartículas de óxido de ferro hidratado adsorvidos sobre eletrodos de diamante dopado com boro podem atuar como um catalizador eficiente num processo do tipo Fenton conduzindo a oxidação do peróxido de hidrogênio.

Os eletrodos baseados em ION podem ser fabricados por diferentes processos de deposição. Entre as estratégias de adsorção se destaca o processo de adsorção por layer-by-layer (LBL). A técnica de LBL consiste num processo físico de adsorção comandado predominantemente por forças eletrostáticas. Neste trabalho uma solução de ION coloidal foi depositado sobre um substrato de ITO com diferentes polieletrólitos. Esta estratégia provou ser bastante simples e eficaz para a produção de filmes com multicamadas de nanocompósitos. [43] O modo de adsorção eletrostática por LBL proporciona um controle da quantidade de material adsorvida por camada (ciclo de deposição), de modo que a espessura do filme e a massa do filme por $\mathrm{cm}^{2}$ podem ser adequadamente manipuladas. [43,44] 


\subsection{COBRE}

O cobre é um elemento essencial e sua necessidade humana em adultos é cerca de $0,9 \mathrm{mg}$ de cobre por dia. Porém em excesso o cobre é tóxico. Assim como outros íons metálicos, o cobre exerce sua função biológica em combinação com proteínas específicas. A principal função do cobre nos organismos está associada a transferência de energia nas células. Adicionalmente, o cobre associado a proteínas também atua nos processos envolvendo transporte de oxigênio. [15] Os distúrbios genéticos síndrome de Wilson e síndrome de Menkes podem afetar a capacidade do corpo humano de utilizar o cobre de maneira apropriada. [16]

Alguns crustáceos utilizam complexos de cobre semelhantes a hemoglobina para transporte de oxigênio pelo seu corpo. Na hemoglobina, o Fe(II) atua como cofator, enquanto nestes crustáceos, o $\mathrm{Cu}$ (II) atua como cofator de uma proteína do grupo heme (tal como a Hemocupreina) responsável pelo transporte de oxigênio intracorpóreo. Adicionalmente, vários alimentos vegetais tais como aspargo, couve, castanha de caju, soja, grãos de café entre outros são fontes nutricionais relevantes de cobre. [45] Ente essas fontes, o café torna-se bastante relevante por ser uma bebida muito consumida no brasil. 


\subsection{CAFÉ}

O Brasil é o maior produtor, maior exportador e segundo maior consumidor de café mundial, com uma área plantada de cerca de 2,3 milhões de hectares. Na safra de 2011 a produção brasileira de café alcançou 43,5 milhões de sacas de $60 \mathrm{~kg}$ representando valores expressivos da produção mundial. O café é uma das commodities mais importantes na economia mundial, sendo uma das bebidas mais consumidas no mundo. No Brasil, o consumo de café cresceu $45 \%$ nos últimos 10 anos podendo alcançando 21 milhões de sacas de $60 \mathrm{~kg}$ (cerca de 6,4 kg café ano ${ }^{-1}$ per capta). Estimase que em 2020 a o consumo brasileiro poderá alcançar 27,5 milhões de saca. [46]

Os atributos físicos e sensoriais de sabor e aroma do café estão relacionados com a composição química e características dos grãos de café. Por sua vez esses atributos são fortemente influenciados pela forma de condução da lavoura, colheita e processamento dos grãos pós-colheita. O preço do café varia devido a sua qualidade e esta está relacionada com as propriedades químicas e organolépticas. A diferenciação do café pela forma de apresentação é um dado fundamental para estudos nutricionais, pois fornece dados sobre a variação dos macro e micronutrientes e dos valores consumidos destes elementos nas dietas por meio do café. Todas essas diferenciações têm sido atestadas por meio da determinação de níveis de íons metálicos, especialmente do $\mathrm{Cu}(\mathrm{II})$. [47-49] 


\subsection{COBRE E OUTROS METAIS EM CAFÉ}

Os íons metálicos têm sido utilizados como descritores químicos (diferenciadores, marcadores) da qualidade do café por serem mais estáveis e menos afetados pelas condições de armazenamento do que vitaminas e outros tipos de compostos orgânicos presentes em sua composição. Estudos diversos da literatura mostram que os íons $\mathrm{Cu}(\mathrm{II})$ podem ser um dos parâmetros importantes para atribuições de qualidade ao café comercializado, pois seus níveis variam de acordo com a origem geográfica, a variedade e a forma de apresentação do café.

Grembecka et al. [50] realizaram um estudo detalhado sobre os níveis de íons metálicos em 60 marcas de café de diferentes origens geográficas em três formas de apresentação (moído: sem características especiais, aromatizado, descafeinado e puro; instantâneo; infusão). Níveis diferentes de $\mathrm{Cu}(\mathrm{II})$ foram observados para as três formas de apresentação e o café instantâneo apresentou as concentrações mais baixas de cobre. Neste mesmo trabalho, as variedades arábica e robusta foram diferenciadas por meio dos níveis de $\mathrm{Cu}(\mathrm{II})$ e de outros íons metálicos e foi possível ainda verificar se o café continha $100 \%$ de uma única variedade proveniente de uma única origem geográfica; ou, se continha misturas de ambas as variedades pertencentes a várias origens geográficas.

Oleszczuk et al. [51] mostraram que grãos de café brasileiro de origens geográficas distintas tais como cerrado mineiro, planalto baiano e a região Mogiana paulista apresentam concentrações diferentes de $\mathrm{Cu}(\mathrm{II})$, sendo que a diferença parece significativa em alguns casos. Ashu \& Chandravanshi [52] mostraram que os níveis de $\mathrm{Cu}(\mathrm{II})$ em grãos torrados de café etíope são significativamente mais baixos que os de outros países, como Brasil, Uganda e Costa do Marfim. Este trabalho mostrou ainda que o cobre é um descritor químico melhor que o ferro, o zinco ou o manganês para distinguir o café brasileiro do café africano. Isso ocorre devida a faixa de variação de concentração de cobre no café brasileiro é mais estreita que a dos outros íons metálicos. 
Anderson e Smith [53] mostraram que grãos de café torrado provenientes das três maiores regiões produtoras (Indonésia, África e América Central e do Sul) apresentam concentrações distintas de cobre. Além de atuar como diferenciador químico do café, os íons $\mathrm{Cu}$ (II) também são utilizados nas lavouras cafeeiras, por meio da aplicação de fungicidas cúpricos, para garantir o crescimento, a produção e a tonificação das plantas de café e para controlar as doenças. Para trazer estes benefícios às lavouras de café, os níveis de $\mathrm{Cu}$ (II) nas folhas devem ser de $80 \mathrm{mg} /$ planta no crescimento e $250 \mathrm{~g} / \mathrm{ha} / \mathrm{ano}$ na fase adulta. [54] Se as concentrações de $\mathrm{Cu}$ (II) estiverem abaixo ou acima destes limites padrões, as plantas de café podem apresentar sintomas de deficiência ou toxidez, respectivamente. Concentrações elevadas de $\mathrm{Cu}(\mathrm{II})$ nas folhas também poderão causar efeitos nocivos à saúde humana e ao meio ambiente. [55] Neste cenário, o monitoramento da concentração dos íons $\mathrm{Cu}$ (II) no café é de vital importância para sua produção e comercialização.

Atualmente, o monitoramento de $\mathrm{Cu}^{2+}$ e de outros íons metálicos é realizado por meio das técnicas espectroscópicas tais como a AAS, ICP-AES e ICP-MS. Estas possibilitam medição precisa e acurada da concentração total dos íons metálicos e no caso das técnicas de ICP-AES e ICP-MS, a concentração de diferentes metais é determinada de forma simultânea. [56,57] A associação destas técnicas com métodos de reconhecimento de padrão tem sido realizada por alguns grupos de pesquisa para diferenciar o café quanto à origem geográfica, variedade e forma de apresentação.

Santos \& Oliveira [58] utilizaram a técnica de ICP-AES para determinar a concentração de $\mathrm{Cu}^{2+}$ e outros íons metálicos em cafés brasileiros e demonstraram que existem diferenças entre as 12 marcas analisadas aplicando a análise de componentes principais (PCA) e análise de agrupamento hierárquico para a interpretação dos resultados. Martín et al. também utilizaram a técnica de ICP-AES para determinar a concentração de $\mathrm{Cu}^{2+}$ e outros íons metálicos em amostras de café das variedades arábica e robusta de diferentes países. Neste trabalho, também foi aplicando métodos de reconhecimento de padrão para classificação das diferentes amostras analisadas. Os autores mostraram que os níveis de $\mathrm{Cu}, \mathrm{Mn}$ e $\mathrm{P}$ variam de acordo com a origem geográfica e a variedade do café. $[59,60]$ 
Em outro trabalho Ashu \& Chandravanshi utilizaram a técnica de AAS (com chama) para determinar os níveis de $\mathrm{Cu}^{2+}$ em cafés comercializados na Etiópia e em outros países; e, demonstraram que há diferença significativa entre origens geográficas (Brasil, Etiópia, Índia, Uganda), marcas (Abyssinia, Alem e Pride) e formas de apresentação. [52] A técnica de AAS (com forno de grafite) também foi utilizada por Oleszczuk et al. para determinar a concentração de cobre, magnésio e cobalto em cafés brasileiros e foram observadas diferenças nos níveis de $\mathrm{Cu}(\mathrm{II})$ entre as sete amostras analisadas de cinco estados brasileiros (BA, ES, MG, PR e SP). As desvantagens das técnicas de AAS e ICP (MS e AES) são o alto custo para aquisição e manutenção dos equipamentos e o fato delas serem de grande porte, ou seja, utilizadas em laboratório e difíceis de serem adaptadas ao campo. [51] 


\section{PARTE EXPERIMENTAL}

\subsection{REAGENTES E SOLUÇÕES}

Todos os produtos químicos utilizados neste trabalho foram de grau analítico, ou melhor, e utilizados como recebidos (Tabela 2). Soluções padrão de $\mathrm{Zn}^{2+}, \mathrm{Mn}^{2+}$, $\mathrm{Ni}^{2+}$ e $\mathrm{Fe}^{3+} 1000 \mathrm{mg} \mathrm{L}^{-1}$ empregados o estudo de interferentes foram obtidos da FLUKA. Todas as soluções foram preparadas exclusivamente com água ultrapuras (18 Mohm cm) fornecidas por um sistema de purificação de água Milli-Q da Millipore. 
Tabela 2. Reagentes utilizados na síntese das nanopartículas de magnetita e preparação do eletrodo ${ }^{\mathrm{a}}$, preparação de soluções tampão e padrões ${ }^{\mathrm{b}}$ e digestão da $\operatorname{amostra}^{\mathrm{c}}$.

\begin{tabular}{|c|c|}
\hline REAGENTE & FONTE \\
\hline $\begin{array}{l}\text { Poliestireno sulfonato de sódio }{ }^{\text {a }} \\
\left(\text { PSS, massa molar } 7000 \mathrm{~g} \mathrm{~mol}^{-1} \text { ) }\right.\end{array}$ & Sigma-Aldrich \\
\hline Sal sódico do ácido propano-3-mercapto a (3-MPS) & Sigma-Aldrich \\
\hline Hidróxido de sódio PA ${ }^{\text {a }}$ & Sigma-Aldrich \\
\hline Ácido perclórico PA ${ }^{\mathrm{a}}$ & Sigma-Aldrich \\
\hline Cloreto de Ferro II dihidratado ${ }^{a}$ & Sigma-Aldrich \\
\hline Cloreto de Ferro (III) hexahidratado ${ }^{\text {a }}$ & Sigma-Aldrich \\
\hline Hexacianoferrato de potássio ${ }^{b}$ & Vetec \\
\hline Sulfato de cobre pentahidratado ${ }^{b}$ & Vetec \\
\hline Ácido acético glacial $100 \%$ b & Merck \\
\hline Acetato de amônio pa ${ }^{b}$ & Vetec \\
\hline Ácido nítrico $65 \%$ suprapuro $^{c}$ & Merck \\
\hline Peróxido de hidrogênio $30 \%{ }^{c}$ & Vetec \\
\hline Cloreto de sódio PA & Vetec \\
\hline Hidrogenofosfato de sódio PA & Vetec \\
\hline
\end{tabular}




\subsection{DETECÇÃO DE $\mathrm{Cu}^{2+}$ UTILIZANDO ELETRODO DE ITO MODIFICADO COM NANOPARTÍCULAS DE MAGNETITA $\left(\mathbf{n p}-\mathrm{Fe}_{2} \mathrm{O}_{4}\right)$}

\subsubsection{Síntese das nanopartículas de magnetita $\left(\mathrm{np}-\mathrm{Fe}_{3} \mathrm{O}_{4}\right)$}

A preparação das np- $\mathrm{Fe}_{3} \mathrm{O}_{4}$ foram realizadas por co-precipitação de $\mathrm{Fe}(\mathrm{II})$ e $\mathrm{Fe}(\mathrm{III})$ em $\mathrm{NaOH}$. [61] Neste experimento, uma solução aquosa contendo $\mathrm{Fe}(\mathrm{II}) / \mathrm{Fe}(\mathrm{III})$ na razão molar 1: 2 (mantida sob agitação e a temperatura ambiente), foi gotejado $\mathrm{NaOH}$. Depois da completa precipitação dos íons ferro, a solução foi mantida sob agitação na mesma temperatura por mais $30 \mathrm{~min}$. $\mathrm{O}$ precipitado preto de $n p-\mathrm{Fe}_{3} \mathrm{O}_{4}$ foi separado do sobrenadante por decantação e lavado 3 vezes com água ultrapura. A estequiometria da reação de co-precipitação pode ser representada pela Eq. (1). [61]

$\mathrm{Fe}^{2+}(\mathrm{aq})+2 \mathrm{Fe}^{3+}(\mathrm{aq})+8 \mathrm{OH}^{-}(\mathrm{aq}) \rightarrow \mathrm{Fe}_{3} \mathrm{O}_{4}(\mathrm{~s})+4 \mathrm{H}_{2} \mathrm{O}(\mathrm{l})$

$\mathrm{O}$ precipitado isolado foi disperso em solução aquosa de $\mathrm{HClO}_{4} \mathrm{pH} 3$ sob agitação magnética por $18 \mathrm{~h}$. Depois dessa etapa, a dispersão obtida foi sonicada por mais 10 min e então centrifugada (4500 rpm, $10 \mathrm{~min}$ ) para remover partículas agregadas. Essa dispersão coloidal final foi empregada como fonte de nanopartículas na preparação dos filmes. A estabilidade da solução coloidal tem origem nas forças de repulsão eletrostática entre as partículas dispersas, as quais estão protonadas em meio ácido. A concentração de ferro $\left(\mathrm{mg} \mathrm{mL}^{-1}\right)$ das dispersões coloidais foram determinadas por espectrometria de absorção molecular UV-vis e FAAS. 


\subsubsection{Deposição dos filmes}

Lâminas ópticas (tipo BK7) e lâminas de vidro revestidas com óxido de estanho dopado com índio (ITO $30 \mathrm{ohm}$ ) de 1x10x25 mm comprados no comércio foram empregadas como substrato para deposição de nanocompósitos de magnetita e para caracterizações por espectroscopia UV-vis e medidas eletroquímicas, respectivamente. Lâminas de BK7 revestidas de Au através da pulverização catódica foram usadas para preparar as amostras para a espectroscopia Raman.

As lâminas de vidro foram previamente limpas num processo em duas etapas com a solução piranha $\left(\mathrm{H}_{2} \mathrm{O}_{2} 30 \%\right.$ e $\mathrm{HNO}_{3}$ conc. 3:1) e a solução RCA $\left(\mathrm{H}_{2} \mathrm{O} ; \mathrm{NH}_{4} \mathrm{OH}\right.$ $25 \%$ e $\mathrm{H}_{2} \mathrm{O}_{2} 30 \%$ 5:1:1) como descrito por Paterno e colaboradores. [62] As lâminas de ITO foram cuidadosamente limpas com detergente neutro por 20 min num banho ultrassônico. O detergente foi então removido com água ultrapura. Os substratos foram então sonicados em água ultrapura por mais 20 min. Uma suspensão coloidal de np$\mathrm{Fe}_{3} \mathrm{O}_{4}\left(0,1 \mathrm{mg} \mathrm{mL}^{-1}\right)$ carregada positivamente e uma solução de PSS $\left(1,0 \mathrm{mg} \mathrm{mL}{ }^{-1}\right.$, pH 3,0 $\mathrm{HClO}_{4}$ ) foram usadas em todas as deposições dos filmes.

As deposições foram realizadas através da técnica LBL no qual o substrato foi alternadamente imerso na suspensão de np- $\mathrm{Fe}_{3} \mathrm{O}_{4}$ e na solução de PSS, seguida por uma etapa de lavagem e secagem antes da imersão em cada solução. O tempo de imersão do substrato (tempo de adsorção) para ambas as soluções foi de 3 min com uma etapa de limpeza de $20 \mathrm{~s}$. A secagem foi realizada em fluxo de gás nitrogênio. Os ciclos de deposição resultaram num filme de multicamadas de $\left(\mathrm{np}-\mathrm{Fe}_{3} \mathrm{O}_{4} / \mathrm{PSS}\right)_{\mathrm{n}}$ onde $\mathrm{n}$ é o número de ciclos ou bicamadas. As condições de deposição do filme foram definidas em trabalhos anteriores. [63] Esse processo de deposição foi o mesmo empregado em todos os substratos (lâminas de ópticas, ITO e vidro recoberto por ouro). Todas as deposições foram realizadas a $25^{\circ} \mathrm{C}$. 


\subsubsection{Caracterizações}

$\mathrm{O}$ tamanho e morfologia das $\mathrm{np}-\mathrm{Fe}_{3} \mathrm{O}_{4}$ foram avaliadas por TEM (Jeol Jim $1011,80 \mathrm{kV}$ ). As amostras para TEM foram preparadas através do gotejamento de uma suspensão de $\mathrm{np}-\mathrm{Fe}_{3} \mathrm{O}_{4}$ altamente diluída e positivamente carregada sobre grids de cobre (TedPela). Em seguida a amostra foi secada num dessecador.

O potencial zeta de np- $\mathrm{Fe}_{3} \mathrm{O}_{4}$ da suspensão coloidal foi medido com um Nano Z590 Malvern Zetasizer Nanoseries. A absorção de cada bicamada de (np- $\mathrm{Fe}_{3} \mathrm{O}_{4} / \mathrm{PSS}$ ) foi medida ex situ por espectrometria UV-vis (Varian Cary 5000). A estrutura vibracional da np- $\mathrm{Fe}_{3} \mathrm{O}_{4}$ no filme de nanocompósitos foi avaliada por espectroscopia Raman (Jobin Yvon T 64000, laser $514 \mathrm{~nm}$ ). A morfologia dos nanocompósitos foi avaliada por AFM (Digital MultiMode Nanoscope IIIa, tapping mode).

As caracterizações eletroquímicas por Voltametria e Impedância Eletroquímica dos eletrodos ION foram todas realizadas num potenciostato da Autolab (EcoChimie, PGSTAT 30) utilizando uma célula eletroquímica com três eletrodos sendo eles: eletrodo de referência de $\mathrm{Ag} / \mathrm{AgCl}$, eletrodo auxiliar de platina e o eletrodo de trabalho ION constituído de uma lâmina de vidro recoberto com ITO e modificado com 1, 3, 5, 7 e 10 bicamadas de $\left(\mathrm{np}-\mathrm{Fe}_{3} \mathrm{O}_{4} / \mathrm{PSS}\right)_{\mathrm{n}}$. O eletrólito foi uma solução de acetato de sódio $0,1 \mathrm{~mol} \mathrm{~L}^{-1} \mathrm{pH} 4,6$. Antes de cada medida, a célula eletroquímica foi purgada com fluxo de gás nitrogênio por $300 \mathrm{~s}$. O período de repouso de $30 \mathrm{~s}$ foi observado antes de cada medida.

Os voltamogramas cíclicos foram adquiridos no eletrólito suporte sem a presença de $\mathrm{Cu}(\mathrm{II})$ (para identificar a janela de potencial) e na presença do par redox $\mathrm{Fe}(\mathrm{CN})_{6}^{-3 /-4} 1,00 \mathrm{mmol} \mathrm{L}^{-1}$. Desses dados foram obtidos os parâmetros: constante de velocidade de transferência eletrônica aparente $\left(\mathrm{k}_{\text {app }}^{\mathrm{o}}\right)$, potencial de separação de picos $\left(\Delta \mathrm{E}_{\mathrm{p}}\right)$ e coeficiente de transferência eletrônica $(\alpha)$. 


\subsection{REDISSOLUÇÃO ANÓDICA POR PULSO DIFERENCIAL DE ÍONS COBRE SOBRE OS ELETRODOS DE ION}

O desempenho analítico do eletrodo ION para detecção de íons $\mathrm{Cu}^{2+}$ foi avaliado por Voltametria de Redissolução Anódica por Pulso Diferencial (DPASV). Estes experimentos foram realizados utilizando o Potenciostato da Metrohm, Modelo 797 VA Computrace numa célula eletroquímica de $5 \mathrm{~mL}$ com três eletrodos (Figura 6). O eletrodo de referência foi um eletrodo de $\mathrm{Ag} / \mathrm{AgCl}(\mathrm{KCl}, 3 \mathrm{M})$, o eletrodo auxiliar utilizado foi um fio de platina e como eletrodo de trabalho foi utilizado uma placa de ITO 15 x $5 \mathrm{~mm}$ com o filme de ION depositado como descrito na Seção 4.2.2. A área do eletrodo de trabalho foi delimitada utilizando fita mágica de $10 \mathrm{~mm}$ (Scotch 3M). As condições experimentais das medidas por DPASV estão resumidas na Tabela 3. Cada eletrodo foi pré-condicionado utilizando o sinal de Voltametria Cíclica de -0,4 a +0,6 V por 5 ciclos na velocidade de varredura de $100 \mathrm{mV} \mathrm{s}^{-1}$ e enxaguado em seguida em água ultrapura antes do seu uso.
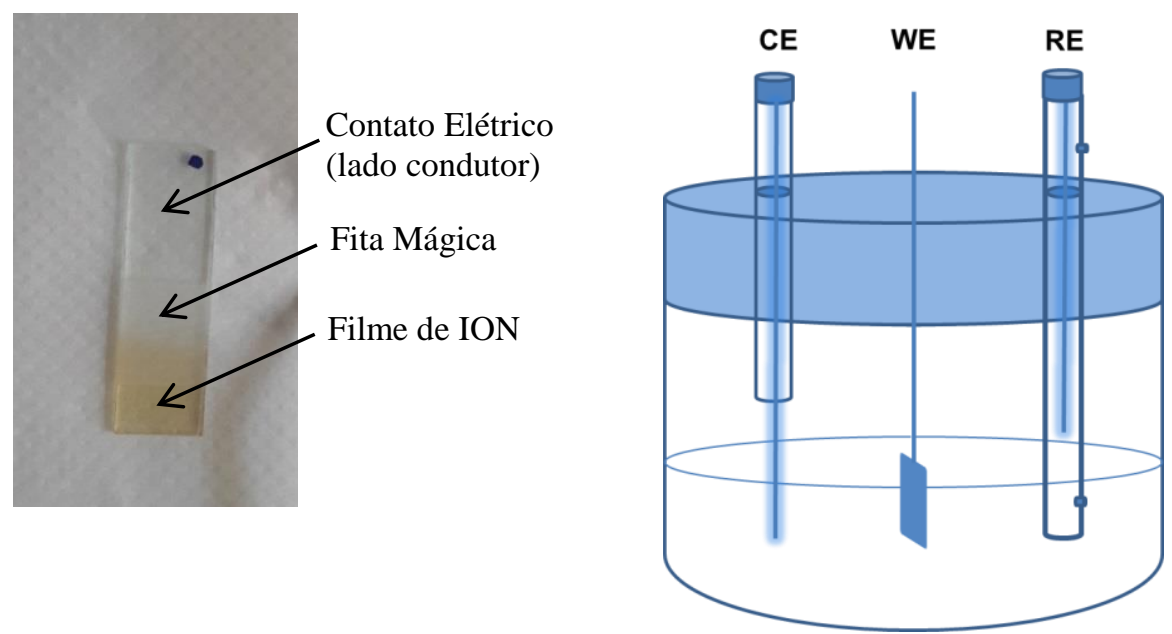

Figura 6. (a) Eletrodo de trabalho (WE) de ITO com filme de ION, mostrando a região de contato elétrico, a fita mágica delimitando a área mais escura onde o filme de ION foi depositado. (b) Célula eletroquímica utilizada para realizar estudos para detecção de $\mathrm{Cu}^{2+}$ por DPASV mostrando o eletrodo de referência (RE), eletrodo auxiliar (CE) e o eletrodo de trabalho (WE). 
Tabela 3. Condições experimentais para a determinação de $\mathrm{Cu}^{2+}$ por DPASV ${ }^{\mathrm{a}}$.

\begin{tabular}{lccc}
\hline Etapa & Agitação & Potencial (V) & Tempo (s) \\
\hline Limpeza/purga & $2000 \mathrm{rpm}$ & Célula em off & 150 \\
Acumulação & 0 a $2000 \mathrm{rpm}$ & $-0,4$ & 120 \\
Equilíbrio & em repouso & $-0,4$ & 30 \\
Determinação $^{\text {a }}$ & em repouso & $-0,4 \mathrm{a}+0,6$ & 60 \\
\hline
\end{tabular}

a. A determinação foi realizada por pulso diferencial utilizando os seguintes parâmetros: amplitude de pulso $50 \mathrm{mV}$, scan rate $10 \mathrm{mV} \mathrm{s}^{-1}$, tempo de pulso de $57 \mathrm{~ms}$.

\subsubsection{Parâmetros inerentes ao sinal de pulso diferencial}

A amplitude de pulso bem como a velocidade de varredura são parâmetros que estão intrinsicamente relacionados com o sinal de pulso diferencial. Uma solução de ácido acético $0,100 \mathrm{M}$ contendo $100 \mu \mathrm{g} \mathrm{L}^{-1}$ de íons $\mathrm{Cu}^{2+}$ foi utilizada para aquisição dos sinais de pulso diferencial. Os parâmetros experimentais foram aqueles apresentados na Tabela 3.

\subsubsection{Parâmetros de redissolução anódica}

Os parâmetros $\mathrm{pH}$, concentração e natureza da solução eletrolítica, potencial de deposição, tempo de deposição e velocidade de agitação foram avaliados para a detecção de íons $\mathrm{Cu}^{2+}$ sobre os eletrodos de ION. As condições experimentais foram aquelas apresentadas na Tabela 3. Em todos os estudos foram utilizados ácido acético $0,100 \mathrm{M}$ como solução eletrolítica e os voltamogramas foram obtidos para os íons $\mathrm{Cu}^{2+}$ na concentração de $100 \mu \mathrm{g} \mathrm{L}{ }^{-1}$. 


\subsection{PARÂMETROS DE VALIDAÇÃO PARA DETECÇÃO DE IONS COBRE COM O ELETRODE DE ION}

\subsubsection{Faixa de Trabalho e Sensibilidade}

A faixa de trabalho compreende o intervalo de concentrações na qual os experimentos são realizados para detectar e quantificar o analito alvo. Neste trabalho avaliamos a resposta analítica para os eletrodos de ION em solução de ácido acético $0,100 \mathrm{M}$ na faixa de concentração de 5 a $400 \mu \mathrm{g} \mathrm{L} \mathrm{L}^{-1}$. As leituras foram realizadas utilizando PDASV nas condições experimentais definidas na Tabela 3. A faixa de trabalho foi definida com base no coeficiente de correlação de Pearson (r).

A resposta analítica (sinal analítico) varia em função da concentração do analito. A magnitude dessa variação, obtida através da inclinação da curva analítica, é denominada de sensibilidade $(\gamma)$. A sensibilidade foi calculada através da Equação (2).

$\gamma=\frac{n \sum\left(x_{i} y_{i}\right)-\sum x_{i} \sum y_{i}}{n \sum\left(x_{i}^{2}\right)-\left(\sum x_{i}\right)^{2}}$

Onde $\mathrm{n}$ é o número de pontos da curva de regressão e $\mathrm{x}_{\mathrm{i}}$ e $\mathrm{y}_{\mathrm{i}}$ representam os valores individuais das concentrações de $\mathrm{Cu}^{2+}$ e resposta analítica respectivamente. 


\subsubsection{Limite de Detecção (LD) e Limite de Quantificação (LQ)}

O Limite de Detecção (LD) é a menor concentração ou massa de uma espécie química que pode ser detectada. É a concentração que gera um sinal analítico k vezes maior que o sinal médio do ruído. Geralmente $\mathrm{k}=3$ é suficiente para se obter um valor de sinal distinguível do ruído com confiança razoável. Já o Limite de Quantificação (LQ) é a menor concentração que pode ser quantificada com exatidão e precisão razoável. O LD e o LQ foram calculados respectivamente através das Eq. (3) e (4).[64]

$L D=\frac{3 S_{b}}{m}$

$L Q=\frac{10 S_{b}}{m}$

Onde, $\mathrm{Sb}$ é o desvio padrão de uma solução do branco e m é a inclinação da curva analítica.

\subsubsection{Precisão}

Quando ensaios independentes são realizados, ocorre uma dispersão entre os resultados devido a ocorrência de erros aleatórios que são inerentes de todos os experimentos. A precisão procura avaliar a dispersão entre esses resultados. Duas formas mais comuns de expressar a precisão são repetitividade e a reprodutibilidade. A primeira procura avaliar a dispersão em condições mais restritas enquanto a segunda procura avaliar a dispersão em condições experimentais mais amplas. [64] 
Esse parâmetro foi avaliado através de 8 leituras de cada uma das soluções de $\mathrm{Cu}^{2+}$ nas concentrações de 10,80 e $160 \mu \mathrm{g} \mathrm{L}^{-1}$ utilizando como solução eletrolítica o ácido acético 0,100 M e nas condições experimentais apresentadas na tabela Tabela 3. Calculou-se o Desvio Padrão Relativo (RSD) a partir desses resultados utilizando a Equação (5).

$R S D=\frac{S}{\bar{x}}$

Onde s e $\bar{x}$ são respectivamente, o desvio padrão e a média aritmética simples das n medidas realizadas em cada nível de concentração.

\subsubsection{Seletividade}

A interferência de alguns íons na determinação de $\mathrm{Cu}^{2+}$ utilizando o eletrodo ION também foi investigada. Soluções padrão de $\mathrm{Zn}^{2+}, \mathrm{Mn}^{2+}, \mathrm{Ni}^{2+} \mathrm{e}^{\mathrm{Fe}^{3+}}$ foram separadamente e em conjunto adicionadas a uma solução de $\mathrm{Cu}^{2+} 50 \mu \mathrm{g} \mathrm{\textrm {L } ^ { - 1 }}$ em três diferentes níveis de concentração: 5,$0 ; 50$ e $500 \mu \mathrm{g} \mathrm{L}^{-1}$. O sinal analítico (altura do pico) do $\mathrm{Cu}^{2+} 50 \mu \mathrm{g} \mathrm{L}^{-1}$ na presença do íon interferente foi calculado relativamente ao sinal analítico do $\mathrm{Cu}^{2+} 50 \mu \mathrm{g} \mathrm{L}^{-1}$ na ausência do íon interferente. Os voltamogramas foram registrados em tampão BR pH 3 por PDASV nas condições experimentais descritas na Tabela 3. Entre cada leitura foi realizada uma purga adicional de $30 \mathrm{~s}$ para garantir solução eletrolítica livre de $\mathrm{O}_{2}$. 


\subsubsection{Comparação entre métodos}

Para avaliar a exatidão dos resultados, os teores de Cobre em amostras de café também foram avaliados por Espectrometria de Absorção Atômica em Chama (FAAS). As medidas foram realizadas num espectrômetro de absorção atômica da Perkin Elmer, Modelo AAnalyst 200 utilizando uma chama de ar/acetileno nas condições experimentais estão descritas na Tabela 4.

Tabela 4. Condições experimentais para determinação de íons Cobre por Espectrometria de Absorção Atômica em Chama em amostras de Café em pó comercial.

\begin{tabular}{lc}
\hline Parâmetros & Valor \\
\hline Fluxo de acetileno & $2,5 \mathrm{~L} \mathrm{~min}^{-1}$ \\
Fluxo de ar & $10 \mathrm{~L} \mathrm{~min}^{-1}$ \\
Fendas de entrada/saída & $2,7 \mathrm{~mm} / 0,8 \mathrm{~mm}$ \\
Linha espectral & $324,8 \mathrm{~nm}$ \\
Faixa de concentração & $0,5 \mathrm{a} 2,5 \mathrm{mg} \mathrm{L}^{-1}$ \\
\hline
\end{tabular}

Amostras de café em pó comercialmente disponíveis foram utilizadas para determinação de Cobre utilizando os eletrodos de ITO modificados com ION bem como por FAAS. Para abertura das amostras cerca de 1,000 g de cada amostra (previamente seca em estufa a $110{ }^{\circ} \mathrm{C}$ por $2 \mathrm{~h}$ ) foi incinerada em forno mufla a $580{ }^{\circ} \mathrm{C}$ por 3 horas. As cinzas foram dissolvidas em $10 \mathrm{~mL}$ de ácido nítrico concentrado suprapuro e aquecido em chapa elétrica (até redução do volume para cerca de $1 \mathrm{~mL}$ ) e o volume completado com água ultrapura para $10 \mathrm{~mL}$. O método de adição de padrão foi utilizado para avaliação da concentração de Cobre nas amostras. $100 \mu \mathrm{L}$ de cada amostras foi adicionada a 5 mL de solução eletrolítica tampão BR pH 3. 


\subsubsection{Estabilidade dos eletrodos de ITO modificados com ION}

Para avaliar a estabilidade dos eletrodos de ION, soluções contendo íons $\mathrm{Cu}^{2+}$ nas concentrações de 50 e $100 \mu \mathrm{g} \mathrm{L}^{-1}$ foram avaliadas por ADASV utilizando o tampão BR pH como eletrólito suporte. As condições experimentais foram as mesmas apresentadas na Tabela 3. Entre cada leitura foi realizada uma purga adicional de $30 \mathrm{~s}$ para garantir solução eletrolítica livre de $\mathrm{O}_{2}$. 


\section{RESULTADOS E DISCUSSÃO}

\subsection{NANOFILMES DE ÓXIDOS DE FERRO}

\subsubsection{Deposição, Estrutura e Morfologia}

As suspensões coloidais de $\mathrm{np}-\mathrm{Fe}_{3} \mathrm{O}_{4}$ foram estudadas por Microscopia de Transmissão Eletrônica apresentando partículas aproximadamente esféricas com diâmetro médio de $8,7 \mathrm{~nm}$. A curva de distribuição de tamanho de partículas apresentado na Figura 7. A rota sintética de co-precipitação leva invariavelmente a amostras polidispersas. Uma típica micrografia de dispersão de np- $\mathrm{Fe}_{3} \mathrm{O}_{4}$ é mostrada no destaque da Figura 7.

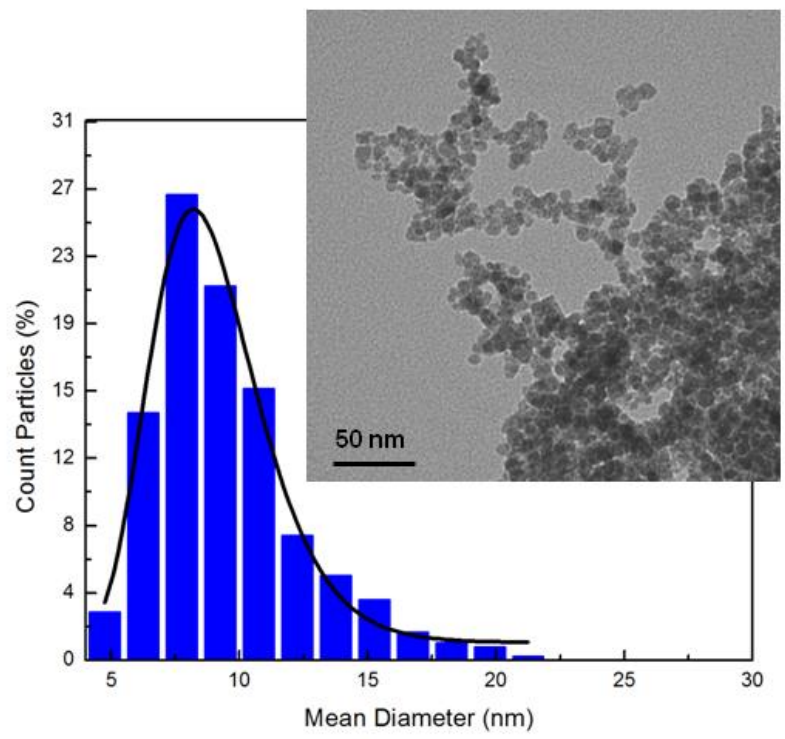

Figura 7. Micrografia TEM de np- $\mathrm{Fe}_{3} \mathrm{O}_{4}$ (obtida da suspensão coloidal de np- $\mathrm{Fe}_{3} \mathrm{O}_{4}$, em destaque) e um histograma de distribuição de tamanho de partículas acompanhado de uma regressão log-normal. 
A estabilidade das suspensões coloidais de $n p-\mathrm{Fe}_{3} \mathrm{O}_{4}$ foi avaliada através da medida do potencial zeta. $\mathrm{O}$ potencial zeta encontrado foi de $+46 \mathrm{mV}$. O potencial zeta é o potencial encontrado no plano hidrodinâmico de cisalhamento das partículas. Este potencial está diretamente relacionado com a magnitude da carga efetiva das partículas, com camada de contraíons adsorvida a interface das partículas e também com a natureza do meio dispersante. Quanto maior o potencial zeta maior é a carga efetiva das partículas e maior será a força de repulsão entre elas aumentando a estabilidade da suspensão coloidal. Suspensões com potenciais zeta maiores que $30 \mathrm{mV}$ apresentam provavelmente boa estabilidade.

A deposição dos nanocompósitos de (np- $\mathrm{Fe}_{3} \mathrm{O}_{4} / \mathrm{PSS}$ ) sobre as lâminas de vidro BK7 foram monitoradas ex situ por espectroscopia UV-vis. Os espectros foram registrados após cada deposição de bicamada (np- $\mathrm{Fe}_{3} \mathrm{O}_{4} / \mathrm{PSS}$ ). Como apresentado na Figura 8, os espectros de nanocompósitos são um pouco desestruturados e exibindo dois ombros em 480 e $360 \mathrm{~nm}$. Estas características são típicas da magnetita e são atribuídos ao processo de transferência eletrônica $\mathrm{Fe}^{2+} \rightarrow \mathrm{Fe}^{3+}$ na estrutura eletrônica de spin invertido [65]. Essas bandas têm sido atribuídas também a uma banda indireta. $\mathrm{O}$ PSS absorve somente a $270 \mathrm{~nm}$ devido à transição $\pi \rightarrow \pi^{*}$ do anel benzênico sulfonado e, portanto, ele não contribui para a absorção do nanocompósito na faixa de comprimento de onda de 800 a $300 \mathrm{~nm}$.

Antes de discutir o gráfico da Figura 8, é notório que a absorbância desses dois ombros aumenta linearmente com o número de bicamadas. Portanto, pode ser concluído que cada bicamada contribui com uma quantidade constante de np- $\mathrm{Fe}_{3} \mathrm{O}_{4}$, como já reportado em sistemas similares. [12,66-68] Uma vez que o processo de adsorção é governado por forças eletrostáticas, ele depende somente da compensação mútua de cargas entre os eletrólitos depositados. Portanto, pode-se assumir que a quantidade de PSS é também constante para cada bicamada. 


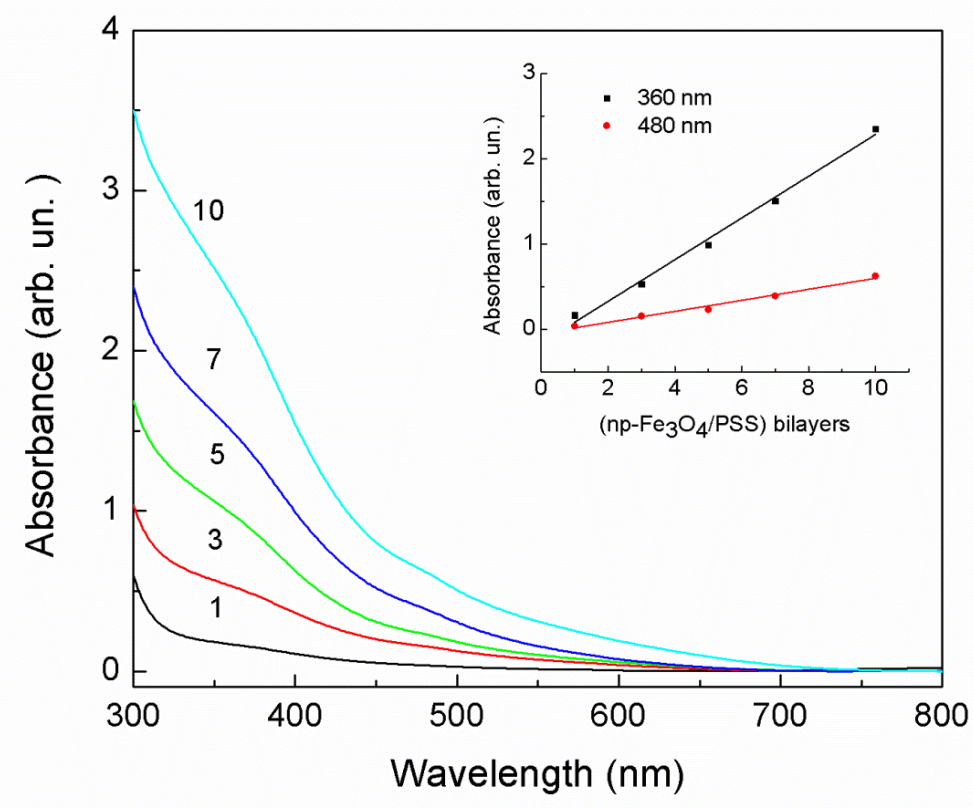

Figura 8. Espectros UV-vis dos nanocompósitos com diferentes números (n) de bicamadas de (np-Fe3O4/PSS), sendo n 1, 3, 5, 7 e 10. O gráfico em destaque apresenta a uma relação linear, medida a 360 e $480 \mathrm{~nm}$, entre a absorbância do nanocompósito e o número de bicamadas depositadas sobre o substrato de ITO.

Como apontado previamente [69], o espectro Raman e o espectros FT-IR [70] são como impressões digitais para cada fase do óxido de ferro de maneira que a discriminação e identificação podem ser realizadas de forma inequívoca. O espectro Raman do filme de nanocompósito (np- $\left.\mathrm{Fe}_{3} \mathrm{O}_{4} / \mathrm{PSS}\right)_{3}$, registrado sob uma potencia de excitação de $0,3 \mathrm{~mW}$ é apresentado na Figura 9. O espectro mostra três bandas principais que são desta forma coerentes por cinco lorentzianas atribuídas aos modos de vibração da magnetita [71]: $\mathrm{T}_{2 \mathrm{~g}}{ }^{1}\left(193 \mathrm{~cm}^{-1}\right) ; \mathrm{E}_{\mathrm{g}}\left(328 \mathrm{~cm}^{-1}\right) ; \mathrm{T}_{2 \mathrm{~g}}{ }^{2}\left(470 \mathrm{~cm}^{-1}\right) ; \mathrm{T}_{2 \mathrm{~g}}{ }^{3}(540$ $\left.\mathrm{cm}^{-1}\right)$; e $\mathrm{A}_{1 \mathrm{~g}}\left(670 \mathrm{~cm}^{-1}\right)$. $\mathrm{O}$ valor mencionado na fase da magnetita, indicado por o modo vibracional em $720 \mathrm{~cm}^{-1}$, está ausente no nanocompósito. 


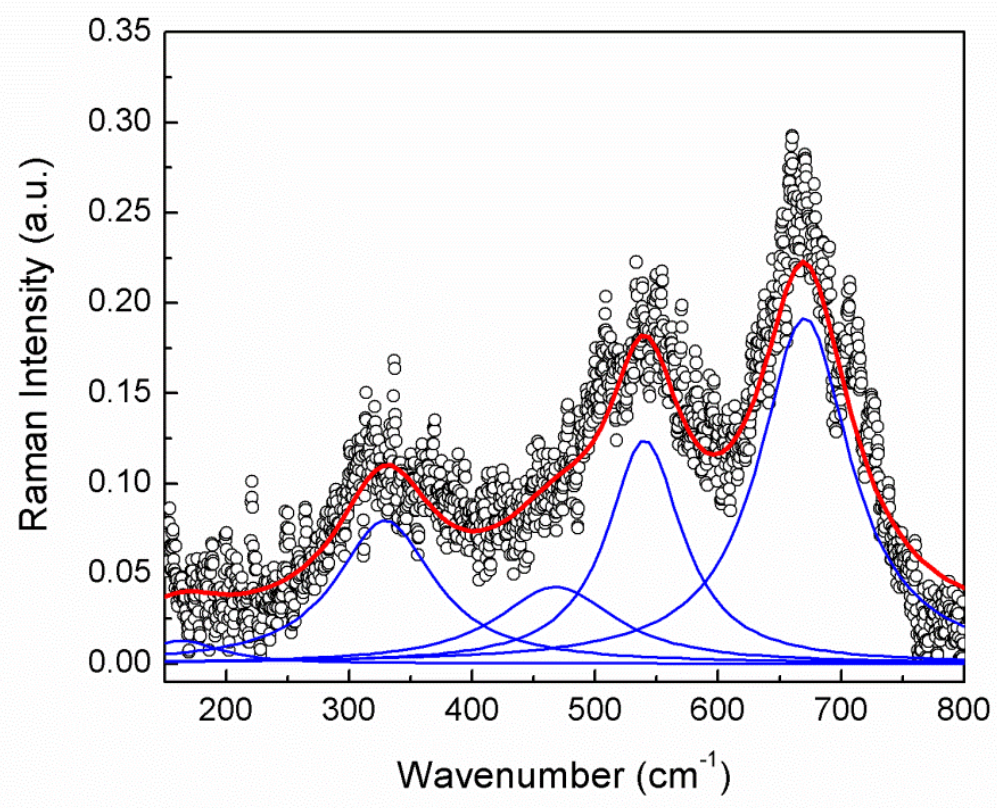

Figura 9. Espectro Raman do filme nanocompósito de (np- $\left.\mathrm{Fe}_{3} \mathrm{O}_{4} / \mathrm{PSS}\right)_{3}$. Comprimento de onda do laser: $514 \mathrm{~nm}$; intensidade de excitação: 0,3 mW.

As imagens de AFM (topografia e de fase) do filme nanocompósito de (np$\left.\mathrm{Fe}_{3} \mathrm{O}_{4} / \mathrm{PSS}\right)_{3}$ são apresentados na Figura 10. A imagem topográfica (Figura 10A) mostra uma camada de np- $\mathrm{Fe}_{3} \mathrm{O}_{4}$ altamente empacotada. Alguns agregados de np- $\mathrm{Fe}_{3} \mathrm{O}_{4}$ também estão presentes. A imagem de fase (Figura 10B) revela que as np- $\mathrm{Fe}_{3} \mathrm{O}_{4}$ (áreas claras) estão envolvidas por uma suave camada de PSS (contornos escuros). Como já observado em investigações prévias, na montagem do filme por LBL, as ION realmente adsorvem sobre o substrato tão bem como sobre as bicamadas já adsorvidas [72,73]. Eles preferem adsorver nos espaços vazios entre as partículas para formar camadas mais compactas ao invés de adsorverem sobre as partículas anteriormente depositadas. Esses vazios, assim como as superfícies das nanopartículas, são cobertas com polieletrólitos que servem como sítios de ancoramento para as nanopartículas próximas.

A rugosidade da superfície dos filmes de nanocompósitos aumentam de 7,5 $\mathrm{nm}$ da primeira bicamada para $12,1 \mathrm{~nm}$ (5 bicamadas de $\mathrm{np}-\mathrm{Fe}_{3} \mathrm{O}_{4} / \mathrm{PSS}$ ) e finalmente para $15 \mathrm{~nm}$ para 10 bicamadas. Portanto, a rugosidade aumenta até alcançar um patamar o que corrobora com a hipótese na qual as nanopartículas são adsorvidas 
preferencialmente nos espaços vazios em volta das nanopartículas das camadas imediatamente anteriores. O aumento da rugosidade dos filmes de nanocompósitos de $\left(\mathrm{np}-\mathrm{Fe}_{3} \mathrm{O}_{4} / \mathrm{PSS}\right)_{\mathrm{n}}$ proporcionam um aumento na área superficial influenciando na sensibilidade do sensor. Neste trabalho estudamos a resposta analítica de um sensor com filmes contendo 3 bicamadas de np- $\mathrm{Fe}_{3} \mathrm{O}_{4} / \mathrm{PSS}$. Estes sensores tem um tempo de preparação menor e apresentaram uma sensibilidade analítica adequada para quantificação de íons $\mathrm{Cu}^{2+}$ em amostras de café.
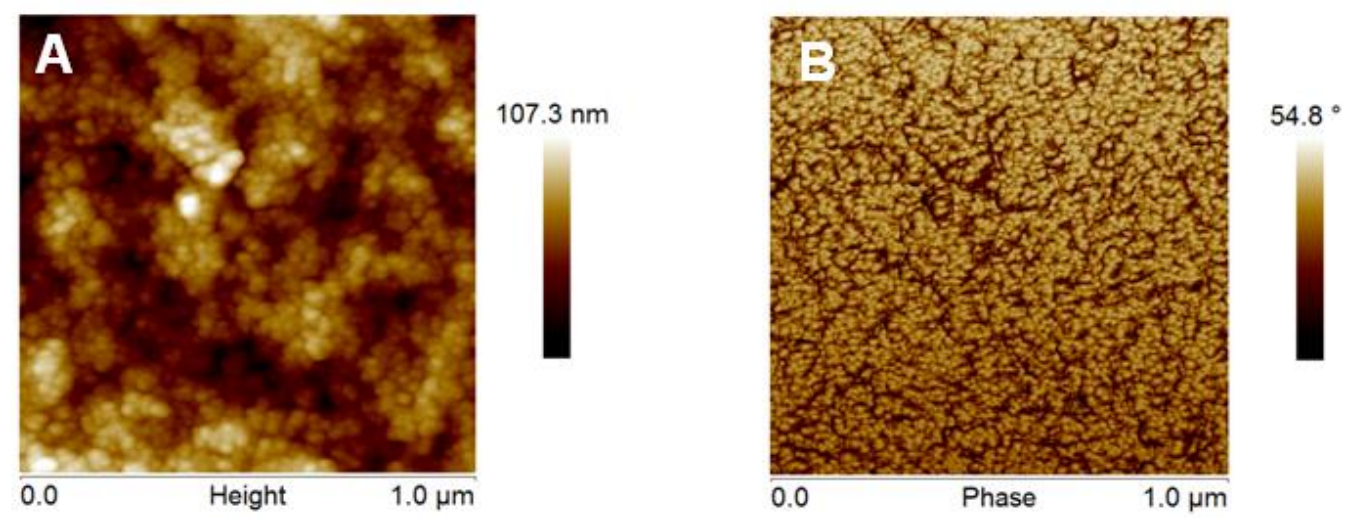

Figura 10. Imagens AFM topográfica (a) e de fase (b) de um filme nanocompósito de $\left(\mathrm{np}-\mathrm{Fe}_{3} \mathrm{O}_{4} / \mathrm{PSS}\right)_{3}$. 


\subsubsection{Propriedades Eletroquímicas}

As propriedades eletroquímicas dos eletrodos de (np- $\left.\mathrm{Fe}_{3} \mathrm{O}_{4} / \mathrm{PSS}\right)$ foram estudados por CV. A CV permite a observação da dinâmica de reações redox que ocorrem na superfície do filme e providencia dados para a determinação da janela eletroquímica e de parâmetros termodinâmicos e cinéticos dos eletrodos, tais como constante de transferência eletrônica, potenciais formais e outros. A Figura 11 apresenta o comportamento eletroquímico dos eletrodos com diferentes números de bicamadas de (np- $\mathrm{Fe}_{3} \mathrm{O}_{4} / \mathrm{PSS}$ ) investigados em tampão acetato $(\mathrm{pH} 4,6)$ na velocidade de varredura de $50 \mathrm{mV} \mathrm{s}^{-1}$. Os voltamogramas apresentados na Figura 11 compartilham características similares, incluindo duas ondas catódicas em -192 mV e + $41 \mathrm{mV}$ e uma onda anódica em $+360 \mathrm{mV}$, para todas as bicamadas do eletrodo. Para os eletrodos com diferentes números de bicamadas, os potenciais são levemente diferentes destes, como descrito na Tabela 5.

De acordo com a literatura, a primeira onda catódica em -192 mV é atribuída a redução do $\mathrm{Fe}(\mathrm{III})$ oxi-hidróxidos para magnetita $\left(\mathrm{Fe}_{3} \mathrm{O}_{4}\right)$. [74,75]. A tendência de oxidação do ION é minimizada, especialmente em virtude da sua grande reatividade causada pelo aumento da razão superfície/área. Por outro lado esses grupos superficiais oxidados são protonados em médio ácido (ou desprotonados em meio básico) e esse fato torna-se essencial para preparação das dispersões coloidais as quais são estabilizadas por forças eletrostáticas. [76] A segunda onda catódica em $+41 \mathrm{mV}$ para os eletrodos com 3 bicamadas (para os outros números de bicamadas veja a Tabela 5) é atribuído para a redução d $\gamma-\mathrm{Fe}_{2} \mathrm{O}_{3}$ (magemita) para $\mathrm{Fe}_{3} \mathrm{O}_{4}$. A respectiva reação de oxidação $\left(\mathrm{Fe}_{3} \mathrm{O}_{4} \rightarrow \gamma-\mathrm{Fe}_{2} \mathrm{O}_{3}\right)$ está relacionada com o pico anódico em $+369 \mathrm{mV}$. O processo é parcialmente irreversível.

Na Figura 11b pode ser visto que a corrente de pico para os três eventos redox $\left(\mathrm{I}_{\mathrm{pc} 1}, \mathrm{I}_{\mathrm{pc} 2}\right.$, corrente de pico para o a primeira e segunda onda catódica; $\mathrm{I}_{\mathrm{pa} 1}$, corrente de pico para a primeira onda anódica) nos eletrodos a base de ION mudam em função do número de bicamadas de (np- $\mathrm{Fe}_{3} \mathrm{O}_{4} / \mathrm{PSS}$ ). É interessante notar que em todos os eventos eletroquímicos, a corrente alcança um valor máximo em cerca de 3 bicamadas e em 
seguida permanece constante. Esse fenômeno pode ser explicado considerando que a transferência eletrônica é rápida no interior do filme e dependente (processo limitante da velocidade) da transferência eletrônica superficial. O aumento do número de bicamadas não aumenta de forma significante a área superficial, portanto a corrente tende a permanecer constante.
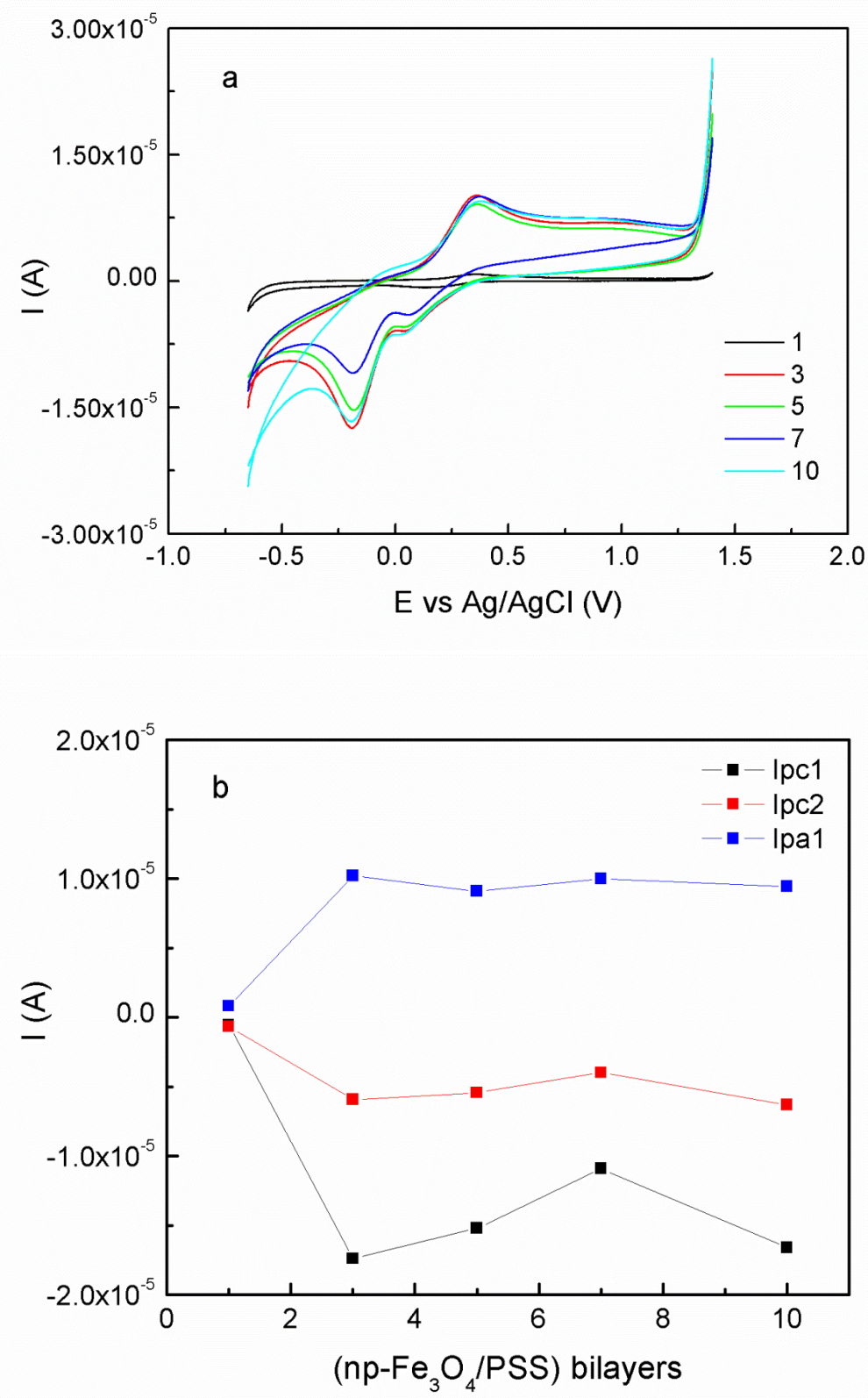

Figura 11. (a) Voltamogramas cíclicos e (b) correntes de pico para três eventos redox dos eletrodos de ION em função do número de bicamadas de (np- $\mathrm{Fe}_{3} \mathrm{O}_{4} / \mathrm{PSS}$ ). Ipc1 e Ipc2 correspondem a primeira e segunda onda catódica respectivamente. Ipa1 corresponde a corrente de pico anódica. 
Tabela 5. Potenciais eletroquímicos para processos redox ocorrendo em eletrodos com diferentes números de bicamadas de (np- $\left.\mathrm{Fe}_{3} \mathrm{O}_{4} / \mathrm{PSS}\right)$. Eletrólito tampão acetato pH 4,6. Velocidade de varredura $50 \mathrm{mV} \mathrm{s}^{-1}$.

\begin{tabular}{cccc}
\hline $\begin{array}{l}\text { Bicamadas de }(\mathrm{np}- \\
\left.\mathrm{Fe}_{3} \mathrm{O}_{4} / \mathrm{PSS}\right)\end{array}$ & $\begin{array}{c}1^{\mathrm{a}} \text { onda catódica } \\
(\mathrm{mV})\end{array}$ & $\begin{array}{c}2^{\mathrm{a}} \text { onda catódica } \\
(\mathrm{mV})\end{array}$ & $\begin{array}{c}1^{\text {a }} \text { onda anódica } \\
(\mathrm{mV})\end{array}$ \\
\hline 1 & -173 & 68 & 357 \\
3 & -192 & 41 & 360 \\
5 & -189 & 41 & 360 \\
7 & -185 & 59 & 373 \\
10 & -196 & 32 & 372 \\
\hline
\end{tabular}

A termodinâmica e cinética eletroquímica dos eletrodos de ION foram investigados através do par redox $\mathrm{Fe}(\mathrm{CN})_{6}^{3-/ 4-}$, o qual é largamente usado como modelo para examinar o comportamento eletroquímico de superfícies. A Figura 12 apresenta os voltamogramas cíclicos do par redox $\mathrm{Fe}(\mathrm{CN})_{6}^{3-/ 4-}$ sobre as superfícies do eletrodos de ION com diferente número de bicamadas de (np- $\left.\mathrm{Fe}_{3} \mathrm{O}_{4} / \mathrm{PSS}\right)$. As áreas eletroativas dos eletrodos de ION foram determinadas pela equação de Randles-Sevcik. [21] A Tabela 6 reúne os parâmetros cinéticos e termodinâmicos dos eletrodos calculados através dos dados obtidos pelos voltamogramas através dos voltamogramas apresentados na Figura 12 e o modelo proposto por Nicholson. [77]

$\mathrm{Na}$ Figura 12a, os voltamogramas adquiridos em $50 \mathrm{mV} . \mathrm{s}^{-1}$ mostram picos catódicos e anódicos bem definidos para a reação $\mathrm{Fe}^{\mathrm{III}}(\mathrm{CN})_{6}{ }^{3-}+\mathrm{e}^{-} \leftrightarrow \mathrm{Fe}^{\mathrm{II}}(\mathrm{CN})_{6}^{4-}$. A densidade de corrente aumenta suavemente pela deposição de bicamadas de np$\mathrm{Fe}_{3} \mathrm{O}_{4} / \mathrm{PSS}$ (Tabela 6, $3^{\mathrm{a}}$ coluna). Esse efeito é mais pronunciado para a primeira bicamada, com o aumento da área superficial do eletrodo em aproximadamente $32 \%$. Como consequência desse fato, ocorre um substancial aumento na constante de transferência eletrônica. Para o eletrodo de ION com 1 bicamada ela é cerca de 4 vezes maior, relativamente ao eletrodo base de ITO (Tabela 6, $5^{\text {a }}$ coluna e $3^{\text {a }}$ linha). Contudo, para as subsequentes bicamadas, a densidade de corrente alcança um máximo e permanece constante. A constante de transferência eletrônica depois de 3 bicamadas é 
menor do que aquela determinada para o eletrodo base de ITO. Por um lado, o aumento na área superficial do eletrodo com o aumenta do número de bicamadas de (np$\left.\mathrm{Fe}_{3} \mathrm{O}_{4} / \mathrm{PSS}\right)$ aumenta a adsorção do par redox $\mathrm{Fe}(\mathrm{CN})_{6}{ }^{3-/ 4-}$, aumentando concentração de elétrons próximo do eletrodo. Contudo, mais bicamadas "bloqueiam" o caminho entre a solução eletrolítica e o substrato de ITO sob o filme de nanocompósito de (np$\left.\mathrm{Fe}_{3} \mathrm{O}_{4} / \mathrm{PSS}\right)$. Apesar do comportamento de semicondutor do np- $\mathrm{Fe}_{3} \mathrm{O}_{4} / \mathrm{PSS}$, ele é ainda menos condutor que o substrato de ITO, de maneira que só aqueles pares redox $\mathrm{Fe}(\mathrm{CN})^{3-/ 4-}$ mais próximos do eletrodos são detectados. Cao e $\mathrm{Hu}$ [5] também observaram que eletrodos baseados em multicamadas de hemoglobina/np- $\mathrm{Fe}_{3} \mathrm{O}_{4}$ alcançam uma corrente limite depois de poucas bicamadas as quais foram depositadas sobre a superfície de carbono vítreo.

Na Figura 12b é visto que a densidade de corrente (anódica e catódica) aumenta, mas não linearmente com a raiz quadrada da velocidade de varredura $\left(v^{1 / 2}\right)$, exceto para o ITO base e para os eletrodos de ION com poucas bicamadas. Este fato é comumente observado para o par redox $\mathrm{Fe}(\mathrm{CN})_{6}^{3-/ 4-}$ o qual apresenta um comportamento quase reversível em muitos diferentes tipos de eletrodos. A Figura 12c corrobora com esse fato, uma vez que $\Delta \mathrm{E}_{\mathrm{p}}$ aumenta com velocidade de varredura também. A primeira e terceira bicamada reduz a irreversibilidade em comparação com o ITO base, mas para um maior número de bicamadas, o regime quase reversível é estabelecido. 

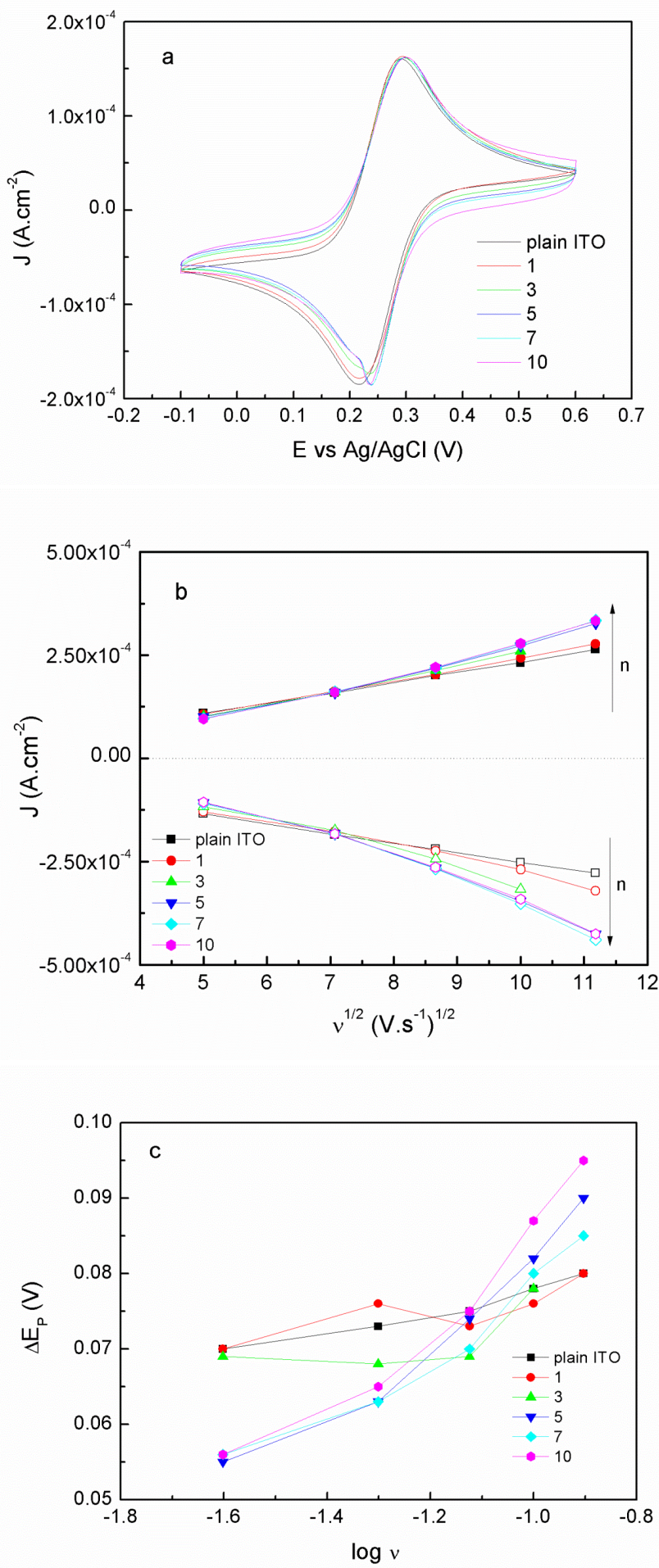

Figura 12. Voltametria cíclica de $1,00 \mathrm{mmol} \mathrm{L}^{-1} \mathrm{~K}_{3} \mathrm{Fe}(\mathrm{CN})_{6}$ em $\mathrm{KCl} 1,00 \mathrm{~mol} \mathrm{~L}^{-1}$ medido com eletrodos de ION com diferente número de bicamadas (n) de (np$\mathrm{Fe}_{3} \mathrm{O}_{4} / \mathrm{PSS}$ ). Plain ITO corresponde a superfície de ITO sem o filme. Os filmes variaram de 1 a 10 bicamadas. (a) Voltamogramas cíclicos adquiridos na velocidade de varredura de $50 \mathrm{mV} \mathrm{s}^{-1}$, (b) Correntes de pico anódica e catódica em função de $v^{1 / 2} \mathrm{e}$ (c) $\Delta$ Ep em função de $\log v$. 
Tabela 6. Dados da Voltametria Cíclica da constante heterogênea de transferência eletrônica aparente $\left(\mathrm{k}_{\mathrm{ap}}{ }^{0}\right)$ para sistemas redox medidos com eletrodos de ION com número diferente de bicamadas de (np- $\left.\mathrm{Fe}_{3} \mathrm{O}_{4} / \mathrm{PSS}\right)$ e para o eletrodo de ITO base.

\begin{tabular}{ccccc}
\hline$\left(\mathrm{np}-\mathrm{Fe}_{3} \mathrm{O}_{4} / \mathrm{PSS}\right)$ & $\Delta \mathrm{E}_{\mathrm{p}}(\mathrm{mV})$ & ${ }^{\mathrm{a}} \mathrm{I}_{\mathrm{pa}}\left(\mu \mathrm{A} \cdot \mathrm{cm}^{-2}\right)$ & $\mathrm{E}^{\mathrm{o}}(\mathrm{mV})$ & $\mathrm{k}_{\text {app }}^{0}\left(\mathrm{~cm} . \mathrm{s}^{-1}\right)$ \\
\hline $\mathrm{ITO}$ & 72 & 157 & 253 & 0,26 \\
1 & 62 & 163 & 253 & 1,1 \\
3 & 69 & 161 & 256 & 0,34 \\
5 & 80 & 162 & 263 & 0,15 \\
7 & 74 & 162 & 262 & 0,16 \\
10 & 87 & 162 & 262 & 0,12 \\
\hline ITO & & ${ }^{\mathrm{b}} \mathrm{Fe}\left(\mathrm{Cu}{ }^{2+/ 0}\right.$ & & $<0,026$ \\
3 & 300 & 93,5 & -110 & 0,026 \\
\hline
\end{tabular}

Observações: Todas as concentrações dos analitos foram $1 \mathrm{mmol} \mathrm{L}^{-1}$. Eletrólito suporte para $\mathrm{Fe}(\mathrm{CN})_{6}^{3-14-} \mathrm{e} \mathrm{Cu}^{2+/ 0}$ foi $\mathrm{KCl}$ 1,0 mol L-1 e acetato de amônio $0,1 \mathrm{~mol} \mathrm{~L}^{-1}(\mathrm{pH} 4,6)$, respectivamente. Os dados mostrados para o quinto scan. (a) Os picos de Oxidação foram normatizados pela área geométrica dos eletrodos. O coeficiente de transferência $(\alpha)$ foi 0,95 obtido do slope de E em função de $\log v$. (b) velocidade de varredura $100 \mathrm{mV} \mathrm{s}^{-1}$. (c) velocidade de varredura $20 \mathrm{mV} \mathrm{s}^{-1}$.

Apesar do eletrodo com bicamadas de (np-Fe ${ }_{3} \mathrm{O}_{4} / \mathrm{PSS}$ ) ter sido apenas levemente mais efetivo na condução da reação eletroquímica de oxidação-redução do par redox $\mathrm{Fe}(\mathrm{CN})_{6}{ }^{3-/ 4-}$, os eletrodos baseados em bicamadas de ION tem consideravelmente melhor desempenho na resposta analítica do $\mathrm{Cu}^{2+}$, o qual é o nosso analito alvo no presente estudo. De acordo com os dados apresentados na Tabela 2 (segunda para a última linha), o eletrodo de ION com 3 bicamadas de (np- $\mathrm{Fe}_{3} \mathrm{O}_{4} / \mathrm{PSS}$ ) simultaneamente reduz o $\Delta \mathrm{E}_{\mathrm{p}}$ e o $\mathrm{E}^{0}$, com um aumento na densidade de corrente ( de aproximadamente 50 \%), bem como a constante de transferência eletrônica para a reação $\mathrm{Cu}^{2+}+2 \mathrm{e}^{-} \rightarrow \mathrm{Cu}$ Em virtude das bicamadas de (np- $\mathrm{Fe}_{3} \mathrm{O}_{4} / \mathrm{PSS}$ ) sempre terminarem em PSS, o qual providencia sítios carregados negativamente (grupos $-\mathrm{SO}_{3}{ }^{-}$) para ancoramento de íons $\mathrm{Cu}^{2+}$. Isso melhora a resposta do eletrodo em comparação com o ITO base. 


\subsection{REDISSOLUÇÃO ANÓDICA POR PULSO DIFERENCIAL PARA DETECÇÃO DE ÍONS Cu(II) SOBRE OS ELETRODOS DE ION (np-Fe $\left.\mathrm{O}_{3} / \mathrm{PSS}\right)_{3}$}

\subsubsection{Amplitude de pulso}

A Figura 13 apresenta os voltamogramas de PDASV apresentando a influência da amplitude de pulso $(\Delta \mathrm{E})$ no sinal analítico de $\mathrm{Cu}^{2+} 100 \mu \mathrm{g} \mathrm{L}^{-1}$ sobre o eletrodo ION $(\text { np-Fe3O4/PSS })_{3}$. O ploter em destaque na Figura 13 representa a regressão da razão altura do sinal (Ip) / largura de meia onda $\left(\mathrm{W}_{1 / 2}\right)$ em função da Amplitude de Pulso em $\mathrm{mV}$. Observa-se que quanto maior a amplitude de pulso maior é o valor da corrente de pico. Em contrapartida, com o aumento da amplitude de pulso, a razão ( $\left(\mathrm{Ip} / \mathrm{W}_{1 / 2}\right)$ é aumentada provocando uma diminuição na resolução. $O$ valor máximo de $I_{p}$ é influenciado por $\Delta \mathrm{E}$ de acordo com a Equação. (6) [78]

$I_{p}=n F A C(D / \pi t)^{1 / 2} \frac{(\sigma-1)}{(\sigma+1)}$

Onde $\sigma=\exp (\mathrm{nF} / \mathrm{RT} \times \Delta \mathrm{E} / 2)$, n é o número de elétrons envolvidos, $\mathrm{C}$ é a concentração do analito na cela eletroquímica em $\mathrm{mol} / \mathrm{cm}^{3}$, t é o tempo de pulso em s, A é a área do eletrodo em $\mathrm{cm}^{2}$, D é o coeficiente de difusão do analito em $\mathrm{cm}^{2} \mathrm{~s}^{-1}$ e $\mathrm{F}$ é a constante de Faraday.

Da Equação (6) pode ser facilmente demonstrado que $\mathrm{I}_{\mathrm{p}}$ é máximo para grandes valores de $\Delta \mathrm{E}$. Para $\mathrm{n}=2$, e $\Delta \mathrm{E}=10,50$ e $100 \mathrm{mV}$ o valor de $\mathrm{I}$ alcança respectivamente 19,3\%,75\% e $96 \%$ do seu valor máximo previsto pela Equação (6). Portanto, a escolha do $\Delta \mathrm{E}$ é um compromisso entre a alta sensibilidade (grande $\Delta \mathrm{E}$ ) e a largura do pico (relacionada com a resolução). Pelos resultados apresentados, o $\Delta \mathrm{E}$ de até $100 \mathrm{mV}$ apresentou um razoável compromisso entre sensibilidade e resolução. 
Observa-se também da Figura 13 um deslocamento do $\mathrm{E}_{\mathrm{p}}$ com o aumento do valor de $\Delta \mathrm{E}$. Para valores de $\Delta \mathrm{E}$ pequenos o $\mathrm{E}_{\mathrm{p}}$ pode ser obtido da Equação (7). [78]

$\mathrm{E}_{\mathrm{p}}=\mathrm{E}_{1 / 2}-\frac{\Delta \mathrm{E}}{2}$

Onde $\mathrm{E}_{1 / 2}$ é o potencial de meia onda característico para cada espécie sob condições específicas.

Sendo o potencial de meia onda $\left(\mathrm{E}_{1 / 2}\right)$ um valor constante para cada espécie em condições experimentais específicas, com $\mathrm{o}$ aumento de $\Delta \mathrm{E} \quad \mathrm{o}$ valor $\mathrm{E}_{1 / 2}-\frac{\Delta \mathrm{E}}{2}$ diminui. Portanto, a Equação (7) mostra que aumentando o valor de $\Delta \mathrm{E}, \mathrm{o}$ valor do potencial de pico desloca-se para valores menores o que está de acordo com os dados apresentados na Figura 13.

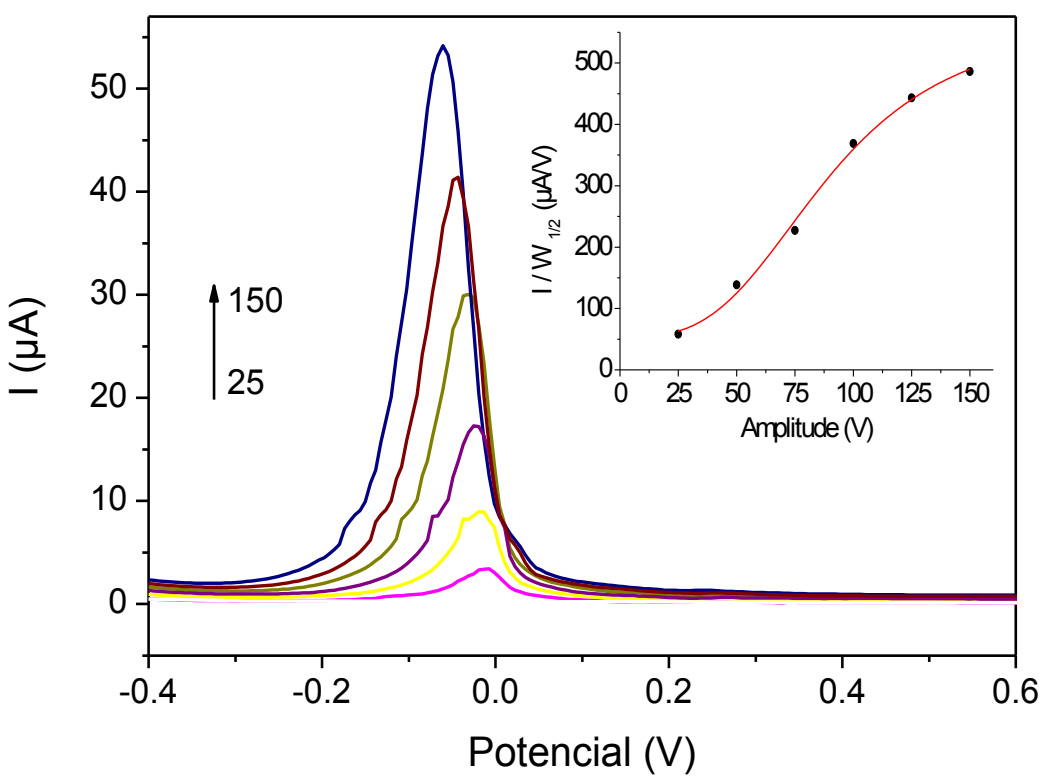

Figura 13. Voltamogramas de PDASV apresentando a influência da amplitude de pulso no sinal analítico de $\mathrm{Cu}^{2+} 100 \mu \mathrm{g} \mathrm{L}^{-1}$ sobre o eletrodo ION (np-Fe $\mathrm{F}_{3} / \mathrm{PSS}$ ) 3 . As amplitudes de pulso foram de 25, 50, 75, 100,125 e $150 \mathrm{mV}$. A deposição ocorreu sob o potencial de $-0,4 \mathrm{~V}$ por $120 \mathrm{~s}$. Varredura anódica de $-0,4 \mathrm{a}+0,6 \mathrm{~V}$ e velocidade de varredura de $5 \mathrm{mV} \mathrm{s}^{-1}$. 


\subsubsection{Velocidade de varredura}

A Figura 14 apresenta voltamogramas de DPASV para uma solução de $\mathrm{Cu}^{2+} 100 \mu \mathrm{g} \mathrm{L}^{-1}$ em $\mathrm{CH}_{3} \mathrm{COOH}$ 0,100 M. Observa-se que a corrente de pico aumenta com o aumento da velocidade de varredura $(v)$ e que esse aumento na corrente de pico é mais expressivo para valores de velocidade de varredura de até $10 \mathrm{mV} \mathrm{s}^{-1}$. Na programação de potencial da voltametria de pulso diferencial (Figura 15) a velocidade de varredura pode ser calculada pela razão entre o Degrau de voltagem (Vs) e o Tempo de pulso (t) de acordo com a Equação (8).

$v=\frac{V_{s}}{\mathrm{Pd}}$

Sendo $\mathrm{Pd}=\Delta+\mathrm{t}$, onde $\Delta$ é o tempo decorrido entre o fim de um pulso e o início do próximo pulso. Portanto, $v=V s /(\Delta+\mathrm{t})$. Sendo $\mathrm{Vs}$ e $\Delta$ constantes, $\mathrm{v}$ e $\mathrm{t}$ são inversamente proporcionais.

Para valores moderados de $\Delta \mathrm{E}$, a corrente de pulso pode ser calculada pela seguinte Equação (9):

$I_{p}=\frac{n^{2} F^{2} A C}{4 R T} \times\left[\frac{D}{\pi t}\right]^{\frac{1}{2}} \times \Delta E$

Onde $\mathrm{I}_{\mathrm{p}}$ representa a corrente de pico, $\mathrm{n}$ o número de elétrons transferidos, $\mathrm{F}$ é a constante de Faraday, $\mathrm{R}$ a constante dos gases, $\mathrm{T}$ a temperatura absoluta, $\mathrm{C}$ a concentração da espécie eletroativa, D é o coeficiente de difusão, A é a área do eletrodo e té tempo de pulo.

Da Equação (9) verifica-se que a corrente de pico é inversamente proporcional a velocidade de varredura $(v)$ e da Equação (8) verifica-se que quanto menor o valor de $t$ maior será o valor de v. Portanto a corrente de pico é diretamente proporciona a velocidade de varredura. Esta constatação está de acordo com os dados apresentados na Figura 14. 
Velocidades de varreduras maiores proporcionam melhor sensibilidade analítica. A velocidade que apresentou a maior corrente de pico (e consequentemente melhor sensibilidade analítica) foi a de $15 \mathrm{mV} \mathrm{s}^{-1}$. Adicionalmente, velocidades de varreduras maiores também proporcionam uma diminuição no tempo leitura das amostras aumentando a frequência analítica. Apesar da maior corrente de pico alcançada com a velocidade de varredura de $15 \mathrm{mV} \mathrm{s}^{-1}$ optamos por utilizar $10 \mathrm{mV} \mathrm{s}^{-1}$ na sequência do trabalho por apresentar melhor reprodutibilidade do sinal analítico.

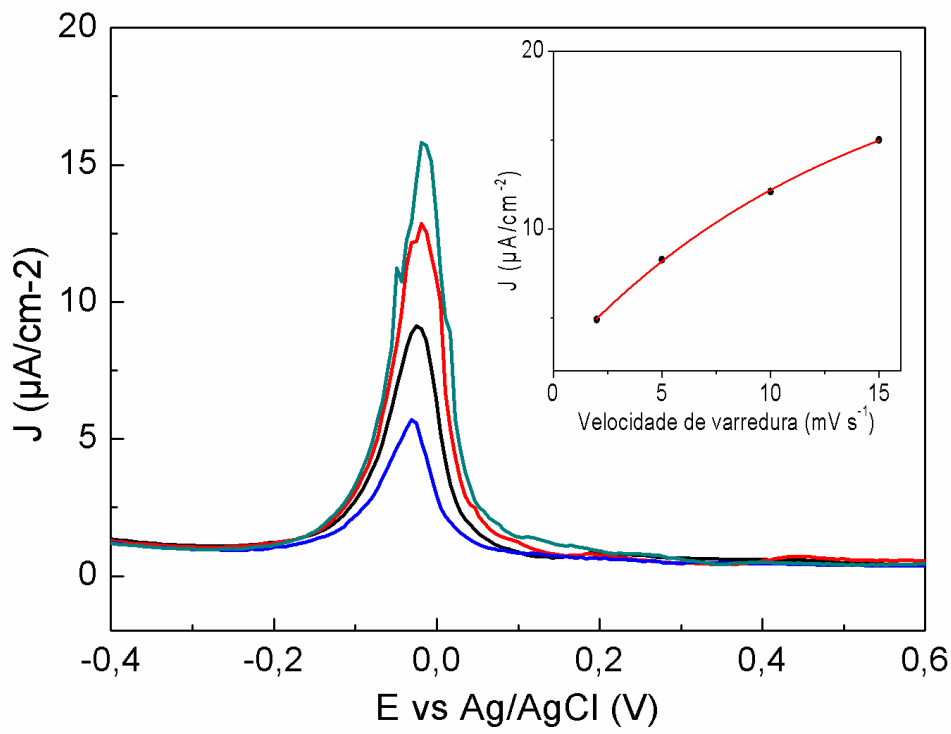

Figura 14. Voltamogramas de DPASV apresentando a influência da velocidade de varredura no sinal analítico de $\mathrm{Cu}^{2+} 100 \mu \mathrm{g} \mathrm{L}^{-1}$ sobre o eletrodo ION (np-Fe $\left.\mathrm{O}_{3} / \mathrm{PSS}\right)_{3}$. As velocidades de varredura foram 2, 5, 10 e $15 \mathrm{mV} \mathrm{s}^{-1}$. Eletrólito suporte $\mathrm{CH}_{3} \mathrm{COOH}$ $0,100 \mathrm{~mol} \mathrm{~L}^{-1}$. Potencial de deposição $-0,4 \mathrm{~V}$. Varredura de $-0,4 \mathrm{a}+0,6 \mathrm{~V}$, amplitude de pulso de $50 \mathrm{mV}$. 


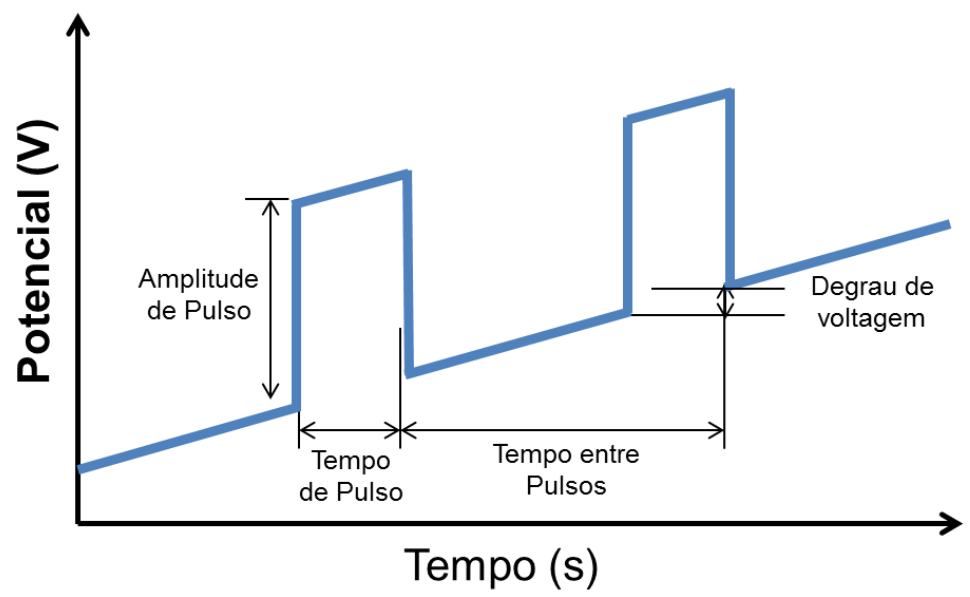

Figura 15. Programação de potencial na voltametria de pulso diferencial mostrando os parâmetros Amplitude de pulso $(\Delta \mathrm{E})$, Degrau de voltagem $\left(\mathrm{V}_{\mathrm{S}}\right)$, Tempo de Pulso (t) e Tempo entre pulsos $(\mathrm{Pd})$. A velocidade de varredura é a razão entre $\mathrm{V}_{S}$ e $\mathrm{Pd}$.

\subsubsection{Influência do pH, natureza e concentração da solução eletrolítica no sinal analítico de $\mathrm{Cu}^{2+}$ sobre o eletrodo de ION (np- $\left.\mathrm{Fe}_{3} \mathrm{O}_{4} / \mathrm{PSS}\right)_{3}$}

$\mathrm{O}$ pH da solução eletrolítica influenciou de forma marcante na corrente de pico $\left(\mathrm{I}_{\mathrm{p}}\right)$ e no potencial de pico $\left(\mathrm{E}_{\mathrm{p}}\right)$ do $\mathrm{Cu}^{2+}$ conforme apresentado na Figura 16. A densidade de corrente alcançou um valor máximo na faixa de $\mathrm{pH}$ entre 4 e 5 e diminui drasticamente para valores de $\mathrm{pH}$ superiores a 5. Pode ser observado também que o Ep torna-se mais negativo em valores de $\mathrm{pH}$ mais elevados. Na faixa de $\mathrm{pH}$ entre 2 e 5 os íons $\mathrm{Cu}^{2+}$ estão na forma solúvel e o aumento da corrente de difusão está relacionado, provavelmente, com a estrutura da interface solução/eletrodo. A superfície do eletrodo ION é carregada negativamente devido aos grupos $-\mathrm{SO}_{3}$ - do polímero PSS (Figura 17). Em pH mais baixo a concentração interfacial de $\mathrm{Cu}^{2+}$ é diminuída devido ao competição dos íons $\mathrm{H}^{+}$para com os grupos $-\mathrm{SO}_{3}{ }^{-}$. Por exemplo, em $\mathrm{pH} 2$ a concentração de íons $\mathrm{H}^{+}$é cerca de 63000 vezes maior que a concentração de $\mathrm{Cu}^{2+}$ na cela eletroquímica. Em pH superior a 5 o íon $\mathrm{Cu}^{2+}$ precipita na forma de $\mathrm{Cu}(\mathrm{OH})_{2(\mathrm{~S})}$ conforme a Eq. (10) diminuindo a concentração de $\mathrm{Cu}^{2+}$ na solução eletrolítica e portanto diminuindo a corrente de difusão. 
A variação do potencial de pico em função do $\mathrm{pH}$ da solução eletrolítica pode ser explicada utilizando a seguinte dedução. A concentração de $\mathrm{Cu}^{2+}$ na cela eletroquímica é governada pelo equilíbrio:

$\mathrm{Cu}(\mathrm{OH})_{2(\mathrm{~s})} \leftrightarrow \mathrm{Cu}_{(\mathrm{aq})}^{2+}+2 \mathrm{OH}_{(\mathrm{aq})}^{-}$

Na qual a expressão da constante de equilíbrio pode ser expressa da seguinte forma:

$\mathrm{K}_{\mathrm{ps}}=\left[\mathrm{Cu}^{2+}\right]\left[\mathrm{OH}^{-}\right]^{2}$

E arranjando em função da concentração de $\mathrm{Cu}^{2+}$ :

$\left[\mathrm{Cu}^{2+}\right]=\frac{\mathrm{K}_{\mathrm{ps}}}{\left[\mathrm{OH}^{-}\right]^{2}}$

Por outro lado, na etapa de redissolução, ocorre o seguinte processo:

$\mathrm{Cu}^{0} \rightarrow \mathrm{Cu}^{2+}+2 \mathrm{e}^{-}$

Aplicando a equação de Nernst a equação, supondo o sistema reversível, fica:

$\mathrm{E}=\mathrm{E}^{0}-\frac{\mathrm{RT}}{\mathrm{nF}} \ln \mathrm{C}_{\mathrm{Cu}^{2+}}$

Pode ser facilmente demonstrado que combinando as Equações (12) e (14), após alguma manipulação algébrica resulta na Equação (15):

$\mathrm{E}_{p}=\mathrm{A}-\mathrm{B} \mathrm{pH}$

Onde $\mathrm{A}=\mathrm{E}^{0}+14,5 \mathrm{RT} / \mathrm{F}$ e $\mathrm{B}=-\mathrm{RT} / \mathrm{F}$.

Portanto, a Eq. (15) demonstra que o potencial de pico diminui linearmente com o aumento do $\mathrm{pH}$ da solução eletrolítica, sendo o slope da equação (B) -RT/F (a $25^{\circ} \mathrm{C}$ é 0,0592). Mas por outro lado, em $\mathrm{pH}$ mais alto (próximo de 5) a concentração de íons $\mathrm{Cu}^{2+}$ diminui devido a precipitação na forma de $\mathrm{Cu}(\mathrm{OH})_{2}$. 

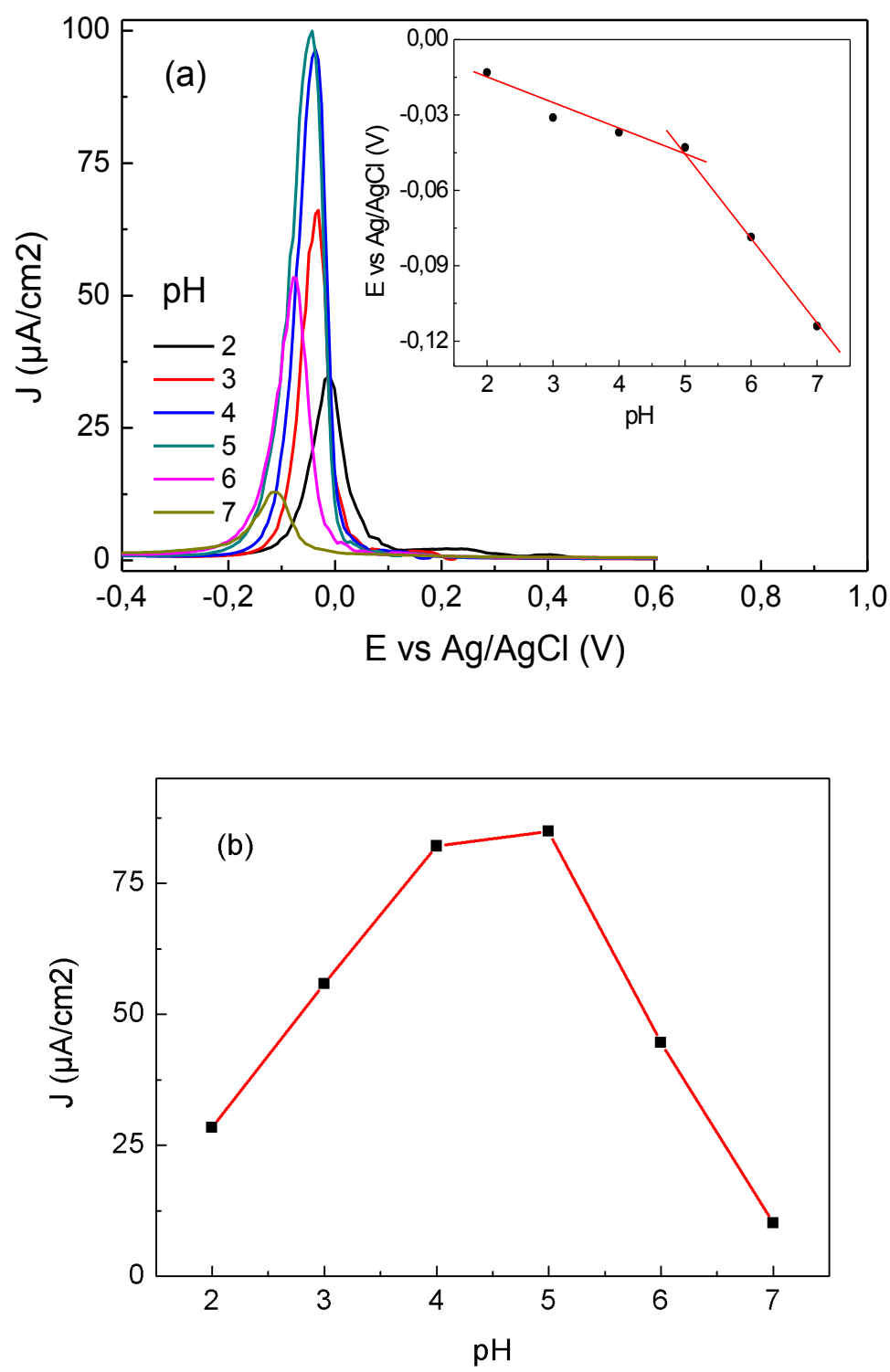

Figura 16. Voltamogramas de DPASV mostrando a influência do $\mathrm{pH}$ da solução eletrolítica (Tampão Robson-Britton) no sinal analítico de uma solução de cobre de $100 \mu \mathrm{g} \mathrm{L}^{-1}$ sobre o eletrodo ION (np- $\left.\mathrm{Fe}_{3} \mathrm{O}_{4} / \mathrm{PSS}\right)_{3}$. A deposição ocorreu no potencial de $-0,4 \mathrm{~V}$ por $120 \mathrm{~s}$. Amplitude de pulso foi de $50 \mathrm{mV}$ e velocidade de varredura de 10 $\mathrm{mV} \mathrm{s}^{-1}$. 


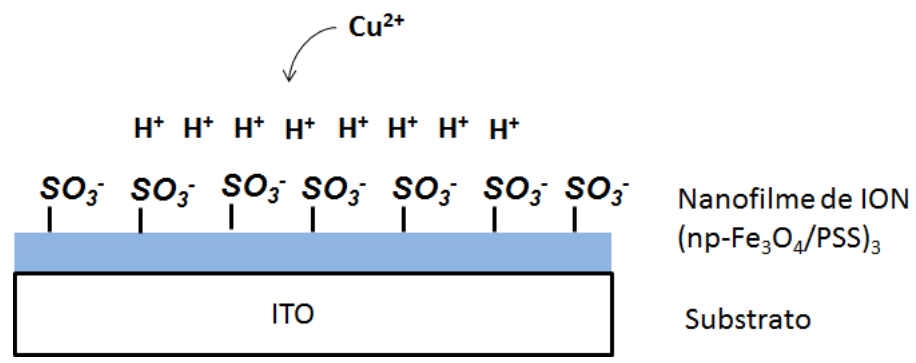

Figura 17. Representação esquemática da superfície do eletrodo de ITO contendo nanofilme de ION dando ênfase aos grupos $-\mathrm{SO}_{3}{ }^{-}$sobre a superfície. $\mathrm{Em} \mathrm{pH}$ baixo, ocorre a diminuição da concentração de $\mathrm{Cu}^{2+}$ próximo a superfície do eletrodo.

A concentração do eletrólito também exerce influência sobre a corrente de pico. Pode ser observado da Figura 18 que a corrente de pico é maior com o aumento da concentração da solução eletrolítica até um valor limite $(\sim 0,100 \mathrm{M})$ a partir do qual a corrente de pico permanece constante. O excesso de eletrólito é fundamental para minimizar a influência da migração de íons devida à polarização do eletrodo de trabalho. Mas a concentração do eletrólito influencia na impedância da cela eletrolítica. Em concentrações baixa a impedância aumenta provocando uma queda hômica da corrente. Este fato explica porque mesmo a solução de $\mathrm{CH}_{3} \mathrm{COOH} 0,0100 \mathrm{M}$ apresentando $\mathrm{pH}$ superior a solução $0,100 \mathrm{M}$ gera uma corrente de difusão menor para o íon $\mathrm{Cu}^{2+}$. 


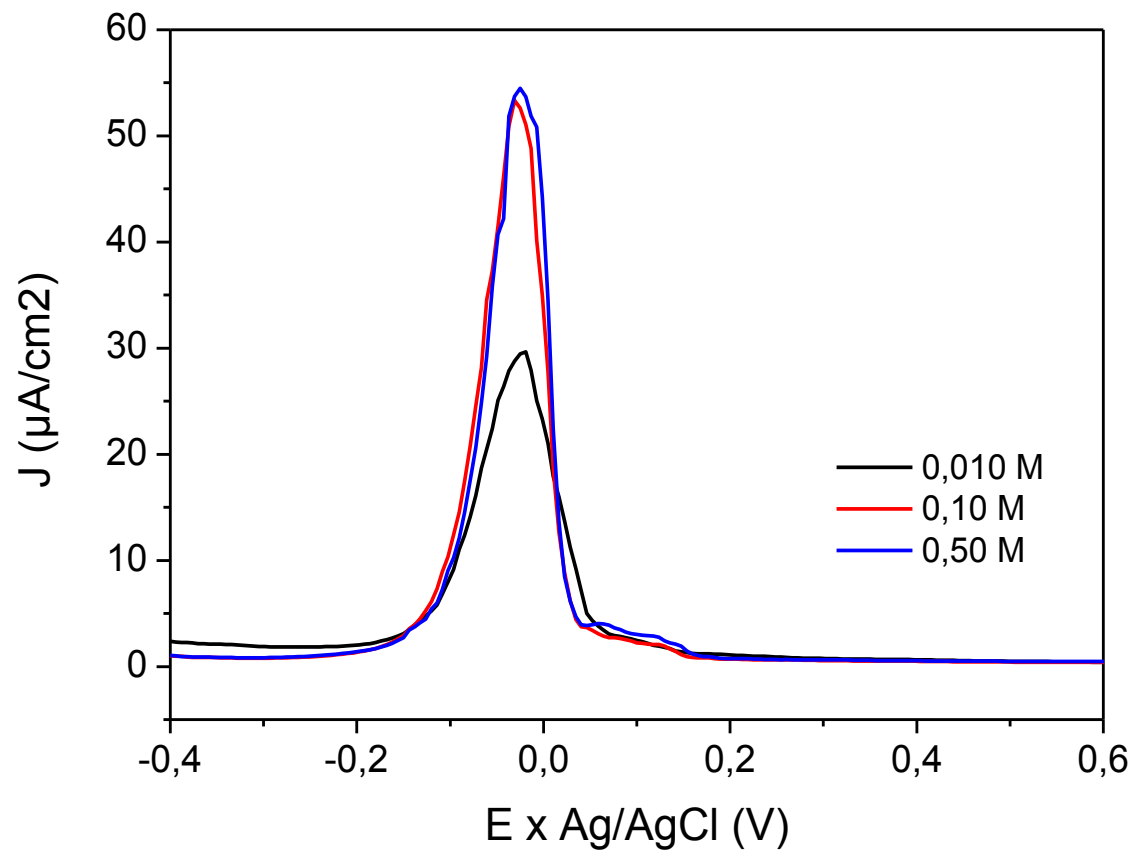

Figura 18. Voltamogramas de DPASV mostrando a influência da concentração do eletrólito ácido acético $\left(\mathrm{CH}_{3} \mathrm{COOH}\right) 0,010 \mathrm{M}(\mathrm{pH} 3,4) ; 0,100 \mathrm{M}(\mathrm{pH} 2,9)$ e 0,500 M (pH 2,5) no sinal analítico de uma solução de cobre de $100 \mu \mathrm{g} \mathrm{L}^{-1}$ sobre o eletrodo ION (np-Fe $\left.{ }_{3} \mathrm{O}_{4} / \mathrm{PSS}\right)_{3}$. A deposição ocorreu no potencial de $-0,4 \mathrm{~V}$ por $120 \mathrm{~s}$. Amplitude de pulso foi de $50 \mathrm{mV}$ e velocidade de varredura de $10 \mathrm{mV} \mathrm{s}^{-1}$.

Estudou-se também a influência da natureza do eletrólito na corrente de difusão dos íons $\mathrm{Cu}^{2+} 100 \mu \mathrm{g} \mathrm{L}^{-1}$. Os eletrólitos estudados foram o ácido acético (pH 2,9), ácido cítrico $(\mathrm{pH} \sim 2,0)$, ácido fosfórico $(\mathrm{pH} \sim 1,5)$ e o ácido clorídrico $(\mathrm{pH} \sim 1,0)$ todos na concentração de 0,100 M. Observaram-se valores de correntes de difusão similares entre os ácidos acético e cítrico. $\mathrm{O}$ ácido fosfórico apresentou a maior corrente de difusão enquanto o ácido clorídrico apresentou a menor corrente (Figura 19). É conhecido em estudos voltamétricos de íons $\mathrm{Cu}^{2+}$ na presença de $\mathrm{Cl}^{-}$a formação de uma camada passiva de $\mathrm{CuCl}_{(\mathrm{s})}$ sobre o eletrodo de trabalho diminuindo a intensidade da corrente de pico.[79] Por outro lado, o eletrólito suporte comporta-se como uma base de Lewis tendendo a ligar-se ao íon $\mathrm{Cu}^{2+}$. Esse efeito tendo a "reter" o íon no interior da solução eletrolítica diminuindo sua concentração da interface eletrodo/solução e, portanto, diminuindo a corrente de difusão do $\mathrm{Cu}^{2+}$. $\mathrm{O}$ ácido acético e cítrico complexam o íon $\mathrm{Cu}^{2+}$ através do mesmo grupo carboxila $(-\mathrm{COOH})$ apresentando 
influências similares. Portanto, os eletrólitos mais apropriados para detecção de $\mathrm{Cu}^{2+}$ são o ácido acético e o ácido cítrico.

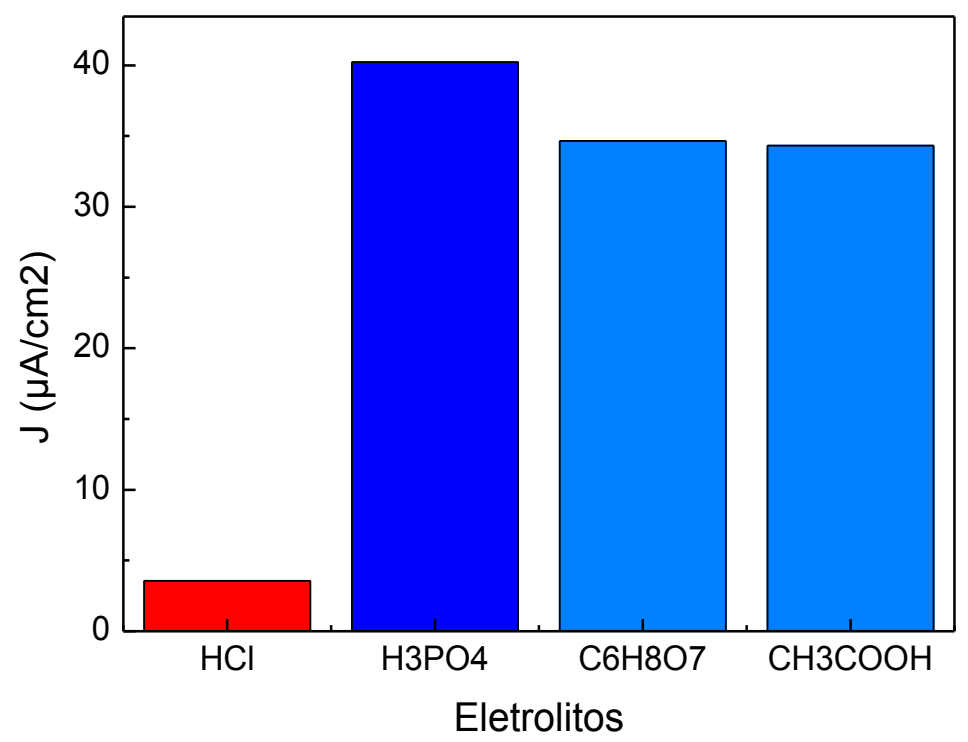

Figura 19. Densidade de corrente para soluções de $\mathrm{Cu}^{2+} 100 \mu \mathrm{g} \mathrm{L}^{-1}$ em função da natureza do eletrólito. Os eletrólitos utilizados foram ácido clorídrico $(\mathrm{HCl})$, ácido fosfórico $\left(\mathrm{H}_{3} \mathrm{PO}_{4}\right)$, ácido cítrico $\left(\mathrm{C}_{6} \mathrm{H}_{3} \mathrm{O}_{7}\right)$ e ácido acético $\left(\mathrm{CH}_{3} \mathrm{COOH}\right)$ todos na concentração de $0,100 \mathrm{M}$. A deposição ocorreu no potencial de $-0,4 \mathrm{~V}$ por $120 \mathrm{~s}$. Amplitude de pulso foi de $50 \mathrm{mV}$ e velocidade de varredura de $10 \mathrm{mV} \mathrm{s}^{-1}$. 


\subsubsection{Influência do potencial de deposição no sinal analítico de $\mathbf{C u}^{2+}$ sobre o eletrodo de ION $\left(\mathrm{np}-\mathrm{Fe}_{3} \mathrm{O}_{4} / \mathrm{PSS}\right)_{3}$}

A escolha do potencial de deposição pode exercer um papel central na voltametria de redissolução anódica. Valores muito baixos pode causar possíveis interferentes na superfície do eletrodo. Por outro lado, o potencial deve ser suficientemente negativo para depositar o analito alvo. A Figura 20 apresenta voltamogramas de DPASV para o íon $\mathrm{Cu}^{2+} 100 \mu \mathrm{g} \mathrm{L} \mathrm{L}^{-1}$ em $\mathrm{CH}_{3} \mathrm{COOH}$ 0,100 M. Observa-se da Figura 20 que a corrente de pico aumentou até o valor de $-0,45 \mathrm{~V}$. Portanto o potencial de deposição de - 0,45 V apresentou a melhor sensibilidade. Entretanto, para aplicação em amostras reais, o potencial de pico deve ser reavaliado sempre buscando o compromisso entre sensibilidade e seletividade.

O potencial de deposição está relacionado com o campo elétrico no qual o analito está exposto na etapa de deposição. Quando maior o potencial, maior a intensidade do campo elétrico e consequentemente aumento da atração eletrostática entre o eletrodo de trabalho (polarizado) e o analito provocando o aumento da concentração de íon $\mathrm{Cu}^{2+}$ na interface eletrodo/solução. 


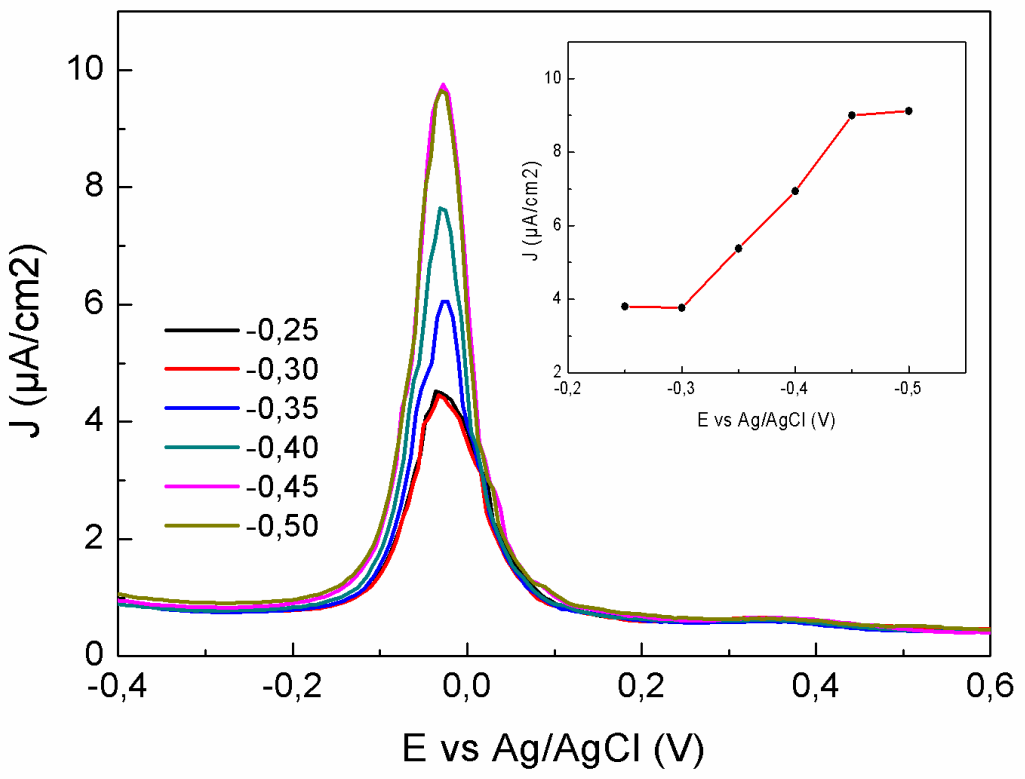

Figura 20. Voltamogramas de DPASV apresentando a influência do potencial de deposição no sinal analítico de $\mathrm{Cu}^{2+} 100 \mu \mathrm{g} \mathrm{L}^{-1}$ sobre o eletrodo ION (np-Fe $\left.\mathrm{O}_{4} / \mathrm{PSS}\right)_{3}$. Os potencial de deposição foram $-0,25,-030,-0,35,-0,40,-0,45$ e $-0,50 \mathrm{~V}$. Eletrólito suporte $\mathrm{CH}_{3} \mathrm{COOH}$ 0,100 mol L ${ }^{-1}$. Potencial de deposição -0,4 V. Varredura de $-0,4$ a $+0,6 \mathrm{~V}$, amplitude de pulso de $50 \mathrm{mV}$. 


\subsubsection{Influência do tempo de deposição no sinal analítico de $\mathrm{Cu}^{2+}$ sobre o eletrodo de ION (np-Fe $\left.\mathrm{O}_{3} / \mathrm{PSS}\right)_{3}$}

$\mathrm{Na}$ etapa de deposição, o analito fica exposto a um potencial constante (potencial de deposição) por um tempo estritamente controlado (Tempo de deposição). Em geral, quanto maior o tempo de deposição maior será a quantidade de analito depositado sobre a superfície do eletrodo e maior será a corrente de pico na etapa de determinação. Usualmente utiliza-se tempos de deposição entre 1 a 10 min. $\mathrm{Na}$ Figura 21 são apresentados os voltamogramas de ADASV de uma solução de $\mathrm{Cu}^{2+} 100$ $\mu \mathrm{g} \mathrm{L}^{-1}$ em $\mathrm{CH}_{3} \mathrm{COOH}$ 0,100 M com os tempo de deposição variando de 0 a $300 \mathrm{~s} \mathrm{sob}$ um potencial de $-0,4 \mathrm{~V}$. Em destaque na figura é apresentado os valores da altura do pico em função do tempo de deposição.

Podemos observar que a corrente de pico aumenta com o aumento do tempo de deposição. Entretanto, a partir de 240 s a corrente de pico tendeu a permanecer constante indicando a saturação de cobre eletroquimicamente depositado na superfície do eletrodo nestas condições. Portanto, para uma solução de $\mathrm{Cu}^{2+} 100 \mu \mathrm{g} \mathrm{L}^{-1}$ o tempo de 240 s é o melhor valor para alcançar uma sensibilidade analítica máxima. Deve ser salientado que em concentrações de íons $\mathrm{Cu}^{2+}$ acima de $100 \mu \mathrm{g} \mathrm{L}^{-1}$ o tempo de saturação provavelmente será alcançado num tempo inferior a $240 \mathrm{~s}$. Outro aspecto que deve ser realçado é que a escolha do tempo de deposição é um compromisso entre a sensibilidade e a frequência analítica. Desta forma, optou-se por utilizar o tempo de $120 \mathrm{~s}$ o qual apresentou uma sensibilidade analítica adequada sem comprometer demasiadamente a frequência analítica. 


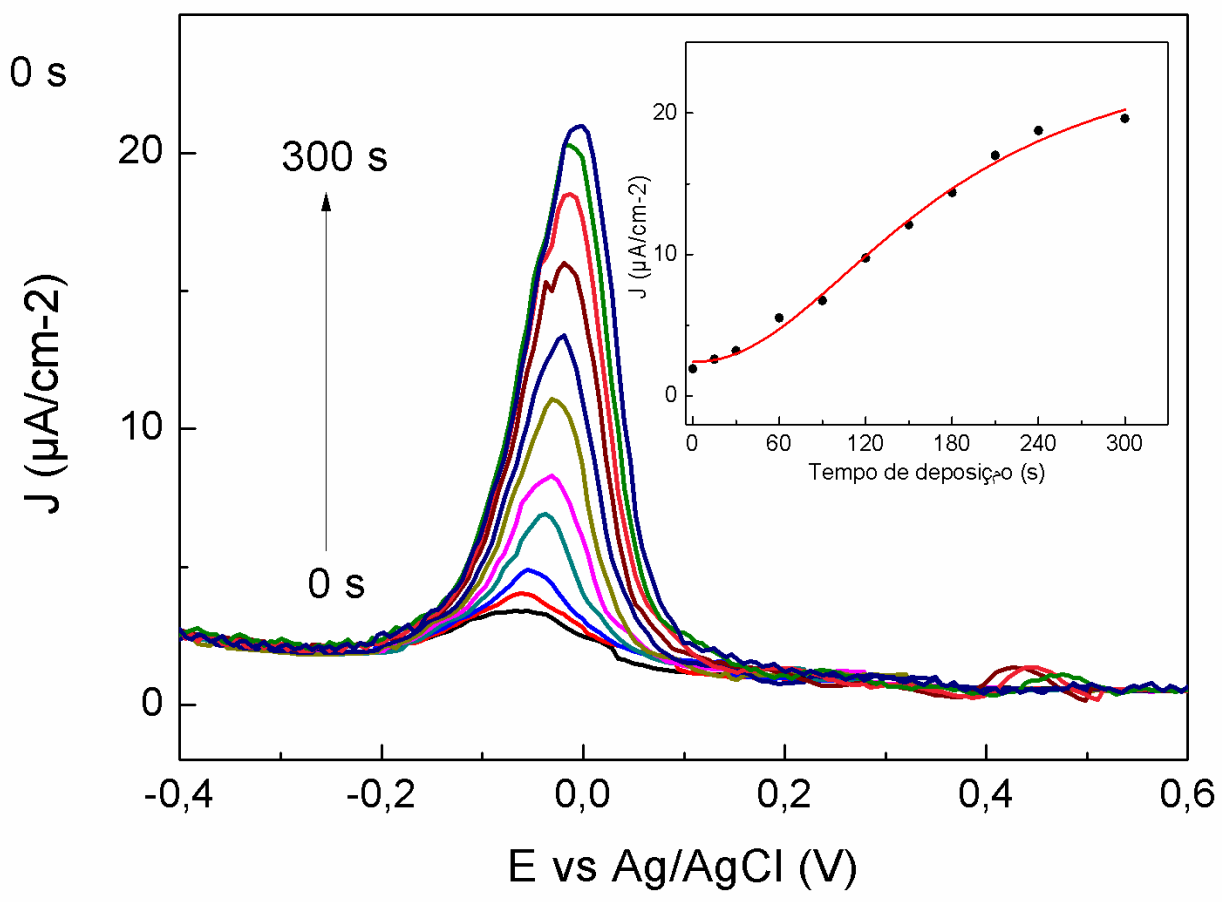

Figura 21. Voltamogramas DPASV apresentando a influência do tempo de deposição no sinal analítico de $\mathrm{Cu}^{2+} 100 \mu \mathrm{g} \mathrm{L}^{-1}$ sobre o eletrodo ION (np-Fe $\left.\mathrm{O}_{4} / \mathrm{PSS}\right)_{3}$. Os tempos de deposição foram de $15,30,60,120,240$ e 480 s. O eletrólito suporte foi HAc 0,100 mol L ${ }^{-1}$. Potencial de deposição $-0,4 \mathrm{~V}$. Varredura de $-0,4$ a $+0,6 \mathrm{~V}$, amplitude de pulso de $50 \mathrm{mV}$. 


\subsubsection{Influência da velocidade de agitação no sinal analítico de $\mathrm{Cu}^{2+}$ sobre o eletrodo de ION $\left(\mathrm{np}-\mathrm{Fe}_{3} \mathrm{O}_{4} / \mathrm{PSS}\right)_{3}$}

A Figura 22 apresenta os voltamogramas de ADASV para soluções de $\mathrm{Cu}^{2+}$ $100 \mu \mathrm{g} \mathrm{L}^{-1}$ em $\mathrm{CH}_{3} \mathrm{COOH}$ 0,100 M para velocidades de varreduras de 0 a $2000 \mathrm{rpm}$. Observou-se um aumento exponencial da corrente de pico com o aumento da velocidade de agitação da solução eletrolítica durante a etapa de deposição. A agitação da solução promove o transporte do analito para a superfície do eletrodo de trabalho por convecção. Os resultados apresentados na Figura 22 sugerem que o aumento da corrente de pico tende a alcançar um valor limiar em virtude da saturação de cobre na superfície do eletrodo. Utilizamos a velocidade de agitação de $2000 \mathrm{rpm}$ no decorrer desse trabalho por apresentar maior sensibilidade analítica.

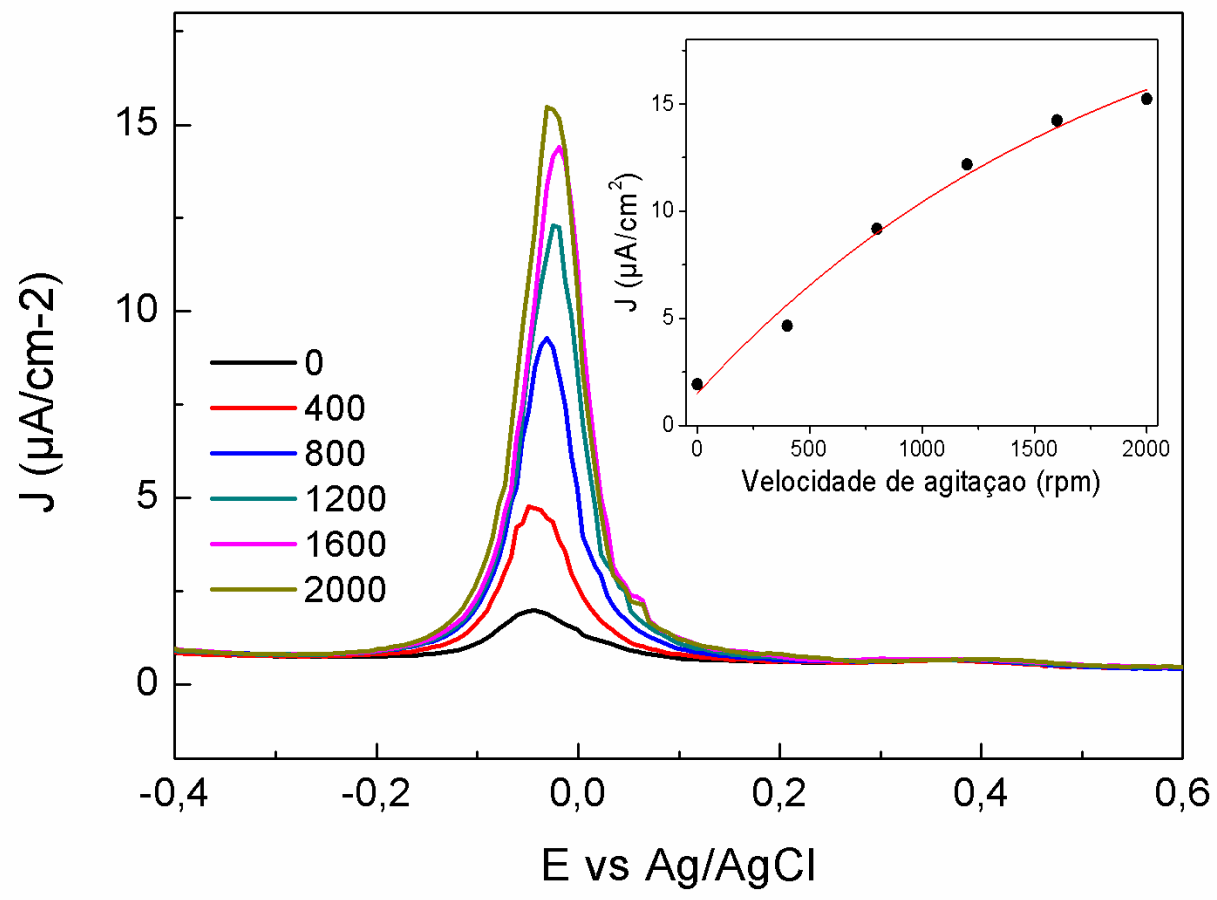

Figura 22. Voltamogramas PDASV apresentando a influência da velocidade de agitação no sinal analítico de $\mathrm{Cu}^{2+} 100 \mu \mathrm{g} \mathrm{L}^{-1}$ sobre o eletrodo ION (np- $\left.\mathrm{Fe}_{3} \mathrm{O}_{4} / \mathrm{PSS}\right)_{3}$. As velocidades de agitação foram 0, 400, 800, 1200, 1600 e 2000 rpm. A deposição ocorreu sob o potencial de $-0,4 \mathrm{~V}$ por $120 \mathrm{~s}$. Varredura anódica de $-0,4$ a $+0,6 \mathrm{~V}$, amplitude de pulso de $50 \mathrm{mV}$ e velocidade de varredura de $5 \mathrm{mV} \mathrm{s}^{-1}$. 


\subsubsection{Durabilidade dos eletrodos de ITO com ION}

Os eletrodos ION $\quad\left(n p-\mathrm{Fe}_{3} \mathrm{O}_{4} / \mathrm{PSS}\right)_{3}$ apresentaram boa durabilidade relativamente a outros sensores voltamétricos relatados na literatura. Alguns eletrodos são descartáveis sendo apropriados para uma única leitura [80,81]. Outros sensores apesar de apresentar boa durabilidade, mas exigem métodos de preparação demorados e ou utilizam reagentes e solventes caros.[82-85] Em contrapartida, os sensores com (np$\left.\mathrm{Fe}_{3} \mathrm{O}_{4} / \mathrm{PSS}\right)_{3}$ são de baixo custo, não utiliza solventes na sua preparação e um único sensor de $\left(\mathrm{np}-\mathrm{Fe}_{3} \mathrm{O}_{4} / \mathrm{PSS}\right)_{3}$ foi capaz de realizar 24 leituras com um desvio padrão relativo de 3,5\% $(n=8)$ (ver Figura 25). Entretanto, o sinal analítico tende a cair com o uso contínuo dos eletrodos. Após 48 leituras consecutivas com purga adicional de $30 \mathrm{~s}$ entre cada leitura o sinal por PDASV sofre uma atenuação de cerca de $19 \%$. Entretanto, devido ao seu baixo custo e simplicidade de confecção, os eletrodos de ION apresentaram boa reação custo benefício comparado com outros sensores de construção mais complexa e dispendiosa.

Um aspecto relevante que deve ser considerado é o tempo de estoque dos eletrodos antes do uso. Eletrodos recém preparados tendem a ter um comportamento eletroquímico diferente de eletrodos preparados há muitos dias (60 dias ou mais). Essa constatação é corroborada com os resultados apresentados por Letti [86] o qual aponta que os óxidos de ferro nanoestruturados sofrem oxidação quando expostos a diferentes condições. Portanto, o ideal é que os eletrodos sejam utilizados num tempo mais curto possível após a sua confecção. 


\subsection{PARÂMETROS DE VALIDAÇÃO ANALÍTICA PARA DETECÇÃO DE $\mathrm{Cu}^{2+}$ SOBRE ELETRODOS ION (np- $\left.\mathrm{Fe}_{3} \mathrm{O}_{4} / \mathrm{PSS}\right)_{3}$}

\subsubsection{Faixa de trabalho e Sensibilidade do sinal analítico de $\mathrm{Cu}^{2+}$ sobre eletrodos de ION $\left(\mathrm{np}-\mathrm{Fe}_{3} \mathrm{O}_{4} / \mathrm{PSS}\right)_{3}$}

A Figura 23 apresenta uma relação entre a área de pico em função da concentração de $\mathrm{Cu}^{2+}$ para soluções de 5 a $400 \mu \mathrm{g} \mathrm{L} \mathrm{L}^{-1}$ em tampão BR pH 3 obtidas a partir de voltamogramas de DPASV. A utilidade de um método depende da extensão da sua faixa analítica. Quanto maior a extensão da faixa maior a sua aplicabilidade. Uma ampla faixa de dinâmica foi observada da Figura 23 com uma ordem de magnitude de cerca de 80 vezes. Entretanto, duas faixas lineares podem ser observadas. A primeira faixa linear (Faixa 1) vai de 5 a até cerca de $40 \mu \mathrm{g} \mathrm{L}^{-1}(\mathrm{r}=0,9991)$ e a segunda faixa (Faixa 2), de 80 a $400 \mu \mathrm{g} \mathrm{L}^{-1}(\mathrm{r}=0,9995)$. Esse comportamento indica uma mudança superficial do eletrodo em concentrações mais altas. Esse mesmo comportamento foi observado num trabalho recente [87] que utilizou eletrodos revestidos de nanotubos de carbono e óxidos de ferro para determinação de ácido salicílico. 


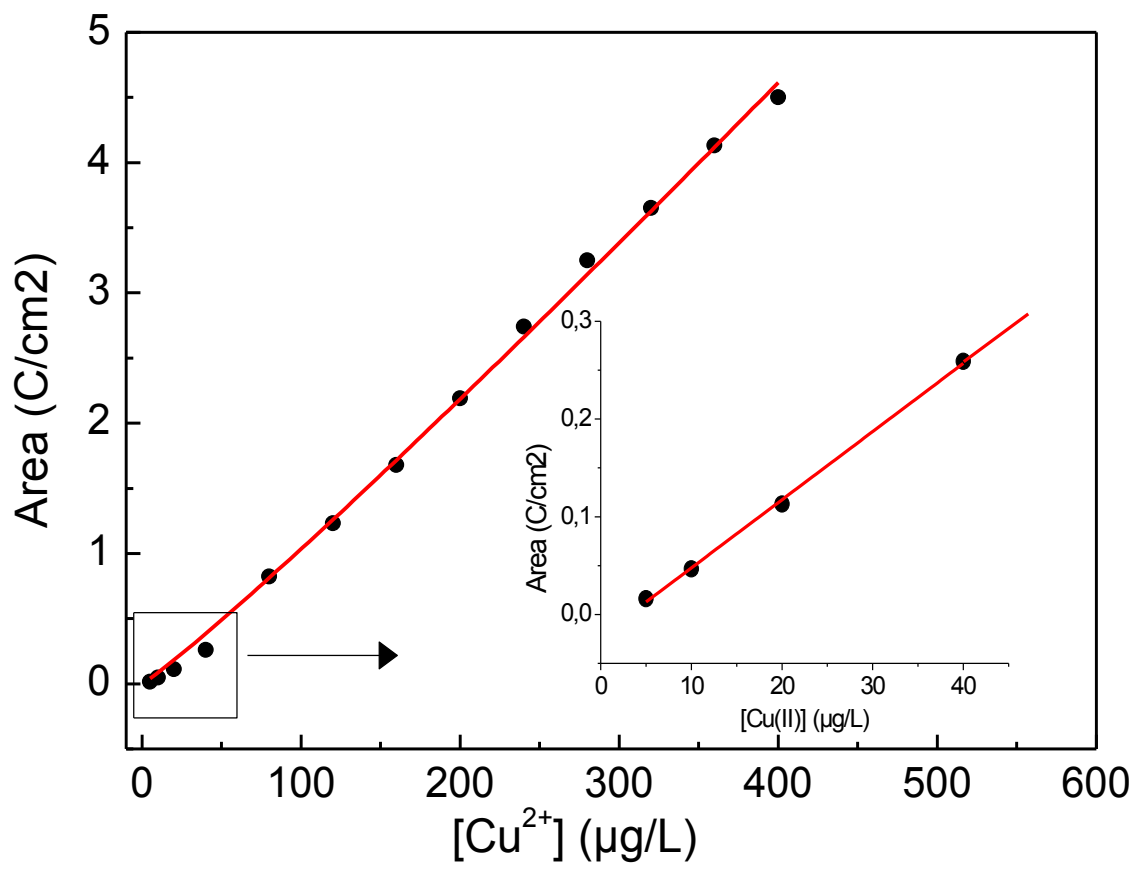

Figura 23. (a) Sinal analítico (área do pico) em função da concentração obtidos através de PDASV para soluções de $\mathrm{Cu}^{2+}$ de concentrações de 5 a $400 \mathrm{em} \mu \mathrm{g} \mathrm{L}^{-1}$ sobre o eletrodo ION (np-Fe $\left.{ }_{3} \mathrm{O}_{4} / \mathrm{PSS}\right)_{3}$. A deposição ocorreu sob o potencial de $-0,4 \mathrm{~V}$ por $120 \mathrm{~s}$. Varredura de $-0,4 \mathrm{a}+0,6 \mathrm{~V}$, Amplitude de pulso $50 \mathrm{mV}$ e velocidade de varredura de 10 $\mathrm{mV} \mathrm{s}^{-1}$. Em destaque área ampliada na faixa de 5 a $40 \mu \mathrm{g} \mathrm{L}^{-1} \mathrm{de} \mathrm{Cu}^{2+}$.

A sensibilidade analítica $(\gamma)$ também foi avaliada através de uma curva analítica na faixa de concentração de 5 a $25 \mu \mathrm{g} \mathrm{L}^{-1}$ (Figura 24). A sensibilidade analítica foi estimada em $5,32 \times 10^{-7} \mu \mathrm{A} / \mu \mathrm{g} \mathrm{L} \mathrm{L}^{-1}$ ou $\left(20,0 \mu \mathrm{A} / \mathrm{mM} \mathrm{cm}^{2}\right.$, área do eletrodo foi de $0,170 \mathrm{~cm}^{2}$ ). A sensibilidade de da metodologia apresentado neste trabalho é próxima de outros trabalho envolvendo determinação de cobre com eletrodos sólidos que vão de 5 a $58 \mu \mathrm{A} / \mathrm{mM} \mathrm{cm}^{2}$. [88-90] 


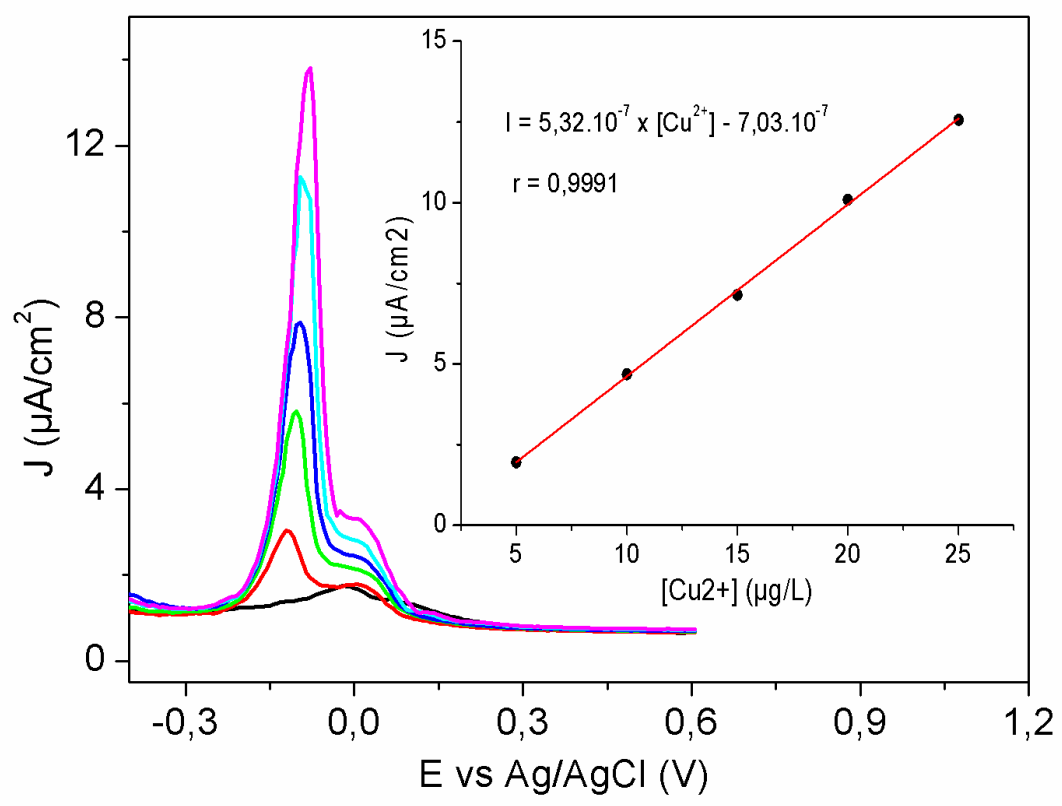

Figura 24. Voltamogramas de DPASV de solução de $\mathrm{Cu}^{2+}$ de concentrações de 5 a 25 em $\mu \mathrm{g} \mathrm{L}^{-1}$ sobre o eletrodo ION (np- $\left.\mathrm{Fe}_{3} \mathrm{O}_{4} / \mathrm{PSS}\right)_{3}$. A deposição ocorreu sob o potencial de $-0,4 \mathrm{~V}$ por $120 \mathrm{~s}$. Varredura de $-0,4 \mathrm{a}+0,6 \mathrm{~V}$, Amplitude de pulso $50 \mathrm{mV}$ e velocidade de varredura de $10 \mathrm{mV} \mathrm{s}^{-1}$. Eletrólito suporte foi tampão BR pH 3. Em destaque uma curva analítica dos valores de $\mathrm{J}$ em função da concentração. 


\subsubsection{Limite de Detecção e Limite de Quantificação do Método proposto para determinação de $\mathrm{Cu}^{2+}$ sobre eletrodos de ION (np- $\left.\mathrm{Fe}_{3} \mathrm{O}_{4} / \mathrm{PSS}\right)_{3}$}

O Limite de Detecção (LD) foi obtido a partir de 8 valores de uma solução do branco analítico. Os valores para o branco são apresentados na Tabela 7. O desvio padrão (s) calculado foi $0,157 \mathrm{nA}$. O LD $\left(\mathrm{k}=3\right.$ ) obtido pela Equação (3) foi $0,33 \mu \mathrm{g} \mathrm{L}{ }^{-1}$ ou $0,52 \mathrm{nmol} \mathrm{L}{ }^{-1}$. O LQ ( $\mathrm{k}=10$ ) obtido pela Equação (4) foi $1,1 \mu \mathrm{g} \mathrm{L}^{-1}$ ou $1,7 \mathrm{nmol} \mathrm{L}^{-1}$. O LD para o eletrodo de ION é promissor relativamente aos valores de LD reportados nas literatura para eletrodos específicos. Por exemplo, eletrodos de ouro modificados por cisteína, o qual tem uma reconhecida habilidade para formar um complexo estável com o $\mathrm{Cu}^{2+}$, exibe um LD na faixa de $10^{-7}$ a $10^{-9} \mathrm{M}$. [91-93] Outras abordagens para desenvolvimento de eletrodos específicos para cobre, incluindo impressão molecular com EDTA [94], Schiff bases [95] ou fragmentos de peptídeos [96,97] tem também alcançado a mesma faixa de LD.

Tabela 7. Leituras de uma solução do branco utilizadas para determinação do limite de detecção para detecção de $\mathrm{Cu}^{2+}$ com eletrodos de ION (np- $\left.\mathrm{Fe}_{3} \mathrm{O}_{4} / \mathrm{PSS}\right)_{3}$.

\begin{tabular}{ccccccccc}
\hline Leitura & 1 & 2 & 3 & 4 & 5 & 6 & 7 & 8 \\
\hline Ip (nA) & 0,478 & 0,432 & 0,318 & 0,210 & 0,226 & 0,446 & 0,367 & 0,403 \\
\hline
\end{tabular}

Estes níveis de LD e LQ reportados neste trabalho são adequados para determinação de íons $\mathrm{Cu}^{2+}$ em amostras de café e outras amostras de alimentos bem como outras amostras de complexidade semelhante. O LD para determinação voltamétrica de $\mathrm{Cu}^{2+}$ com eletrodos de ITO modificados com (np- $\left.\mathrm{Fe}_{3} \mathrm{O}_{4} / \mathrm{PSS}\right)_{3}$ é cerca de 40 vezes maior que por FAAS [98] $\left(\sim 20 \mathrm{nmol} \mathrm{L}^{-1}\right)$. 


\subsubsection{Avaliação da precisão do sinal analítico de $\mathrm{Cu}^{2+}$ sobre eletrodos de ION (np- $\left.\mathrm{Fe}_{3} \mathrm{O}_{4} / \mathrm{PSS}\right)_{3}$}

A precisão foi avaliada através de estudos de repetitividade. Estes estudos foram realizados através das medidas da resposta analítica por PDASV de um soluções padrão para o mesmo eletrodo e no mesmo dia contendo 20, 80 e $160 \mu \mathrm{g} \mathrm{L} \mathrm{L}^{-1}$ (Figura 25) sem qualquer etapa adicional de regeneração. Os RSD calculados foram respectivamente 17,$9 ; 2,9$ e 2,2 \%. Além da boa repetitividade, eletrodos de ION tem a vantagem de ser convenientemente e rapidamente regenerado. Não é necessário fazer qualquer tipo de limpeza física ou eletroquímica do eletrodo após cada medida ou série de medidas. Após cada medida, o eletrodo é regenerado (com a célula eletroquímica mantida em off) sob agitação por 150 s e sob injeção de gás de purga na própria solução de leitura. A não necessidade de utilização de solução de processos de regeneração demorados e elaborados faz com que o eletrodo ION seja bastante conveniente para determinação de $\mathrm{Cu}^{2+}$.

A conveniência e rapidez de condicionamento dos eletrodos de ION refletem na frequência analítica. Para determinação de metais em nível traço, a frequência analítica é frequentemente baixa devido a etapas de pré-concentração longas (10 min ou mais) combinado com estratégias adicionais de condicionamento do eletrodo. Para o eletrodo ION a frequência analítica foi avaliada em torno de 12 determinações por hora (5 min por determinação). Outros estudos apresentados na literatura [84,99] para determinação de $\mathrm{Cu}$ apresentaram baixíssima frequência analítica sendo de difícil utilização em ensaios de rotina. Outro aspecto relevante dos eletrodos de ION é o baixo custo, rapidez e simplicidade no processo de confecção dos eletrodos. 


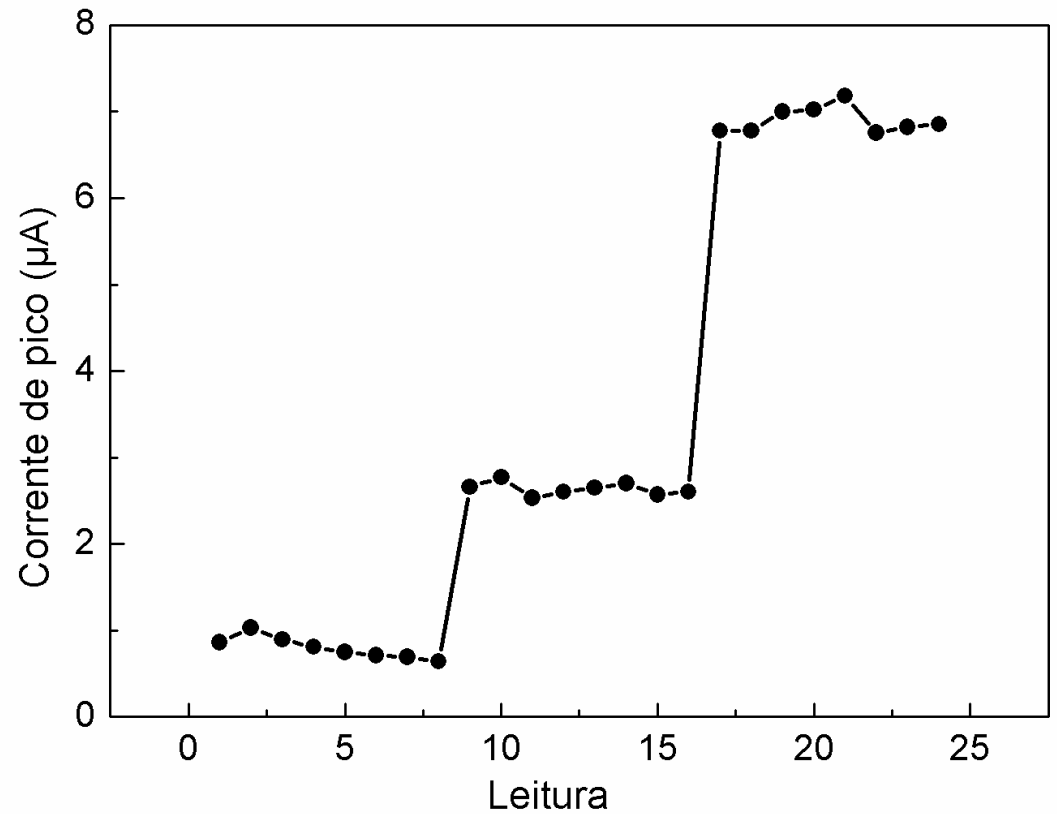

Figura 25. Corrente de pico obtidos por PDASV para soluções de $\mathrm{Cu}^{2+} \mathrm{de}$ concentrações de $20( \pm 17,9 \%), 80( \pm 2,9 \%)$ e $160\left(( \pm 2,2 \%) \mu \mathrm{g} \mathrm{L}^{-1}\right.$ sobre o eletrodo ION (np-Fe $\left.\mathrm{O}_{4} / \mathrm{PSS}\right)_{3}$. Os valores de $\mathrm{CV}$ foram de respectivamente 17,$9 ; 2,9$ e A deposição ocorreu sob o potencial de $-0,4 \mathrm{~V}$ por $120 \mathrm{~s}$. Varredura de $-0,4$ a $+0,6 \mathrm{~V}$, Amplitude de pulso $50 \mathrm{mV}$ e velocidade de varredura de $10 \mathrm{mV} \mathrm{s}^{-1}$. 


\subsubsection{Determinação de $\mathrm{Cu}^{2+}$ em amostras de café em pó}

A exatidão do sinal analítico de $\mathrm{Cu}^{2+}$ sobre os eletrodos de ION (np$\left.\mathrm{Fe}_{3} \mathrm{O}_{4} / \mathrm{PSS}\right)_{3}$ foi avaliada através da determinação de $\mathrm{Cu}^{2+}$ em amostras de café comercialmente disponíveis. Com essa finalidade, o teor de $\mathrm{Cu}$ também foi avaliado por Espectrometria de Absorção Atômica em chama (FAAS) e os resultados estão apresentados na Tabela 8. Estes resultados são compatíveis com os teores de cobre encontrados por outros autores em grãos de café. [49,100] A aplicação de sensores de ION para determinação dos teores de cobre em café foi verificada, tendo em vista da sua importância para cultura do café e também da segurança alimentar.

Os teores de $\mathrm{Cu}^{2+}$ em amostras de café utilizando os eletrodos de ION (np$\left.\mathrm{Fe}_{3} \mathrm{O}_{4} / \mathrm{PSS}\right)_{3}$ foi avaliada por adição de padrão (Figura 26). Enquanto que para determinar $\mathrm{Cu}^{2+}$ por FAAS fui utilizada curvas analíticas na faixa de concentração de 0,5 a 2,5 $\mathrm{mg} \mathrm{L}^{-1}$ (linha espectral 324,8 nm) sem adição de padrão. (Figura 27).

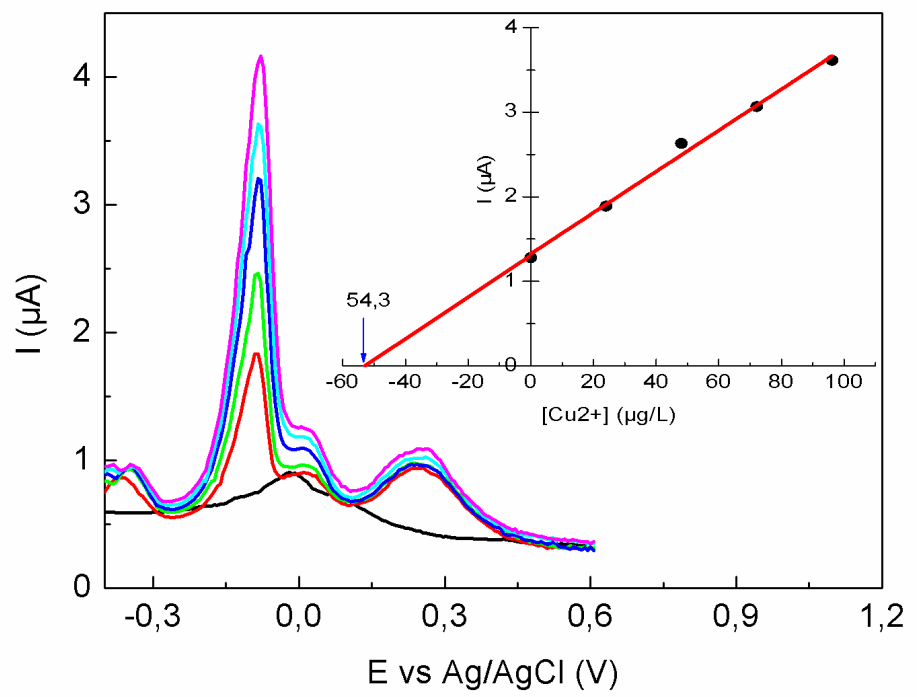

Figura 26. (a) Voltamogramas de PDASV para amostra café em pó orgânico comercialmente disponível $\left(0,1 \mathrm{~mL}\right.$ de amostra $+0,1 \mathrm{ml}$ de padrão $2,5 \mathrm{mg} \mathrm{L}^{-1} \mathrm{em} 5 \mathrm{~mL}$ de eletrólito tampão $\mathrm{BR}$ pH 3) e adições de $10,20,30$ e $40 \mu \mathrm{L}$ de padrão de $\mathrm{Cu}^{2+} 5 \mathrm{mg}$ $\mathrm{L}^{-1}$ sobre o eletrodo ION (np- $\left.\mathrm{Fe}_{3} \mathrm{O}_{4} / \mathrm{PSS}\right)_{3}$. Em destaque, uma curva de adição de padrão para os voltamogramas. A deposição ocorreu sob o potencial de $-0,4 \mathrm{~V}$ por $120 \mathrm{~s}$. Varredura anódica de $-0,4 \mathrm{a}+0,6 \mathrm{~V}$, amplitude de pulso de $50 \mathrm{mV}$ e velocidade de varredura de $10 \mathrm{mV} \mathrm{s}^{-1}$. Uma purga adicional de $60 \mathrm{~s}$ foi realizada entre cada adição. 


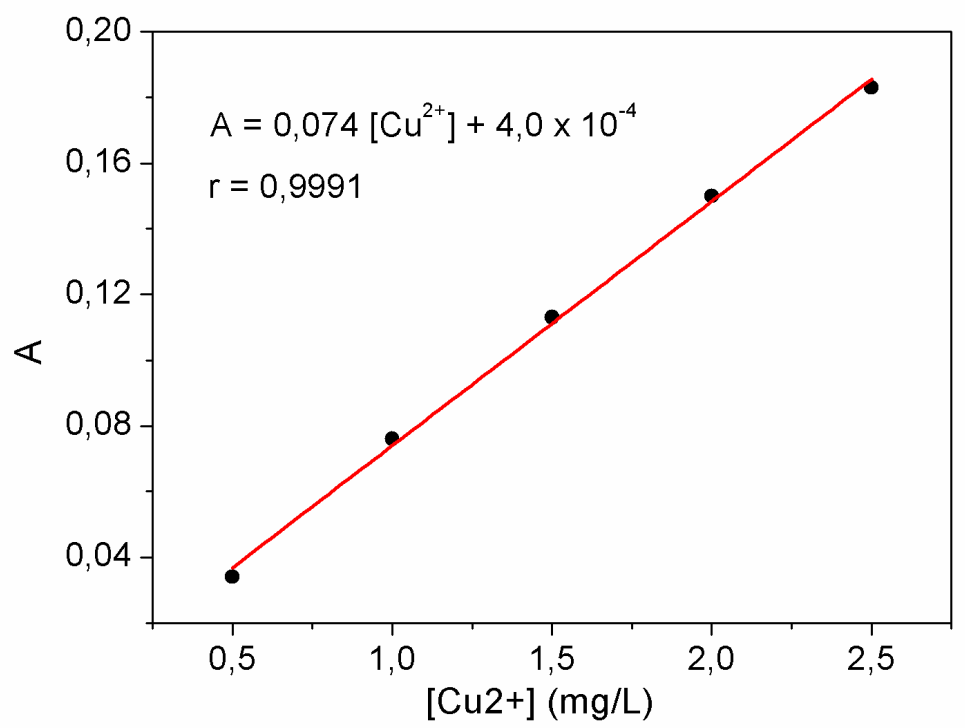

Figura 27. Curva analítica para determinação de $\mathrm{Cu}^{2+}$ em amostras de café por Espectrometria de Absorção Atômica em Chama (FAAS) na faixa de concentração de 0,5 a 2,5 $\mathrm{mg} \mathrm{L}^{-1}$. As condições experimentais estão resumidas na Tabela 4.

A concentração de $\mathrm{Cu}^{2+}$ nas amostras de café, utilizando os eletrodos de ION (np- $\left.\mathrm{Fe}_{3} \mathrm{O}_{4} / \mathrm{PSS}\right)_{3}$, foi calculada pela seguinte equação $\left[\mathrm{Cu}^{2+}\right]=\left[\mathrm{Cu}^{2+}\right]_{\text {cel }} * \mathrm{Fd}-\mathrm{B}$. Como exemplo, para a amostra $\mathrm{A} 1$, o valor de B foi $1,19 \mathrm{mg} \mathrm{L}^{-1}$ (correspondente a uma adição de $100 \mu \mathrm{L}$ de padrão $2,5 \mathrm{mg} \mathrm{L}^{-1}$ ), o Fd $52(5,2 / 0,1)$ e $\left[\mathrm{Cu}^{2+}\right]_{\text {cel }} 53,4 \mu \mathrm{g} \mathrm{L}^{-1}$ (ver a Figura 26). Portanto, para amostra A1 a concentração obtida foi $1,63 \mathrm{mg} \mathrm{L}^{-1}$ ou 16,3 $\mathrm{mg} / \mathrm{kg}$ de café em pó. 
Tabela 8. Resultados de determinação de $\mathrm{Cu}^{2+}$ em amostras de café em pó comercialmente disponíveis utilizando o eletrodo de ION (np- $\left.\mathrm{Fe}_{3} \mathrm{O}_{4} / \mathrm{PSS}\right)_{3}$ e por Espectrofotometria de Absorção Atômica em Chama (FAAS).

\begin{tabular}{ccc}
\hline Amostra & {$\left[\mathrm{Cu}^{2+}\right](\mathrm{mg} / \mathrm{kg})$} & FAAS $(\mathrm{mg} / \mathrm{kg})$ \\
\hline A1 & $16,3 \pm 4,8 \%$ & $16,4 \pm 2,76 \%$ \\
A2 & $17,5 \pm 5,2 \%$ & $18,2 \pm 2,65 \%$ \\
A3 & $16,9 \pm 3,8 \%$ & $17,5 \pm 2,64 \%$ \\
A4 & $17,0 \pm 6,3 \%$ & $16,5 \pm 2,65 \%$ \\
\hline
\end{tabular}

A Comparando os valores dos teores de café obtidos com os eletrodos de ION e com os valores obtidos por FAAS, foi verificado que não há diferença significativa entre os dois resultados para um nível de confiança de $95 \%$. Entretanto, o método FAAS apresentou menor incerteza que os valores obtidos pelo ION (np- $\left.\mathrm{Fe}_{3} \mathrm{O}_{4} / \mathrm{PSS}\right)_{3}$. Por outro lado, o método desenvolvido neste trabalho apresentou uma sensibilidade analítica muito superior ( $L Q 1,1 \mu \mathrm{g} \mathrm{L}^{-1}$ ) e foi capaz de quantificar $\mathrm{Cu}^{2+}$ em quantidades traço. 


\subsubsection{Estudo de interferentes na determinação de $\mathrm{Cu}^{2+}$ utilizando eletrodos de ION $\left(\mathrm{np}-\mathrm{Fe}_{3} \mathrm{O}_{4} / \mathrm{PSS}\right)_{3}$}

A resposta dos eletrodos de $\mathrm{ION}\left(\mathrm{np}-\mathrm{Fe}_{3} \mathrm{O}_{4} / \mathrm{PSS}\right)_{3}$ relativamente ao $\mathrm{Cu}^{2+}$ também foi testada na presença de possíveis íons interferentes em tampão BR pH 3. Os dados estão reunidos na Tabela 9. Todos os íons interferentes testados $\left(\mathrm{Zn}^{2+}, \mathrm{Mn}^{2+}\right.$, $\mathrm{Ni}^{2+}$ e $\mathrm{Fe}^{3+}$ ) apresentaram interferência insignificante para um nível de confiança de 95 $\%$ relativamente a uma solução de $\mathrm{Cu}^{2+}$ (em concentrações inferiores ou compatível com os níveis de $\mathrm{Cu}^{2+}$ na cela eletrolítica). Estes íons foram selecionados para este estudo tendo em vista que são comumente encontrados em amostras de café.

Quando os íons $\mathrm{Zn}^{2+}, \mathrm{Mn}^{2+}$ e $\mathrm{Ni}^{2+}$ estiveram presentes na concentração 9,1 vezes superior a concentração de $\mathrm{Cu}^{+}$, o sinal analítico foi aumentado em cerca de $11 \%$ propiciando uma interferência positiva (para um nível de confiança de $95 \%$ ). Diferentemente dos outros íons interferentes, o íon $\mathrm{Fe}^{3+}$ atenuou o sinal analítico em cerca de $11,4 \%$ propiciando interferência negativa sobre o sinal de $\mathrm{Cu}^{2+}$. As interferências desses íons provavelmente estão relacionadas com mudança na camada iônica na interface solução/eletrodo. No caso dos íons $\mathrm{Fe}^{3+}$ (de raio atômico menor) é razoável supor que esses íons tendem a ser adsorvidos a superfície do eletrodo provocando um "bloqueio" a adsorção dos íons $\mathrm{Cu}^{2+}$ provocando diminuição de $\mathrm{Cu}^{2+}$ eletrodepositado. Como foi discutido na Seção 5.5.3, a superfície do eletrodo ION é carregada negativamente devido aos grupos $-\mathrm{SO}_{3}$ - do polímero PSS. Conduto, o efeito de matriz pode ser minimizado através da avaliação do teor de cobre através do método de adição de padrão. 
Tabela 9. Efeito de íons interferentes relativamente ao sinal analítico médio de $\mathrm{Cu}^{2+}$ 49,0 $\mu \mathrm{g} \mathrm{L}^{-1}$ em tampão BR pH 3 medido com o eletrodo ION (np- $\left.\mathrm{Fe}_{3} \mathrm{O}_{4} / \mathrm{PSS}\right)_{3}$. As medidas foram realizadas por DPASV nas condições apresentadas na Tabela 3.

\begin{tabular}{lccc}
\hline & \multicolumn{3}{c}{ Nível de interferência / Sinal remanescente } \\
\cline { 2 - 4 } Íon interferente & $5 \mu \mathrm{g} \mathrm{L}^{-1}$ & $48,1 \mu \mathrm{g} \mathrm{L}^{-1}$ & $446 \mu \mathrm{g} \mathrm{L}^{-1}$ \\
\hline $\mathrm{Zn}^{2+}$ & $96,7 \%$ & $95,0 \%$ & $110 \%$ \\
$\mathrm{Mn}^{2+}$ & $96,8 \%$ & $97,0 \%$ & $112 \%$ \\
$\mathrm{Ni}^{2+}$ & $94,8 \%$ & $97,2 \%$ & $111 \%$ \\
$\mathrm{Fe}^{3+}$ & $98 \%$ & $100 \%$ & $88,6 \%$ \\
$\mathrm{Zn}^{2+} ; \mathrm{Mn}^{2+} ; \mathrm{Ni}^{2+} \mathrm{e} \mathrm{Fe}^{3+}$ & - & $104 \%$ & - \\
\hline
\end{tabular}




\section{CONCLUSÕES}

A montagem de nanopartículas de magnetita $\left(\mathrm{np}-\mathrm{Fe}_{3} \mathrm{O}_{4}\right)$ e poliestireno sulfonado (PSS) por LBL sobre o substrato de ITO possibilitou a construção de eletrodos de óxido de ferro nanoestruturados (ION). O crescimento do filme de ION foi realizado ex situ com sucesso através da espectrometria UV-Vis indicando um crescimento linear relativamente ao número de bicamadas. Adicionalmente, espectros RAMAN do nanofilme mostraram bandas de absorção características da magnetita e imagens de Microscopia de Força Atômica (AFM) mostrou uma camada de np- $\mathrm{Fe}_{3} \mathrm{O}_{4}$ altamente empacotada. Os tamanhos caracterizados nas imagens de AFM corroboram com os tamanhos das np- $\mathrm{Fe}_{3} \mathrm{O}_{4}$ nas suspensões coloidais medidos por TEM.

A presença de np- $\mathrm{Fe}_{3} \mathrm{O}_{4}$ no nanofilme foi evidenciado pelo comportamento eletroquímico dos eletrodos de ION. O efeito do número de bicamadas de np- $\mathrm{Fe}_{3} \mathrm{O}_{4} / \mathrm{PSS}$ no desempenho dos eletrodos de ION foi um leve aumento das correntes anódicas e catódicas produzidas pela oxidação-redução do par redox $\mathrm{Fe}(\mathrm{CN})_{6}{ }^{3-/ 4-}$. O par redox $\mathrm{Fe}(\mathrm{CN})_{6}^{3-/ 4-}$ exibiu um comportamento quase reversível sobre o eletrodo de ION como já observado com outros eletrodos de trabalho.

A detecção de $\mathrm{Cu}^{2+}$ foi realizada utilizando eletrodos com ION (np$\left.\mathrm{Fe}_{3} \mathrm{O}_{4} / \mathrm{PSS}\right)_{3}$ através da técnica de voltametria de redissolução anódica por pulso diferencial (PDASV). Os parâmetros amplitude de pulso, velocidade de varredura, $\mathrm{pH}$, eletrólito suporte, potencial de deposição, tempo de deposição e velocidade de agitação foram estudados. A faixa de $\mathrm{pH}$ ideal foi de 4 a 5 e o eletrólito de trabalho escolhido foi o tampão BR. Apesar do pH ideal estar entre 4 e 5 optou-se por trabalhar com pH 3 o qual apresentou sensibilidade analítica adequada para determinação de $\mathrm{Cu}^{2+}$ e por ser o pH no qual o nanofilme de ION foi montado.

Finalmente, os eletrodos de ION apresentaram uma resposta linear relativamente ao $\mathrm{Cu}^{2+}$ com um limite de quantificação de $1,1 \mu \mathrm{g} \mathrm{L}^{-1}$ o qual pode ser considerado bastante promissor em comparação com os valores reportados na literatura para outros eletrodos sólidos. A faixa linear é bastante ampla e cerca de 40 ordens de grandeza. Eletrodos ION tem a vantagem de não ser necessário troca de célula 
eletroquímica para condicionamento do eletrodo. As etapas de acumulação e determinação ocorrem na mesma solução eletrolítica. Os eletrodos de ION também apresentaram boa seletividade relativamente aos íons interferentes comuns tais como $\mathrm{Zn}^{2+}, \mathrm{Mn}^{2+}, \mathrm{Ni}^{2+}$ e $\mathrm{Fe}^{3+}$. Amostras de café em pó comercial foram utilizadas para quantificação de $\mathrm{Cu}$ através dos eletrodos ION bem como também por FAAS. Os resultados mostraram se estatisticamente equivalentes para um nível de confiança de $95 \%$. A precisão também foi avaliada através de estudos de repetitividade ficando em torno de $2,9 \%$.

Os eletrodos de ION mostraram-se bastante promissores para detecção de íons $\mathrm{Cu}^{2+}$ em amostras de café. As superfícies dos eletrodos são carregadas negativamente e facilmente regenerada sem etapas adicionais e tediosas. Os eletrodos ION abrem uma nova perspectiva de sensores Enzyme-less para detecção de íons metálicos em diversos tipo de matrizes. 


\section{REFERÊNCIAS}

[1] G. Decher, Fuzzy Nanoassemblies: Toward Layered Polymeric Multicomposites, Science (80-. ). 277 (1997) 1232-1237. doi:10.1126/science.277.5330.1232.

[2] A.S. Adekunle, B.O. Agboola, J. Pillay, K.I. Ozoemena, Electrocatalytic detection of dopamine at single-walled carbon nanotubes-iron (III) oxide nanoparticles platform, Sensors Actuators B Chem. 148 (2010) 93-102. doi:10.1016/j.snb.2010.03.088.

[3] T.T. Baby, S. Ramaprabhu, $\mathrm{SiO} 2$ coated Fe3O4 magnetic nanoparticle dispersed multiwalled carbon nanotubes based amperometric glucose biosensor, Talanta. 80 (2010) 2016-2022. doi:10.1016/j.talanta.2009.11.010.

[4] A. Kaushik, P.R. Solanki, A.A. Ansari, G. Sumana, S. Ahmad, B.D. Malhotra, Iron oxide-chitosan nanobiocomposite for urea sensor, Sensors Actuators B Chem. 138 (2009) 572-580. doi:10.1016/j.snb.2009.02.005.

[5] D. Cao, N. Hu, Direct electron transfer between hemoglobin and pyrolytic graphite electrodes enhanced by $\mathrm{Fe} 3 \mathrm{O} 4$ nanoparticles in their layer-by-layer selfassembly films, Biophys. Chem. 121 (2006) 209-217. doi:10.1016/j.bpc.2005.11.003.

[6] G. Zhao, J.-J. Xu, H.-Y. Chen, Fabrication, characterization of Fe3O4 multilayer film and its application in promoting direct electron transfer of hemoglobin, Electrochem. Commun. 8 (2006) 148-154. doi:10.1016/j.elecom.2005.11.001.

[7] C.Y. Cummings, M.J. Bonné, K.J. Edler, M. Helton, A. McKee, F. Marken, Direct reversible voltammetry and electrocatalysis with surface-stabilised $\mathrm{Fe} 2 \mathrm{O} 3$ redox states, Electrochem. Commun. 10 (2008) 1773-1776. doi:10.1016/j.elecom.2008.09.018.

[8] K.J. McKenzie, D. Asogan, F. Marken, Adsorption and reactivity of hydrous iron oxide nanoparticles on boron-doped diamond, Electrochem. Commun. 4 (2002) 820-824. doi:10.1016/S1388-2481(02)00463-0.

[9] R. Krishna, S. Chandra, N. Bardhan, M. Salimian, Y.Y. Yang, E. Titus, J. Gracio, D. Bahadur, Design of an Amperometric Glucose Biosensor Based on Glucose Oxidase/Arginated-Fe3O4/Glassy Carbon Electrode, Sci. Adv. Mater. 5 (2013) 333-340. doi:10.1166/sam.2013.1462.

[10] X. You, J. Kim, Y.K. Pak, J.J. Pak, Preparation and Application of GraphenePoly (diallyldimethylammoniumchloride)-Iron Oxide Nanoparticles Buckypaper 
for Hydrogen Peroxide Detection, J. Nanosci. Nanotechnol. 13 (2013) 73497357. doi:10.1166/jnn.2013.7862.

[11] C.J. Belle, A. Bonamin, U. Simon, J. Santoyo-Salazar, M. Pauly, S. Bégin-Colin, G. Pourroy, Size dependent gas sensing properties of spinel iron oxide nanoparticles, Sensors Actuators B Chem. 160 (2011) 942-950. doi:10.1016/j.snb.2011.09.008.

[12] G.B. Alcantara, L.G. Paterno, F.J. Fonseca, M.A. Pereira-da-Silva, P.C. Morais, M.A.G. Soler, Layer-by-Layer Assembled Cobalt Ferrite Nanoparticles for Chemical Sensing, J. Nanofluids. 2 (2013) 175-183. doi:10.1166/jon.2013.1053.

[13] V. Mahendran, J. Philip, Sensing of Biologically Important Cations Such as $\mathrm{Na}+$ , $\mathrm{K}+, \mathrm{Ca} 2+, \mathrm{Cu} 2+$, and $\mathrm{Fe} 3+$ Using Magnetic Nanoemulsions, Langmuir. 29 (2013) 4252-4258. doi:10.1021/la400502b.

[14] J. Philip, V. Mahendran, L.J. Felicia, A Simple, In-Expensive and Ultrasensitive Magnetic Nanofluid Based Sensor for Detection of Cations, Ethanol and Ammonia, J. Nanofluids. 2 (2013) 112-119. doi:10.1166/jon.2013.1050.

[15] B.R. Malkin, B.O.G. Malmstrom, THE STATE AND FUNCTION OF COPPER IN BIOLOGICAL SYSTEMS, in: F.. Nord (Ed.), Adv. Enzymol. Relat. Areas Os Mol. Biol., John Wiley \& Sons, Goteborg, 1970: p. 178.

[16] E.A. Roberts, M.L. Schilsky, Diagnosis and treatment of Wilson disease: An update, Hepatology. 47 (2008) 2089-2111. doi:10.1002/hep.22261.

[17] G. Aragay, J. Pons, A. Merkoçi, Recent trends in macro-, micro-, and nanomaterial-based tools and strategies for heavy-metal detection, Chem. Rev. 111 (2011) 3433-3458. doi:10.1021/cr100383r.

[18] J. Wang, Analytical Electrochemistry, 3rd ed., John Wiley \& Sons, New Jersey, 1986.

[19] P.T. Kissinger, W.R. Heineman, Cyclic voltammetry, J. Chem. Educ. 60 (1983) 702. doi:10.1021/ed060p702.

[20] J. Wang, Stripping Analysis, VCH, Deerfild Beach, 1985.

[21] A.M.C.F.O. Brett, C.M.A. Brett, Electroquímica: princípios, métodos e aplicações, Livraria Almeida, Coimbra, 1996.

[22] J. Wang, D. Lu, S. Thongngamdee, Y. Lin, O. a Sadik, Catalytic adsorptive stripping voltammetric measurements of trace vanadium at bismuth film electrodes., Talanta. 69 (2006) 914-7. doi:10.1016/j.talanta.2005.11.029. 
[23] D.A. Skoog, F.J. Holler, S.. Crouch, Principles of Instrumental Analysis., 6th ed., CA, 2007.

[24] J. Wang, Stripping Analysis, in: Encycl. Electrochem., Wiley-VCH Verlag $\mathrm{GmbH} \&$ Co. KGaA, Weinheim, Germany, 2007. doi:10.1002/9783527610426.bard030203.

[25] G. Herzog, D.W.M. Arrigan, Determination of trace metals by underpotential deposition-stripping voltammetry at solid electrodes, TrAC Trends Anal. Chem. 24 (2005) 208-217. doi:10.1016/j.trac.2004.11.014.

[26] D.C. Harris, Exploring Chemical Analysis, 4th ed., W. H. FREEMAN AND COMPANY, New York, 2009.

[27] I. Oda, Y. Shingaya, H. Matsumoto, M. Ito, Upd mechanisms of copper and thallium on a Pt(111) electrode studied by in-situ IRAS and EC-STM, J. Electroanal. Chem. 409 (1996) 95-101. doi:10.1016/0022-0728(95)04490-6.

[28] Y. Bonfil, M. Brand, E. Kirowa-Eisner, Determination of sub- $\mu$ g 1-1 concentrations of copper by anodic stripping voltammetry at the gold electrode, Anal. Chim. Acta. 387 (1999) 85-95. doi:10.1016/S0003-2670(99)00066-5.

[29] G. Herzog, V. Beni, P.H. Dillon, T. Barry, D.W.M. Arrigan, Effect of humic acid on the underpotential deposition-stripping voltammetry of copper in acetic acid soil extract solutions at mercaptoacetic acid-modified gold electrodes, Anal. Chim. Acta. 511 (2004) 137-143. doi:10.1016/j.aca.2004.01.032.

[30] C.-S. Lai, X.-X. Hu, S. Yau, W.-P. Dow, Y.-L. Lee, Electrodeposition of copper on an $\mathrm{Au}(111)$ electrode modified with mercaptoacetic acid in sulfuric acid, Electrochim. Acta. 203 (2016) 272-280. doi:10.1016/j.electacta.2016.04.055.

[31] P. Salaün, C.M.G. Van Den Berg, Voltammetric detection of mercury and copper in seawater using a gold microwire electrode, Anal. Chem. 78 (2006) 5052-5060. doi:10.1021/ac060231+.

[32] J. Orozco, C. Ferna $\bullet$ ndez-Sa $\bullet$ nchez, C. Jime $\bullet$ nez-Jorquera, Underpotential Deposition-Anodic Stripping Voltammetric Detection of Copper at Gold Nanoparticle-Modified Ultramicroelectrode Arrays, Environ. Sci. Technol. 42 (2008) 4877-4882. doi:doi:10.1021/es8005964.

[33] N. Chauhan, C.S. Pundir, An amperometric acetylcholinesterase sensor based on $\mathrm{Fe} \quad 3 \mathrm{O} \quad 4$ nanoparticle/multi-walled carbon nanotubemodified ITO-coated glass plate for the detection of pesticides, Electrochim. Acta. 67 (2012) 79-86. doi:10.1016/j.electacta.2012.02.012. 
[34] A.A. Ansari, A. Kaushik, P.R. Solanki, B.D. Malhotra, Electrochemical cholesterol sensor based on tin oxide-chitosan nanobiocomposite film, Electroanalysis. 21 (2009) 965-972. doi:10.1002/elan.200804499.

[35] A. Ghosh, B.B. Show, S. Ghosh, N. Mukherjee, G. Bhattacharya, S.K. Datta, A. Mondal, Electrochemical synthesis of p-CuO thin films and development of a p$\mathrm{CuO} / \mathrm{n}-\mathrm{ZnO}$ heterojunction and its application as a selective gas sensor, RSC Adv. 4 (2014) 51569-51575. doi:10.1039/C4RA05360E.

[36] H.L.C. Mattoso, M. Ferreira, O.N.O. Jr, The polymeric Materials Encyclopedia, in: Polym. Mater. Encycl., CRC Press, Boca Raton, 1996: pp. 1432-1439.

[37] L.G. Paterno, H.L.C. Mattoso, O.N. de Oliveira, Ultrathin polymer films produced by the self-assembly technique: Preparation, properties and applications, Quim. Nova. 24 (2001) 228-235. doi:10.1590/S010040422001000200013.

[38] R.M. Cornell, U. Schwertmann, The Iron Oxides - Structure, Reactions, Occurrences and Uses, 2nd ed., Wiley-VCH Verlag GmbH \& Co. KGaA, Weinheim, 2003.

[39] H.-T. Jeng, G. Guo, First-principles investigations of the electronic structure and magnetocrystalline anisotropy in strained magnetite Fe3O4, Phys. Rev. B. 65 (2002) 1-9. doi:10.1103/PhysRevB.65.094429.

[40] C. Luminy, CRYSTALLIZATION MECHANISMS IN SOLUTION, 90 (1988) $14-30$.

[41] H.-C. Schwarzer, W. Peukert, Tailoring Particle Size Through Nanoparticle Precipitation, Chem. Eng. Commun. 191 (2004) 580-606. doi:10.1080/00986440490270106.

[42] R. Massart, E. Dubois, V. Cabuil, E. Hasmonay, Preparation and properties of monodisperse magnetic fluids, J. Magn. Magn. Mater. 149 (1995) 1-5. doi:10.1016/0304-8853(95)00316-9.

[43] M.A.G. Soler, L.G. Paterno, P.C. Morais, Layer-by-Layer Assembly of Magnetic Nanostructures, J. Nanofluids. 1 (2012) 101-119. doi:10.1166/jon.2012.1015.

[44] L.G. Paterno, M.A.G. Soler, Layer-by-Layer Enabled Nanomaterials for Chemical Sensing and Energy Conversion, JOM. 65 (2013) 709-719. doi:10.1007/s11837-013-0608-1.

[45] M.S. Cozzoline, Biodisponibilidade de Nutrientes, 5th ed., Manole, 2016. 
[46] Mapa, Plano Estratégico para o Desenvolvimento do Setor Cafeeiro, (2012) 27.

[47] A.R. Lima, R.G.F.A.P. Pereira, S.A. Abrahão, Compostos Bioativos do café: atividade antioxidante in vitro do café verde e torrado antes e após a descafeinação, Quim. Nov. 33 (2010) 20-24. http://www.scielo.br/pdf/qn/v33n1/04.pdf.

[48] S. andrade Abrahão, R.G.F.A. Pereira, S.M. da S. Duarte, A.R. Lima, D.J. Alvarenga, E.B. Ferreira, COMPOSTOS BIOATIVOS E ATIVIDADE ATIOXIDANTE DO CAFÉ (Coffea arabica L.), Ciênc. Agrotec. 34 (2010) 414420. http://www.scielo.br/pdf/cagro/v34n2/20.pdf.

[49] C.A.P. Schmidt, É. Miglioranza, G. Nagashima, Concentrações de metais pesados em grãos de café produzidos em lavouras sobre solos originados do basalto e do arenito Caiuá, Ciência Rural. 39 (2009) 1590-1593. http://www.scielo.br/pdf/cr/v39n5/a195cr480.pdf.

[50] M. Grembecka, E. Malinowska, P. Szefer, Differentiation of market coffee and its infusions in view of their mineral composition, Sci. Total Environ. 383 (2007) 59-69. doi:10.1016/j.scitotenv.2007.04.031.

[51] N. Oleszczuk, J.T. Castro, M.M. da Silva, M.D.G. a Korn, B. Welz, M.G.R. Vale, Method development for the determination of manganese, cobalt and copper in green coffee comparing direct solid sampling electrothermal atomic absorption spectrometry and inductively coupled plasma optical emission spectrometry, Talanta. 73 (2007) 862-869. doi:10.1016/j.talanta.2007.05.005.

[52] R. Ashu, B.S. Chandravanshi, Concentration levels of metals in commercially available ethiopian roasted coffee powders and their infusions, Bull. Chem. Soc. Ethiop. 25 (2011) 11-24. doi:10.4314/bcse.v25i1.63356.

[53] K.A. Anderson, B.W. Smith, Chemical Profiling To Differentiate Geographic Growing Origins of Coffee, J. Agric. Food Chem. 50 (2002) 2068-2075. doi:10.1021/jf011056v.

[54] J.B. Matiello, S.R.A. Engs, A. Mapa, G.N. Rosa, E. Agr, S. Leite, O Cobre na nutrição do cafeeiro, Folhas Técnicas - Fundação Procafé. FT/015 (2008).

[55] J.Ø. Loland, B.R. Singh, Copper contamination of soil and vegetation in coffee orchards after long-term use of $\mathrm{Cu}$ fungicides, Nutr. Cycl. Agroecosystems. 69 (2004) 203-211. doi:10.1023/B:FRES.0000035175.74199.9a.

[56] T. Roychowdhury, H. Tokunaga, M. Ando, Survey of arsenic and other heavy metals in food composites and drinking water and estimation of dietary intake by 
the villagers from an arsenic-affected area of West Bengal, India., Sci. Total Environ. 308 (2003) 15-35. doi:10.1016/S0048-9697(02)00612-5.

[57] Y. Sahan, F. Basoglu, S. Gucer, ICP-MS analysis of a series of metals (Namely: $\mathrm{Mg}, \mathrm{Cr}, \mathrm{Co}, \mathrm{Ni}, \mathrm{Fe}, \mathrm{Cu}, \mathrm{Zn}, \mathrm{Sn}, \mathrm{Cd}$ and $\mathrm{Pb}$ ) in black and green olive samples from Bursa, Turkey, Food Chem. 105 (2007) 395-399. doi:10.1016/j.foodchem.2006.12.026.

[58] É.J. Dos Santos, E. de Oliveira, Determination of Mineral Nutrients and Toxic Elements in Brazilian Soluble Coffee by ICP-AES, J. Food Compos. Anal. 14 (2001) 523-531. doi:10.1006/jfca.2001.1012.

[59] M.J. Martin, F. Pablos, a. G. Gonzalez, Characterization of green coffee varieties according to their metal content, Anal. Chim. Acta. 358 (1998) 177-183. doi:10.1016/S0003-2670(97)00610-7.

[60] M.J. Martín, F. Pablos, A.. G. González, Characterization of arabica and robusta roasted coffee varieties and mixture resolution according to their metal content, Food Chem. 66 (1999) 365-370. doi:10.1016/S0308-8146(99)00092-8.

[61] X. Liang, Dispersibility, Shape and Magnetic Properties of Nano-Fe3O4 Particles, Mater. Sci. Appl. 2 (2011) 1644-1653. doi:10.4236/msa.2011.211219.

[62] L.G. Paterno, M. a. G. Soler, F.J. Fonseca, J.P. Sinnecker, E.H.C.P. Sinnecker, E.C.D. Lima, M. a. Novak, P.C. Morais, Layer-by-Layer Assembly of Bifunctional Nanofilms: Surface-Functionalized Maghemite Hosted in Polyaniline, J. Phys. Chem. C. 113 (2009) 5087-5095. doi:10.1021/jp8092463.

[63] L.G. Paterno, M.A.G. Soler, F.J. Fonseca, J.P. Sinnecker, E.H.C.P. Sinnecker, E.C.D. Lima, S.N. Báo, M.A. Novak, P.C. Morais, Magnetic Nanocomposites Fabricated via the Layer-by-Layer Approach, J. Nanosci. Nanotechnol. 10 (2010) 2679-2685. doi:10.1166/jnn.2010.1411.

[64] INMETRO, Orientação Sobre Validação de Métodos de Ensaios Químicos, DOQ-CGCRE-008. (2007) 24.

[65] U. Schwertmann, R.M. Cornell, Iron Oxides in the Laboratory: Preparation and Characterization, VCH Publishers, New York, 1991.

[66] G.B. Alcantara, L.G. Paterno, A.S. Afonso, R.C. Faria, M. a Pereira-da-Silva, P.C. Morais, M. a G. Soler, Adsorption of cobalt ferrite nanoparticles within layer-by-layer films: a kinetic study carried out using quartz crystal microbalance., Phys. Chem. Chem. Phys. 13 (2011) 21233-42. doi:10.1039/c1cp22693b. 
[67] L.G. Paterno, F.J. Fonseca, G.B. Alcantara, M. a. G. Soler, P.C. Morais, J.P. Sinnecker, M. a. Novak, E.C.D. Lima, F.L. Leite, L.H.C. Mattoso, Fabrication and characterization of nanostructured conducting polymer films containing magnetic nanoparticles, Thin Solid Films. 517 (2009) 1753-1758. doi:10.1016/j.tsf.2008.09.062.

[68] L.G. Paterno, E.H.C.P. Sinnecker, M.A.G. Soler, J.P. Sinnecker, M.A. Novak, P.C. Morais, Tuning of Magnetic Dipolar Interactions of Maghemite Nanoparticles Embedded in Polyelectrolyte Layer-by-Layer Films, J. Nanosci. Nanotechnol. 12 (2012) 6672-6678. doi:10.1166/jnn.2012.4554.

[69] M.A.G. Soler, Q. Fanyao, Raman Spectroscopy for Nanomaterials Characterization, Springer Berlin Heidelberg, Berlin, Heidelberg, 2012. doi:10.1007/978-3-642-20620-7.

[70] P. Tartaj, M. a del P. Morales, S. Veintemillas-Verdaguer, T. Gonz lez-Carre o, C.J. Serna, The preparation of magnetic nanoparticles for applications in biomedicine, J. Phys. D. Appl. Phys. 36 (2003) R182-R197. doi:10.1088/0022$3727 / 36 / 13 / 202$.

[71] O.N. Shebanova, P. Lazor, Raman spectroscopic study of magnetite (FeFe2O4): a new assignment for the vibrational spectrum, J. Solid State Chem. 174 (2003) 424-430. doi:10.1016/S0022-4596(03)00294-9.

[72] M. a. G. Soler, L.G. Paterno, J.P. Sinnecker, J.G. Wen, E.H.C.P. Sinnecker, R.F. Neumann, M. Bahiana, M. a. Novak, P.C. Morais, Assembly of $\gamma$ Fe2O3/polyaniline nanofilms with tuned dipolar interaction, J. Nanoparticle Res. 14 (2012) 653. doi:10.1007/s11051-011-0653-z.

[73] G.B. Alcantara, L.G. Paterno, F.J. Fonseca, P.C. Morais, M. a. G. Soler, Morphology of cobalt ferrite nanoparticle-polyelectrolyte multilayered nanocomposites, J. Magn. Magn. Mater. 323 (2011) 1372-1377. doi:10.1016/j.jmmm.2010.11.049.

[74] G.V.M. Jacintho, P. Corio, J.C. Rubim, Surface-enhanced Raman spectra of magnetic nanoparticles adsorbed on a silver electrode, J. Electroanal. Chem. 603 (2007) 27-34. doi:10.1016/j.jelechem.2007.02.019.

[75] E. Dubois, J. Chevalet, R. Massart, Magnétic conductive liquids: preparation and properties of iron nanoparticles in mercury., J. Mol. Liq. 83 (1999) 243-254.

[76] J.-C. BACRI, R. PERZYNSKI, D. SALIN, IONIC FERROFLUIDS: A CROSSING OF CHEMISTRY AND PHYSICS, J. Magn. Magn. Mater. 85 (1990) 27-32. 
[77] R. Nicholson, Theory and Application of Cyclic Voltammetry f m Measurement of Electrode Reaction Kinetics, Anal. Chem. 37 (1965) 1351-1355.

[78] E.P. Parry, R.A. Osteryoung, Evaluation of Analytical Pulse Polarography, Anal. Chem. 37 (1965) 1634-1637. doi:10.1021/ac60232a001.

[79] J. Crousier, L. Pardessus, J.-P. Crousier, Voltammetry study of copper in chloride solution, Electrochim. Acta. 33 (1988) 1039-1042. doi:10.1016/00134686(88)80192-0.

[80] E.S. Almeida, E.M. Richter, R.A.A. Munoz, On-site fuel electroanalysis: determination of lead, copper and mercury in fuel bioethanol by anodic stripping voltammetry using screen-printed gold electrodes., Anal. Chim. Acta. 837 (2014) 38-43. doi:10.1016/j.aca.2014.05.031.

[81] V. Meucci, S. Laschi, M. Minunni, C. Pretti, L. Intorre, G. Soldani, M. Mascini, An optimized digestion method coupled to electrochemical sensor for the determination of $\mathrm{Cd}, \mathrm{Cu}, \mathrm{Pb}$ and $\mathrm{Hg}$ in fish by square wave anodic stripping voltammetry., Talanta. 77 (2009) 1143-8. doi:10.1016/j.talanta.2008.08.008.

[82] M.M. Rahman, K.A. Alamry, T.S. Saleh, A.M. Asiri, Sensitive and selective $\mathrm{Cu} 2+$ sensor based on 4-(3-(thiophen-2-yl)-9H-carbazol-9-yl)benzaldehyde (TPCBZ) conjugated copper-complex, J. Organomet. Chem. 817 (2016) 43-49. doi:10.1016/j.jorganchem.2016.05.013.

[83] J. Bai, Y. Chen, P. Li, D. Sun, Y. Tang, Phosphonate-functionalized threedimensional gold nanocomposite as a sensitive interface for facile electrochemical stripping detection of trace copper ( II ) ions, JEAC. 754 (2015) 1-7. doi:10.1016/j.jelechem.2015.06.014.

[84] I. Kerekovic, S. Milardovic, M. Palcic, Z. Grabaric, Characterization of cysteamine self assembled on gold functionalized with nitrilotriacetic acid and evaluation of copper(II) binding capacity with adsorption transfer stripping voltammetry, J. Electroanal. Chem. 724 (2014) 103-110. doi:10.1016/j.jelechem.2014.04.017.

[85] R.S. Freire, L.T. Kubota, Application of self-assembled monolayer-based electrode for voltammetric determination of copper, Electrochim. Acta. 49 (2004) 3795-3800. doi:10.1016/j.electacta.2003.12.055.

[86] C.J. Letti, Estudo de nanocompósitos formados por partículas de óxidos de ferro e polímeros por meio da espectroscopia raman, Universidade de Física (Unb), 2013. 
[87] C. de L. Ribeiro, DETERMINAÇÃO ELETROANALÍTICA DE ÁCIDO SALICÍLICO EM PRODUTO DERMATOLÓGICO COM ELETRODOS DE NANOTUBOS DE CARBONO E NANOPARTÍCULAS DE ÓXIDO DE FERRO, Unb, 2016.

[88] J.F. Huang, B.T. Lin, Application of a nanoporous gold electrode for the sensitive detection of copper via mercury-free anodic stripping voltammetry, Analyst. 134 (2009) 2306-2313. doi:10.1039/b910282e.

[89] S. Yuan, D. Peng, X. Hu, J. Gong, Bifunctional sensor of pentachlorophenol and copper ions based on nanostructured hybrid films of humic acid and exfoliated layered double hydroxide via a facile layer-by-layer assembly., Anal. Chim. Acta. 785 (2013) 34-42. doi:10.1016/j.aca.2013.04.050.

[90] H. Goudarziafshar, M. Nikoorazm, S.S. Mortazavi, S. Abbasi, A. Farmany, Ultra-sensitive quantification of copper in food and water samples by electrochemical adsorptive stripping voltammetry., Environ. Monit. Assess. 185 (2013) 8823-9. doi:10.1007/s10661-013-3215-2.

[91] D.W.M. Arrigan, L. Le Bihan, A study of L-cysteine adsorption on gold via electrochemical desorption and copper(II) ion complexation, Analyst. 124 (1999) 1645-1649. doi:10.1039/a905370k.

[92] A.C. Liu, D.C. Chen, C.C. Lin, H.H. Chou, C.H. Chen, Application of cysteine monolayers for electrochemical determination of sub-ppb copper(II), Anal. Chem. 71 (1999) 1549-1552. doi:10.1021/ac980956g.

[93] W. Yang, J.J. Gooding, D.B. Hibbert, Characterisation of gold electrodes modified with self-assembled monolayers of L-cysteine for the adsorptive stripping analysis of copper, J. Electroanal. Chem. 516 (2001) 10-16. doi:10.1016/S0022-0728(01)00649-0.

[94] M. Heitzmann, C. Bucher, J.-C.C. Moutet, E. Pereira, B.L. Rivas, G. Royal, E. Saint-Aman, Complexation of poly(pyrrole-EDTA like) film modified electrodes: Application to metal cations electroanalysis, Electrochim. Acta. 52 (2007) 3082-3087. doi:10.1016/j.electacta.2006.09.041.

[95] L.P. Singh, J.M. Bhatnagar, Copper(II) selective electrochemical sensor based on Schiff Base complexes, Talanta. 64 (2004) 313-319. doi:10.1016/j.talanta.2004.02.020.

[96] M. Lin, M.S. Cho, W.S. Choe, Y. Lee, Electrochemical analysis of copper ion using a Gly-Gly-His tripeptide modified poly(3-thiopheneacetic acid) biosensor, Biosens. Bioelectron. 25 (2009) 28-33. doi:10.1016/j.bios.2009.05.035. 
[97] C.S.P. de Castro, J.R. SouzaDe, M.P. Bemquerer, W.P. de Oliveira Filho, A voltammetric study of the binding of copper(II) to peptide fragments of prion, Polyhedron. 28 (2009) 4131-4135. doi:10.1016/j.poly.2009.10.002.

[98] PerkinElmer, Atomic spectroscopy - A Guid to Selecting the Appropriate $\begin{array}{llll}\text { Technique and } & \text { System, }\end{array}$ http://www.perkinelmer.com/atomicspectroscopy.

[99] R.S. Freire, C.A. Pessoa, L.T. Kubota, Emprego de monocamadas autoorganizadas no desenvolvimento de sensores eletroquímicos, Quim. Nova. 26 (2003) 381-389. doi:10.1590/S0100-40422003000300016.

[100] M.A. Morgano, L.F. Pauluci, M.D. Mantovani, E.E.M. Mory, Determinação de Minerais em Café Cru, Ciênc. Tecnol. Aliment. 22 (2002) 19-23. http://www.scielo.br/pdf/cta/v22n1/a04v22n1. 